\title{
Does Trust in Government Increase Support for Redistribution? Evidence from Randomized Survey Experiments
}

\author{
Kyle Peyton*
}

\author{
Forthcoming at American Political Science Review
}

\begin{abstract}
Why have decades of high and rising inequality in the United States not increased public support for redistribution? An established theory in political science holds that Americans' distrust of government decreases their support for redistribution, but empirical support draws primarily on regression analyses of national surveys. I discuss the untestable assumptions required for identification with regression modeling and propose an alternative design that uses randomized experiments about political corruption to identify the effect of trust in government on support for redistribution under weaker assumptions. I apply this to three survey experiments and estimate the effects that large, experimentally-induced increases in political trust have on support for redistribution. Contrary to theoretical predictions, estimated effects are substantively negligible, statistically indistinguishable from zero, and comparable to estimates from two placebo experiments. I discuss implications for theory-building about causes of support for redistribution in an era of rising inequality and eroding confidence in government.
\end{abstract}

${ }^{*}$ Postdoctoral Fellow in Law and Social Science, The Justice Collaboratory, Yale Law School. Email: kyle.peyton@yale.edu. Previous versions of this manuscript were presented and benefited from feedback in the Department of Political Science and the Institution for Social and Policy Studies (ISPS) at Yale. Thanks to Peter Aronow, Vivek Ashok, Alex Coppock, Matthew Graham, Jacob Hacker, Gregory Huber, Hakeem Jefferson, Adam Levine, Ro'ee Levy, Matthew Masten, Guatam Nair, Molly Offer-Westort, Fredrik Sävje, Michael Sierra-Arévalo, Francesco Trebbi, Ian Turner, and Jennifer Wu for helpful comments and suggestions. Thanks to Benjamin Lauderdale and three anonymous reviewers for constructive feedback during the review process. Thanks to Nicholas Faulkner, Aaron Martin and Raymond Orr for collaborating on data collection. Research support was provided by ISPS and the University of Melbourne. Experiments 1, 2, 4 were approved by the University of Melbourne Human Ethics Committee. Experiments 3 and 5 were approved by the Yale University Institutional Review Board. Replication materials are available on Dataverse: https://doi.org/10.7910/DVN/L3NT6P. 
Why don't the poor soak the rich? This is an enduring puzzle in democratic political theory (see Shapiro, 2002), and the relative lack of support for redistribution in the United States is especially surprising given high and rising income inequality (see Meltzer and Richard, 1981). One possible explanation, advanced in prior work, is that voters' antipathy toward government undermines their support for policies designed to address inequality. Specifically, that opposition to federal spending on redistributive social policies can be explained by their distrust of government (see Hetherington, 2005). A key prediction from this theory is that, in the counter-factual world where Americans trusted the government more, they would be more supportive of redistribution.

Prior empirical studies have shown that political trust - an individual-level attitude - predicts support for federal spending on a variety of redistributive social policies, such as welfare and food stamps (Hetherington and Globetti, 2002; Hetherington, 2005; Rudolph and Evans, 2005). The dominant approach to demonstrating the impact of political trust on support for redistribution has been to apply a multiple regression design to cross-sectional survey data. This process entails starting with a short regression of policy attitudes on political trust, and then controlling for potential common causes that would lead to biased estimation if left out. The parameters in these long regressions, however, are not causally identified and estimation is biased and inconsistent unless strong (and untestable) assumptions hold (see Samii, 2016).

I depart from prior studies that rely on the multiple regression framework and instead use an approach that leverages a randomly assigned instrument to identify and estimate the effect of political trust on support for redistribution. Across three independent survey experiments, I find that large increases in political trust have negligible effects on support for redistributive social policy that are indistinguishable from zero. Although declining political trust may have caused the "demise of American liberalism" (see Hetherington, 2005), the evidence reported here suggests increased trust in government, on its own, is unlikely to restore it. 


\section{Theory and Identification}

The measurement and meaning of voters' judgments about "the honesty and other ethical qualities of public officials" (Stokes, 1962, p. 64) has attracted attention since the concept of political trust was introduced to survey research in the 1950s. Although early studies focused on the causes of political trust (see Miller, 1974; Citrin, 1974), subsequent research shifted toward its wide-ranging effects on support for government and its leaders (see Hetherington, 1998, 2005; Hetherington and Rudolph, 2008), and the role perceived corruption plays in undermining this support (see Anderson and Tverdova, 2003; Bowler and Karp, 2004). More recent studies have found that publicizing corruption has strong and lasting effects on political trust (Green, Zelizer and Kirby, 2018), and downstream consequences for voting behavior (Chong et al., 2014).

An influential theory posits that political trust also affects voters' policy preferences: "other things equal, if people perceive the architect of policies as untrustworthy, they will reject its policies; if they consider it trustworthy, they will be more likely to embrace them" (Hetherington, 2005, p. 51). While this theory has broad implications for a variety of policies, the core claim is that political trust has the largest effects on support for policies that are explicitly redistributive in nature (e.g. welfare). This is because, unlike distributive social policies that spread costs and benefits across a broad political constituency (e.g. social security), redistributive policies require political majorities to make material sacrifices (e.g. increased taxes) for the benefit of political minorities (see Hetherington and Globetti 2002, Hetherington 2005, Ch. 5; Rudolph 2017 for review).

This is a linear causal model: if an individual's trust in government increases, their support for government spending on redistributive social policy increases. The dominant approach to testing has been to fit regression models of individuals' policy preferences on their trust in government using national opinion surveys (e.g. Hetherington and Globetti, 2002; Hetherington, 2005; Rudolph and Evans, 2005). The simplest approach would fit a 
bivariate model where support for redistribution is a linear function of trust in government. In the special case where factors omitted from the model are uncorrelated with political trust, this short regression is an unbiased and consistent estimator; otherwise, estimates are biased in an unknown direction. Prior studies have attempted to avoid this problem by adding a variety of control variables (e.g. Hetherington, 2005, Table 5.6), but long regressions are still biased and inconsistent when untestable assumptions fail.

The key assumption is that added controls are sufficient for eliminating the association between any unobserved determinants of policy attitudes and political trust. The President's party is one important factor that affects both policy preferences and political trust (see Citrin 1974, Morisi, Jost and Singh 2019), but others include Congressional approval ratings (e.g. Hetherington, 1998), voters' evaluations of partisan conflict and legislative gridlock (e.g. Hibbing and Theiss-Morse, 2002), prevailing economic conditions (e.g. Citrin and Green, 1986), and voter ideology (e.g. Rudolph and Evans, 2005). Regression estimates are biased, typically in an unknown direction, when common causes are omitted or unobserved.

Additional assumptions include: 1) policy preferences do not affect political trust; 2) no control variables are affected by political trust (see Clarke 2005; Angrist and Pischke 2009, Chapter 3); and 3) the correct specification is used (see Ho et al., 2007; Aronow and Samii, 2016). In prior studies, this would imply omnibus opinion polls 1) measured all potential common causes of political trust and support for redistribution; and 2) the minimally sufficient set of controls to include in a correctly specified regression were known. Whether these assumptions hold is ultimately a matter of faith (see Samii, 2016).

To overcome these inherent challenges, I use a Causal Instrumental Variables (IV) design that instead relies on a randomly assigned instrument, which is therefore uncorrelated with both observed and unobserved factors (see Hernán and Robins 2006; Sovey and Green 2011 on causal and non-causal IV). Figure 1 compares regression adjustment to Causal IV, which rests on two assumptions: 1 ) the instrument, $Z$, has a causal effect on political trust, $T$; and 2) $Z$ only affects support for redistribution, $Y$, through the path $Z \rightarrow T \rightarrow Y$. Here I use three 
survey experiments that randomly assigned information about levels of political corruption, $Z$, to identify and estimate the effect of political trust, $T$, on support for redistribution, $Y$. I verify the first assumption using the observed data, and examine testable implications of violations to the second "Exclusion Restriction" (ER) assumption using placebo experiments, and by testing for effects on other outcomes.

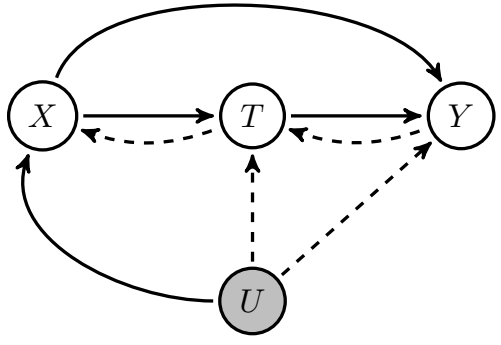

(a) Regression Adjustment

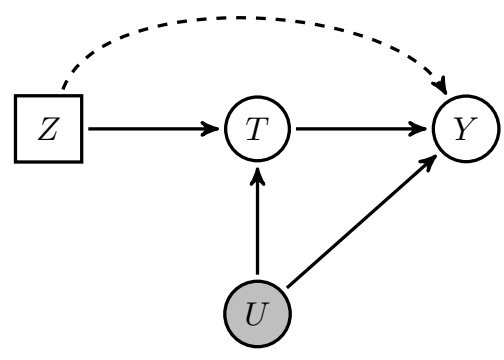

(b) Causal IV

Figure 1: Political trust $T$ affects support for redistribution $Y$, but the relationship is confounded by unmeasured common causes $U$. (a) $X$ denotes the minimally sufficient set of controls. (b) $Z$ denotes a randomized instrument. Solid arrows are assumed causal pathways and dashed arrows represent violations of identification assumptions.

\section{Corruption Experiments}

The link between corruption perceptions and trust in government is well established in prior work. In theory, reducing the information asymmetries that prevent voters from learning about political corruption enables them to hold politicians accountable and forces elected officials to act in the public interest (Persson and Tabellini, 2002; Besley, 2006). Empirically, the link between perceived corruption and voters' trust and confidence in public institutions has been demonstrated across multiple observational (see Anderson and Tverdova, 2003; Bowler and Karp, 2004; Clausen, Kraay and Nyiri, 2011; Ares and Hernández, 2017) and experimental studies (see Kuziemko et al., 2015; Chong et al., 2014; Green, Zelizer and Kirby, 2018). Given the important role that media play in shaping perceptions of corruption (see e.g. Brunetti and Weder, 2003), treatments were designed to inform respondents about levels of corruption using Opinion pieces ("Op-Eds"): instruments of civic discourse that 
have powerful and persistent persuasion effects (see Coppock, Ekins and Kirby, 2018).

These Op-Ed treatments were presented as written in the New York Times by a former prosecutor in the DOJ's Public Integrity Section - the branch that prosecutes public corruption. Op-Eds were designed to affect readers' beliefs about levels of generic government corruption, and to be devoid of partisan content that might suggest corruption was related to a particular party or administration. In Experiments 1-2, subjects completed a short survey (including demographics and partisanship) and were then randomly assigned to one of three treatment arms: Honest, Corrupt, or Control. In Honest, participants read an Op-Ed that emphasized the integrity of government officials and low levels of political corruption. In Corrupt, participants read an Op-Ed that used contrasting language about the lack of integrity among government officials and the prevalence of political corruption. In Control, participants read a piece about celebrity chef Anthony Bourdain. Experiment 1 ( $\mathrm{N}=643$ ) was conducted on Amazon Mechanical Turk (MTurk) in June 2014. Experiment 2 ( $\mathrm{N}=$ 1,324), in September 2014, was a direct replication on a nationally representative panel. Experiment $3(\mathrm{~N}=1,870)$, on MTurk in March 2017, added data visualizations on DOJ corruption convictions that supported the Op-Eds; Control, an Op-Ed about recycling, also included a data visualization. These visualizations were added with the aim of increasing design power by making the Corrupt and Honest treatments more persuasive (see Nyhan and Reifler, 2018). See Online Appendix S1-S2 for additional details.

\subsection{Placebo Experiments}

The ER assumption here is that effects on support for redistribution only occur through political trust. This could be violated if treatment affected support for redistribution via another pathway (i.e. $Z \rightarrow Y$ in Fig. 1). An important potential violation here is psychological valence, since positive (or negative) stimuli tend to generate corresponding reactions (see Fredrickson, 2013, for review), and the media content in the Honest and Corrupt treatment arms is either positive (absence of corruption) or negative (widespread corruption). I 
investigate this with Experiments 4-5, which were equivalent to Experiments 1-2 except the Honest and Corrupt arms provided information about the absence or presence of corruption in the National Football League (NFL). These "placebo experiments", detailed in S3, serve two purposes. First, if effects on political trust in Experiments 1-3 are simply a function of content valence, they should also be detectable when political content is removed. More importantly, if support for redistribution - but not political trust - is affected by treatments about non-political corruption, this provides evidence of an ER violation and suggests an alternative mechanism could bias estimates in Experiments 1-3.

\subsection{Measurement}

Prior work cautions that estimates from regressions fit to ANES measures of political trust (e.g. "How much of the time do you think you can trust the government in Washington to do what is right?") are attenuated due to measurement error (see Hetherington, 2005, pp. 14-16). To mitigate this, I measure political trust by combining four survey items (e.g. "We generally cannot trust politicians") recorded on the same measurement interval from "Strongly Disagree" to "Strongly Agree" into an additive scale ${ }^{1}$. Support for redistribution is also measured using an additive scale of responses to four questions about federal spending on food stamps, welfare, programs that assist "blacks and other minorities", and assistance to the homeless. These dependent variables were used in foundational studies of political trust and support for redistribution (e.g. Hetherington, 2005). See S4 for details on measurement and reliability.

\footnotetext{
${ }^{1}$ This measure comes from Faulkner, Martin and Peyton 2015. See Ansolabehere, Rodden and Snyder 2008 for explanation of why scales reduce measurement error.
} 


\section{Results}

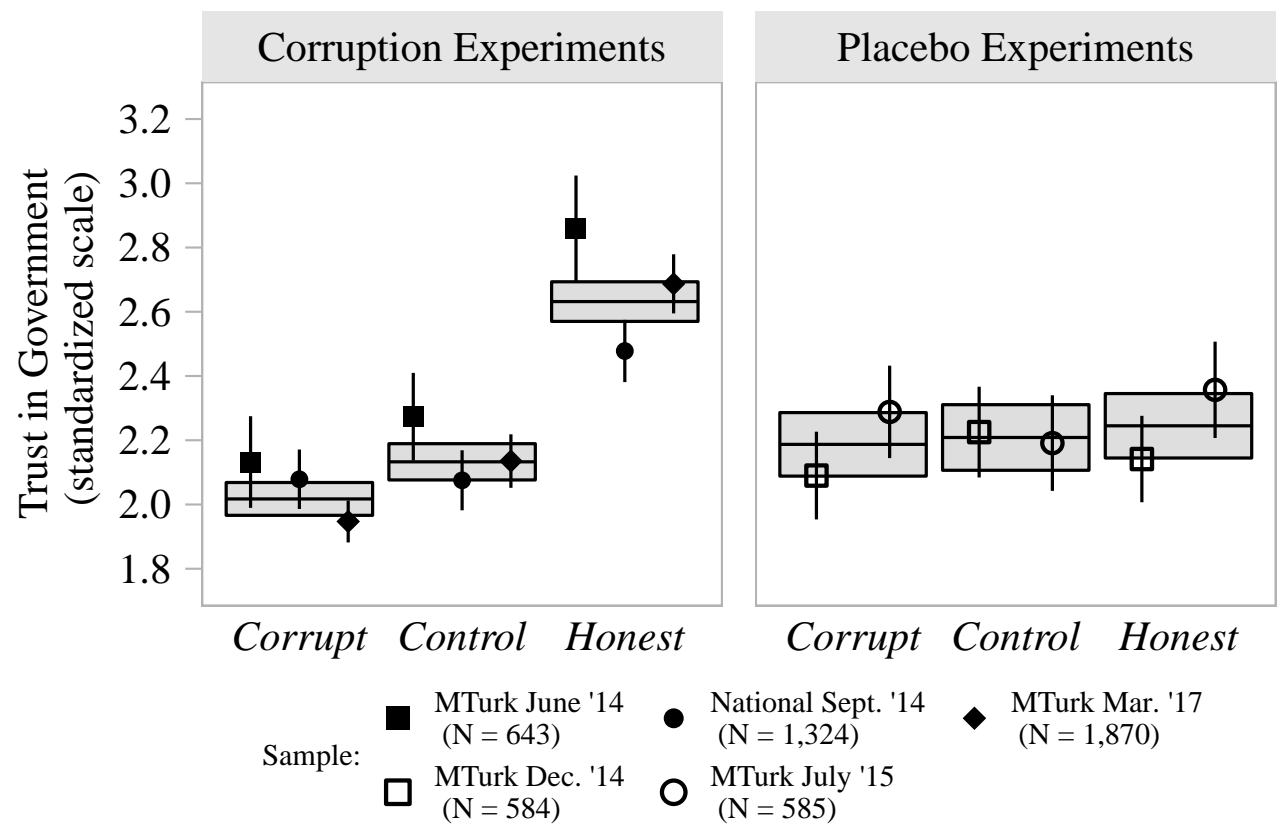

Figure 2: Trust in government by treatment arm and study type. Point estimates (with 95\% CIs) are scaled by the standard deviation in Control and denote average levels of trust in government for each experiment. Crossbars (with 95\% CIs) denote group means pooled across experiments. See Table S15 for point estimates and standard errors.

Figure 2 shows that, in the corruption experiments, average levels of political trust were lowest in the Corrupt arm and highest in the Honest arm, but approximately the same across conditions in the placebo experiments. I leverage these experimentally induced changes to estimate the effect of increased political trust on support for redistribution with instrumental variables regression using Two-Stage Least Squares (2SLS). The 2SLS estimator,

$$
\widehat{\beta}_{I V}=\frac{\widehat{\operatorname{Cov}}\left(Y_{i}, Z_{i}\right)}{\widehat{\operatorname{Cov}}\left(T_{i}, Z_{i}\right)}=\frac{\widehat{\operatorname{Cov}}\left(Y_{i}, Z_{i}\right) / \widehat{\operatorname{Var}}\left(Z_{i}\right)}{\widehat{\operatorname{Cov}}\left(T_{i}, Z_{i}\right) / / \widehat{\operatorname{Var}}\left(Z_{i}\right)}
$$

is the ratio of the "reduced-form" effect of subject $i$ 's treatment assignment (the "instrument" $Z_{i}$ ) on their support for redistribution $Y_{i}$, and the "first-stage" effect on their trust in government, $T_{i}$. I code $Z_{i}=0$ if subject $i$ is assigned Corrupt, $Z_{i}=0.5$ if assigned Control, and $Z_{i}=1$ if assigned Honest. Given random assignment of the instrument, $\widehat{\beta}_{I V}$ is consistent for 
the causal effect of political trust on support for redistribution, provided the ER assumption holds and the first-stage effect is positive. With a multivalued instrument, $\widehat{\beta}_{I V}$ is a weighted average of causal estimates for different sub-populations of compliers, and my coding scheme assumes political trust increases with higher values of $Z_{i}$ (see Fig. 2). This structural model mirrors the theory and estimation approach in prior literature, which specifies a linear causal relationship between political trust and support for redistribution (see Angrist and Pischke 2009 Chapter 4.5 on generalizing IV for multivalued treatments/instruments, and S5.2 for results using Corrupt and Honest as separate instruments).

I use covariate-adjusted regression on the stacked dataset of individual experiments to estimate effects. Results are standardized using Glass's $\Delta$, which scales outcomes by the standard deviation in the control group (see SM Section 5), and presented graphically with $90 \%$ and $95 \%$ confidence intervals (CIs), and a Margin of Equivalence (MOE) bound of \pm 0.20 standard units, which corresponds to an effect size of about one-fifth of one standard deviation. The hypothesis that an effect is indistinguishable from zero is rejected if a 95\% CI excludes zero, and the hypothesis of non-equivalence is rejected in favor of equivalence when a $90 \% \mathrm{CI}$ is contained within the MOE. I conclude an estimate is indistinguishable from zero and equivalent to a "negligible" effect size (larger than -0.20 , and smaller than 0.20 ) when a 95\% CI covers zero and a 90\% CI falls inside the MOE (see Rainey 2014; Lakens 2017).

Figure 3 presents first-stage and reduced-form estimates across corruption and placebo experiments. The first-stage effect on trust in government (a 1 unit increase in $Z$ from Corrupt to Honest $)$ is 0.62 standard units $(t=15.20, P<0.001,90 \%$ CI: $[0.55,0.68])$ in the corruption experiments, but approximately zero $(\Delta=0.06, t=0.82, P=0.41,90 \% \mathrm{CI}$ : $[-0.06,0.18])$ in the placebo experiments and statistically equivalent to a negligible effect size. This comparison supports the notion that first-stage effects in Experiments 1-3 are driven by content about political corruption.

Reduced-form estimates in the corruption $(\Delta=0.01, t=0.20, P=0.84,90 \% \mathrm{CI}$ : $[-0.05,0.06])$ and placebo experiments $(\Delta=-0.03, t=-0.45, P=0.66,90 \%$ CI: $[-0.12,0.07])$ 
are indistinguishable from zero. Since reduced-form estimates are proportional to the causal effect of interest this can be taken as evidence that the effect of political trust on support for redistribution is approximately zero. The 2SLS estimate confirms this $(\Delta=0.01, t=0.21$, $P=0.83,90 \% \mathrm{CI}:[-0.08,0.10])$. For context, the reduced-form and 2SLS estimates are approximately one one-hundredth the 1.05 point partisan gap in support for redistribution observed in Control. Since the corresponding 90\% CIs are all within the MOE (roughly one-fifth the partisan gap) I conclude these effects are substantively negligible.

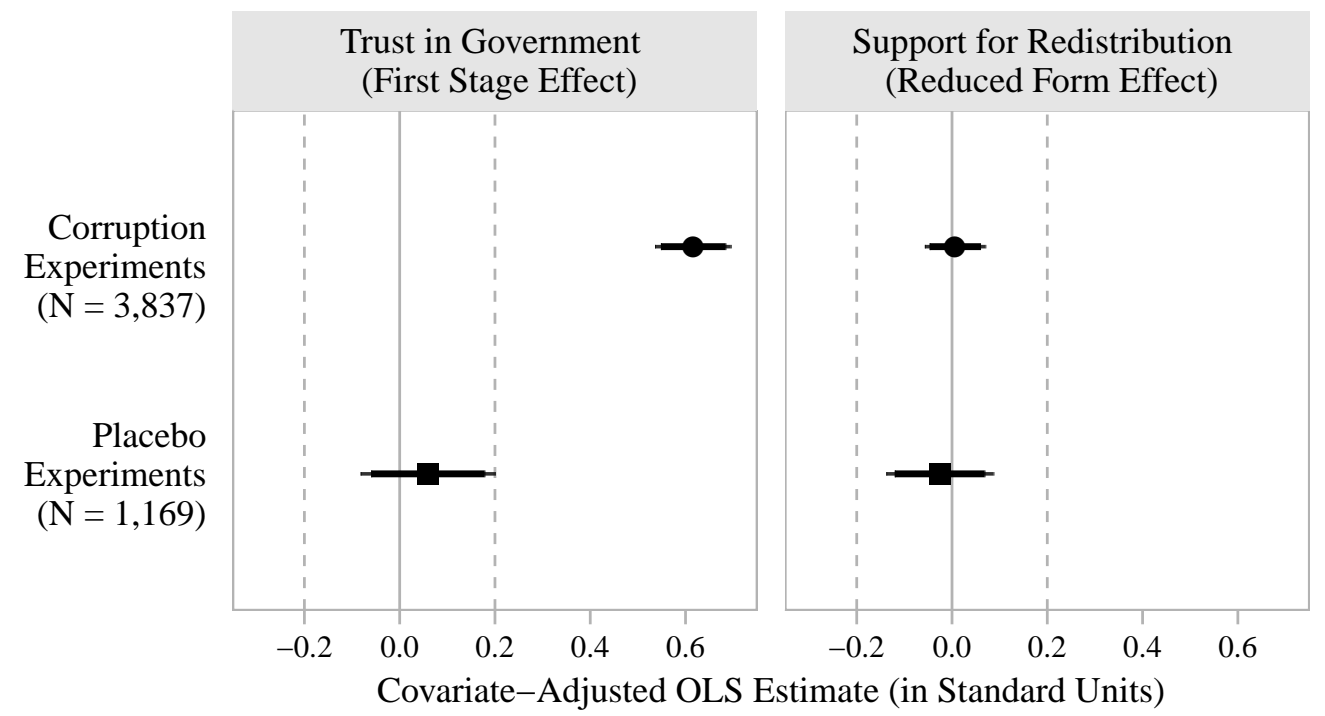

Figure 3: Estimates from OLS regression with HC2 robust standard errors. Thick horizontal lines denote $90 \%$ CIs and thin lines denote 95\% CIs. Dotted vertical lines denote a MOE of \pm 0.20 standard units. Covariates: age, conservatism, income, indicators for partisanship (Republican, Democrat, Independent), sex (male or female), education (college degree or not), race (white or non-white), employed (yes or no), and a study fixed effect. See Table S21 for point estimates and standard errors.

The 2SLS estimator is justified by random assignment and strong first-stage effects; and the combination of negligible reduced-form and first-stage estimates in the placebo experiments provides empirical support for the ER assumption. S5 of the Online Appendix contains a variety of supplementary material, including estimates for individual experiments, results without covariate-adjustment, tests for instrument strength, consideration of "demand effects" and alternative definitions of "negligible," and tests of the sharp null of no effect for any subject. Results are also robust to using the ANES measure of political trust, par- 
titioning the redistribution scale, using alternative measures of support for redistribution, and dropping subjects that failed pre-treatment attention checks. I do not find evidence of first-stage effects on other attitudes that might indicate an ER violation, such as concerns about inequality. I also test the prediction that political trust should have weaker effects on distributive policies and find similar results, suggesting political trust has negligible effects on support for both distributive and redistributive policies.

\subsection{Heterogeneity}

Political trust is predicted to have especially large effects among individuals that must make both material and ideological sacrifices to support redistribution (e.g. Popp and Rudolph, 2011). This has been supported by studies showing political trust is a stronger predictor of redistributive preferences for certain sub-groups, e.g. high income white Republicans (see Rudolph, 2017, for review). I investigate this using Generalized Random Forests (GRF), a machine learning algorithm that automates the search for treatment effect heterogeneity (see Athey, Tibshirani and Wager, 2019). GRF estimates heterogeneity as a function of subject-level covariates, with the key advantage that the "Instrumental Forest" estimator in the GRF framework is designed for IV estimation. Following graphical presentations in prior work (e.g. Guess and Coppock, 2018), Figure 4 plots predicted treatment effects as a function of individuals' covariate profiles, along with $95 \%$ CIs, to provide an overall summary of effect heterogeneity in Experiments 1-3. According to this analysis, only $3 \%$ of predictions were positive and statistically distinguishable from zero. S5.4 examines treatment-covariate interactions for race, employment status, partisanship, and ideology. None are statistically significant after correcting for multiple comparisons. 


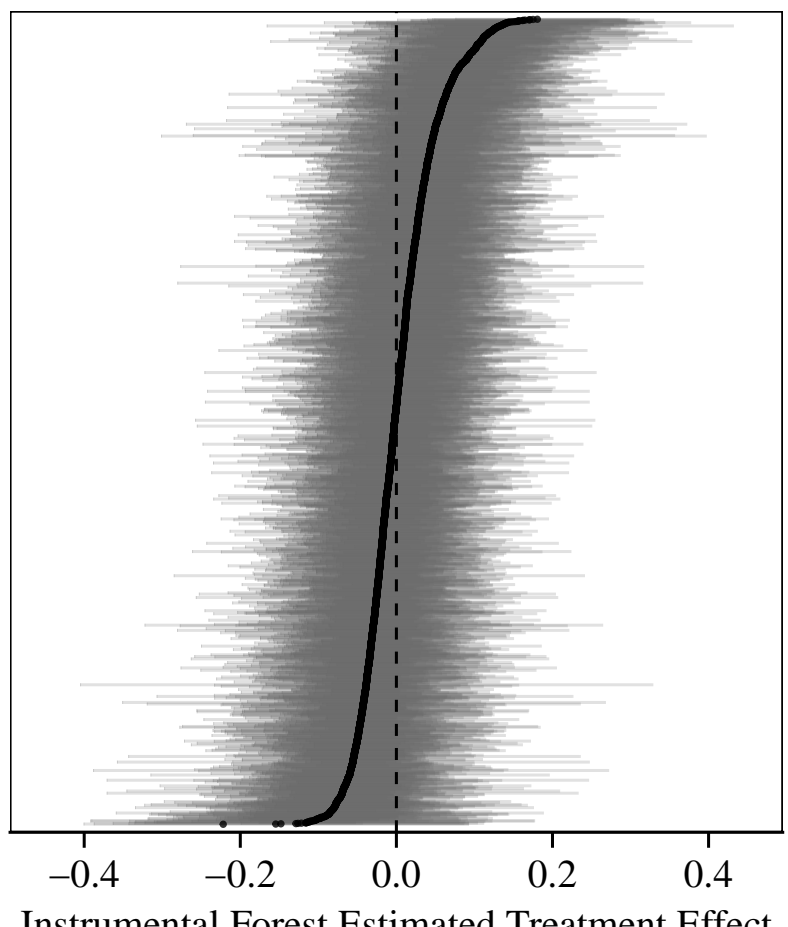

Figure 4: Estimated effects of political trust on support for redistribution using the Instrumental Forest estimator in the grf package for $R$ with the recommended settings of honest splitting and 4000 trees. Black dots indicate estimated treatment effects for each individual in Experiments 1-3, as a function of their covariate profile, ordered by effect size. Grey horizontal lines indicate 95\% CIs. Covariates: age, conservatism, income, indicators for partisanship (Republican, Democrat, Independent), sex (male or female), education (college degree or not), race (white or non-white), employed (yes or no), and a study fixed effect.

\section{Implications}

In the United States, income for the top 1\% of adults more than tripled from 1980-2014 while earnings for the bottom 50\% remained stagnant (Piketty, Saez and Zucman, 2017, p. 557). This should, in theory, increase demand for redistribution, yet support for government policies designed to ameliorate inequality has not increased since the 1970s (see Ashok, Kuziemko and Washington, 2016). An alternative theory, which might explain this puzzling divergence, holds that trust in government causes support for redistribution.

According to this account, the post-1960s decline in political trust "played the central role in the demise of progressive public policy in the United States" (see Hetherington, 
2005, p. 3). Trust in government remains at historic lows, and the vast majority polled in recent years believe corruption is "widespread" throughout the government (see Gallup, 2015; Doherty, Kiley and Johnson, 2017). In the counter-factual world where Americans trust their government more, are they more supportive of redistribution?

Prior studies have not provided a clear answer, leaving open a question with direct implications for the puzzling disconnect between economic conditions and public support for redistribution. Here I find that large increases in political trust - more than enough to eliminate the gap between Democrats and Republicans - have negligible effects on support for redistribution that are statistically indistinguishable from zero. This provides new evidence, and raises additional questions, about the theory that political trust causes support for redistribution.

Though I do not find support for this theory, it should be noted that the experiments reported here caused larger increases in political trust than decreases (see Fig. 2, S5.2), and inducing distrust via other methods may produce different results. For example, Kuziemko et al. (2015) found telling Americans Transparency International ranked the U.S. among the most corrupt in a class of countries with similar levels of income and development induced small decreases in political trust and support for direct transfer policies (e.g. Food Stamps), and increased support for private charity as a non-governmental solution to inequality. Although I was unable to replicate these results using Op-Ed treatments (see S5.7), information about domestic corruption delivered by an NGO with a cross-national comparative frame may introduce exclusion restriction violations by priming other considerations that undermine support for redistribution, such as nationalism (see Shayo, 2009). Nair (2018), for example, finds that simply priming Americans to think about their relative affluence also decreases support for domestic redistribution (p. 826).

The estimates reported here are also local to sub-groups of "compliers" - respondents who would be induced to change their political trust if treated. This important caveat applies to all IV estimates, since effects in a broader population may be different. Further, strong effects 
on reported political trust could reflect experimentally induced measurement error in survey instruments rather than effects on underlying attitudes. This would imply the direction of error depended on treatment assignment: negative in Corrupt and positive in Honest. Given estimates from the placebo experiments, one would also need to assume asymmetric error depended on domain-specific content about political corruption. The potential disconnect between effects on self-reported versus latent attitudes is a potential limitation of all surveybased research. Since prior studies draw largely on correlations among survey responses, accumulated knowledge about the measurement and meaning of self-reported political trust may be inadequate (see Levi and Stoker 2000; Intawan and Nicholson 2018).

A related consideration is that even large increases in political trust may not be enough to increase support for redistribution. If both are largely determined by partisanship and long-standing ideological convictions, this could also explain their association and the results reported here. If they are not causally related, their association may nevertheless be indicative of a particular political equilibrium. For example, individuals with higher levels of political trust were more opposed to food stamps in the 1980s, a period dominated by Republican administrations, political rhetoric about "welfare fraud," and media content that over-represented the proportion of black individuals in receipt of government assistance (see Gilens, 1999). Other correlates of political trust - including racial prejudice and views about government inefficiency - may provide better insights into Americans' opposition to redistribution than their distrust of government.

The effects of political trust on support for redistribution may ultimately prove more complex than prior theory suggests. This paper provides new empirical benchmarks that demonstrate increased trust in government, on its own, has a negligible effect on support for redistribution. This should provide a starting point for further discussion about the relationship between policy preferences and attitudes toward the state during an era of rising inequality and eroding confidence in public institutions. 


\section{References}

Anderson, Christopher J and Yuliya V Tverdova. 2003. "Corruption, political allegiances, and attitudes toward government in contemporary democracies." American Journal of Political Science 47(1):91-109.

Angrist, Joshua D and Jörn-Steffen Pischke. 2009. Mostly Harmless Econometrics: An Empiricist's Companion. Princeton: Princeton University Press.

Ansolabehere, Stephen, Jonathan Rodden and James M Snyder. 2008. "The strength of issues." American Political Science Review 102(2):215-232.

Ares, Macarena and Enrique Hernández. 2017. "The corrosive effect of corruption on trust in politicians." Research \& Politics 4(2):2053168017714185.

Aronow, Peter M and Cyrus Samii. 2016. "Does regression produce representative estimates of causal effects?" American Journal of Political Science 60(1):250-267.

Ashok, Vivekinan, Ilyana Kuziemko and Ebonya Washington. 2016. "Support for Redistribution in an Age of Rising Inequality." Brookings Papers on Economic Activity 2015(1):367433.

Athey, Susan, Julie Tibshirani and Stefan Wager. 2019. "Generalized Random Forests." The Annals of Statistics 47(2):1148-1178.

Besley, Timothy. 2006. The Political Economy of Good Government. Oxford: Oxford University Press.

Bowler, Shaun and Jeffrey A Karp. 2004. "Politicians, scandals, and trust in government." Political Behavior 26(3):271-287.

Brunetti, Aymo and Beatrice Weder. 2003. "A free press is bad news for corruption." Journal of Public Economics 87(7):1801-1824.

Chong, Alberto, Ana L De La O, Dean Karlan and Leonard Wantchekon. 2014. "Does corruption information inspire the fight or quash the hope?" The Journal of Politics $77(1): 55-71$.

Citrin, Jack. 1974. "The political relevance of trust in government." American Political Science Review 68(03):973-988.

Citrin, Jack and Donald Philip Green. 1986. "Presidential leadership and the resurgence of trust in government." British Journal of Political Science 16(04):431-453.

Clarke, Kevin A. 2005. "The phantom menace." Conflict Management and Peace Science 22(4):341-352.

Clausen, Bianca, Aart Kraay and Zsolt Nyiri. 2011. "Corruption and confidence in public institutions." The World Bank Economic Review 25(2):212-249. 
Coppock, Alexander, Emily Ekins and David Kirby. 2018. "The Long-lasting Effects of Newspaper Op-Eds on Public Opinion." Quarterly Journal of Political Science 13(1):5987.

Doherty, Carroll, Jocelyn Kiley and Bridget Johnson. 2017. "Public Trust in Government Remains Near Historic Lows as Partisan Attitudes Shift." Pew Research Center .

URL: $\quad$ https://www.people-press.org/wp-content/uploads/sites/4/2017/05/05-03-17Trust-release.pdf

Faulkner, Nicholas, Aaron Martin and Kyle Peyton. 2015. "Priming political trust." Australian Journal of Political Science 50(1):164-173.

Fredrickson, Barbara L. 2013. Positive emotions broaden and build. In Advances in Experimental Social Psychology, ed. Patricia Devine and Ashby Plant. Vol. 47 Cambridge: Academic Press pp. 1-53.

Gallup. 2015. "75\% in U.S. See Widespread Government Corruption.".

URL: http://news.gallup.com/poll/185759/widespread-government-corruption.aspx

Gilens, Martin. 1999. Why Americans Hate Welfare. Chicago: University of Chicago Press.

Green, Donald P, Adam Zelizer and David Kirby. 2018. "Publicizing Scandal." Quarterly Journal of Political Science 13(3):237-261.

Guess, Andrew and Alexander Coppock. 2018. "Does counter-attitudinal information cause backlash?" British Journal of Political Science pp. 1-19.

Hernán, Miguel A and James M Robins. 2006. "Instruments for causal inference." Epidemiology pp. 360-372.

Hetherington, Marc J. 1998. "The political relevance of political trust." American Political Science Review 92(4):791-808.

Hetherington, Marc J. 2005. Why Trust Matters. Princeton: Princeton University Press.

Hetherington, Marc J and Suzanne Globetti. 2002. "Political trust and racial policy preferences." American Journal of Political Science pp. 253-275.

Hetherington, Marc J. and Thomas J. Rudolph. 2008. "Priming, Performance, and the Dynamics of Political Trust." The Journal of Politics 70(2):498-512.

Hibbing, John R and Elizabeth Theiss-Morse. 2002. Stealth Democracy. Cambridge: Cambridge University Press.

Ho, Daniel E, Kosuke Imai, Gary King and Elizabeth A Stuart. 2007. "Matching as nonparametric preprocessing for reducing model dependence in parametric causal inference." Political Analysis 15(3):199-236.

Intawan, Chanita and Stephen P Nicholson. 2018. "My trust in government is implicit." The Journal of Politics 80(2):601-614. 
Kuziemko, Ilyana, Michael I Norton, Emmanuel Saez and Stefanie Stantcheva. 2015. "How elastic are preferences for redistribution?" The American Economic Review 105(4):14781508 .

Lakens, Daniël. 2017. "Equivalence tests." Social Psychological and Personality Science $8(4): 355-362$.

Levi, Margaret and Laura Stoker. 2000. "Political trust and trustworthiness." Annual Review of Political Science 3(1):475-507.

Meltzer, Allan H and Scott F Richard. 1981. "A rational theory of the size of government." Journal of Political Economy 89(5):914-927.

Miller, Arthur H. 1974. "Political issues and trust in government." American Political Science Review 68(03):951-972.

Morisi, Davide, John T Jost and Vishal Singh. 2019. "An asymmetrical 'president-in-power' effect." American Political Science Review 113(2):614-620.

Nair, Gautam. 2018. "Misperceptions of relative affluence and support for international redistribution." The Journal of Politics 80(3):815-830.

Nyhan, Brendan and Jason Reifler. 2018. "The roles of information deficits and identity threat in the prevalence of misperceptions." Journal of Elections, Public Opinion and Parties pp. 1-23.

Persson, Torsten and Guido Enrico Tabellini. 2002. Political Economics. Cambridge: MIT Press.

Piketty, Thomas, Emmanuel Saez and Gabriel Zucman. 2017. "Distributional national accounts." The Quarterly Journal of Economics 133(2):553-609.

Popp, Elizabeth and Thomas J Rudolph. 2011. "A tale of two ideologies." The Journal of Politics 73(3):808-820.

Rainey, Carlisle. 2014. "Arguing for a negligible effect." American Journal of Political Science 58(4):1083-1091.

Rudolph, Thomas J. 2017. Political Trust as a Heuristic. In The Handbook of Political Trust, ed. Sonja Zmerli and Tom var der Meer. Cheltenham: Edward Algar Publishing pp. 197-211.

Rudolph, Thomas J and Jillian Evans. 2005. "Political trust, ideology, and public support for government spending." American Journal of Political Science 49(3):660-671.

Samii, Cyrus. 2016. "Causal empiricism in quantitative research." The Journal of Politics 78(3):941-955.

Shapiro, Ian. 2002. "Why the poor don't soak the rich." Daedalus 131(1):118-128. 
Shayo, Moses. 2009. "A model of social identity with an application to political economy." American Political Science Review 103(2):147-174.

Sovey, Allison J and Donald P Green. 2011. "Instrumental variables estimation in political science." American Journal of Political Science 55(1):188-200.

Stokes, Donald E. 1962. Popular Evaluations of Government. In Ethics and Bigness, ed. Harlan Cleveland and Harold D Lasswell. New York: Harper and Brothers pp. 61-72. 


\title{
Online Appendix for "Does Trust in Government Increase Support for Redistribution? Results from Randomized Survey Experiments"
}

\author{
Kyle Peyton*
}

Version: January 2020

\section{Contents}

\section{List of Figures}

\section{List of Tables}

$\begin{array}{lr}\text { S1 Overview } & 1\end{array}$

S2 Political Corruption Experiments $\quad 4$

S2.1 Experiment 1 (June 2014) . . . . . . . . . . . . . . . . . . . . 4

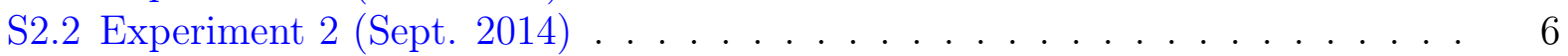

S2.3 Experiment $3($ March 2017) . . . . . . . . . . . . . . . 8

S3 Placebo Experiments $\quad 11$

S3.1 Experiment 4 (December 2014) . . . . . . . . . . . . . . . . . 11

S3.2 Experiment 5 (July 2015) . . . . . . . . . . . . . . . 13

$\begin{array}{ll}\text { S4 Outcome measurement } & 16\end{array}$

S4.1 Trust in Government . . . . . . . . . . . . . . . . . . 16

S4.1.1 Likert Scale . . . . . . . . . . . . . . . . . . 16

S4.1.2 ANES Item . . . . . . . . . . . . . . . . . . . . . 19

S4.2 Support for Redistribution . . . . . . . . . . . . . . . . . . 22

*Postdoctoral Fellow in Law and Social Science, The Justice Collaboratory, Yale Law School. Email: kyle.peyton@yale.edu. 
S5 Supplementary analyses and explanatory notes

S5.1 Average Political Trust and Support for Redistribution by Treatment Arm in Experiments 1-5 . . . . . . . . . . . . . . . .

S5.2 Estimated Treatment Effects of Honest and Corrupt Conditions on Trust and Support for Redistribution, Relative to Control . . . . . . . . . . . . 30

S5.3 First Stage, Reduced Form, and 2SLS Estimates (Main Results) . . . . . . . 32

S5.4 Estimated Treatment Effects from Regression Models with Treatment-Covariate Interactions . . . . . . . . . . . . . . . . . . . . 34

S5.5 Effects on Other Policy Preferences . . . . . . . . . . . . . . . . . . . . 39

S5.6 Effects on Trust in Other Organizations/Groups . . . . . . . . . . . . . 42

S5.7 Effects on Additional Measures in Experiment $3 \ldots \ldots$. . . . . . . . 45

S5.7.1 Effects on Perceptions of Inequality, Resentment of the Rich, Tax Rates, and Policy Solutions to Inequality . . . . . . . . . . . 47

S5.8 Subject Recruitment, Attention Check Questions and "Demand Effects" . . . 52

S5.8.1 Demand Effects . . . . . . . . . . . . . . . . . 54

A Treatment Text and Additional Supporting Information 57

A.1 Experiment $1-2 \ldots \ldots \ldots \ldots \ldots \ldots \ldots$. . . . . . . . . . . . . . . 57

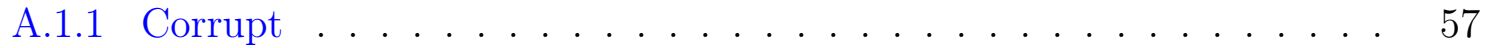

A.1.2 Control . . . . . . . . . . . . . . . . . . . . 60

A.1.3 Honest . . . . . . . . . . . . . . . . . . . . 63

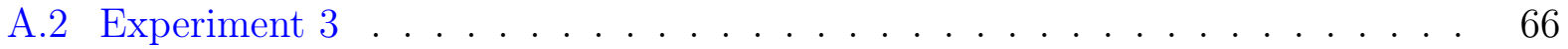

A.2.1 Corrupt . . . . . . . . . . . . . . . . . . . 72

A.2.2 Control . . . . . . . . . . . . . . . . . . . . . . 74

A.2.3 Honest . . . . . . . . . . . . . . . . . . . 76

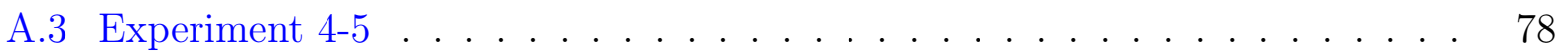

A.3.1 Corrupt . . . . . . . . . . . . . . . . . . . 78

A.3.2 Control . . . . . . . . . . . . . . . . . . . . 80

A.3.3 Honest . . . . . . . . . . . . . . . . . . . . . 81

$\begin{array}{lr}\text { Bibliography } & 84\end{array}$

\section{List of Figures}

S1 Experiment flow diagram . . . . . . . . . . . . . . . . . . 3

S2 Randomization Inference for Covariate Balance in Experiment $1 \ldots \ldots$. . . . 5

S3 Randomization Inference for Covariate Balance in Experiment $2 \ldots . . .8$

S4 Randomization Inference for Covariate Balance in Experiment 3 . . . . . . 10

S5 Randomization Inference for Covariate Balance in Experiment 4 . . . . . . 13

S6 Randomization Inference for Covariate Balance in Experiment 5 . . . . . 15

S7 Response distribution in Control Group for Likert Scale . . . . . . . . . . . . 18

S8 Response distribution in Control Group for ANES Item . . . . . . . . . . . 21 
S9 Attention Check Question in Third Politics Study . . . . . . . . . . . 54

S10 Debrief in Experiments 1-2 and 4-5 . . . . . . . . . . . . . . 57

S11 Debrief in Experiment $3 \ldots \ldots$. . . . . . . . . . . . . . . 69

S12 Trends in DOJ Prosecutions of Public Officials by Level of Government . . . 70

S13 Interpretation of trends by treatment arm . . . . . . . . . . . . 71

S14 Interpretation of support by treatment arm . . . . . . . . . . . . . 71

S15 Corrupt Op-Ed in Experiment 3 . . . . . . . . . . . . . . . 72

S16 Data Visualization of increasing Corruption in Experiment 3 . . . . . . . 73

S17 Control Op-Ed in Experiment $3 \ldots \ldots$. . . . . . . . . . . . 74

S18 Data Visualization of increasing Municipal Waste in Experiment 3 . . . . 75

S19 Honest Op-Ed in Experiment $3 \ldots \ldots$. . . . . . . . . . . . 76

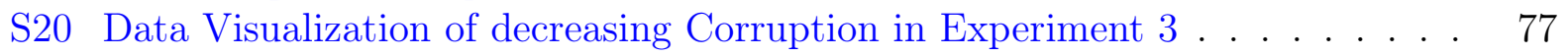

\section{List of Tables}

S1 Summary of Experiments 1-5 . . . . . . . . . . . . . . . . . 2

S2 Treatment Assignments in Experiment 1 . . . . . . . . . . . . 4

S3 Sample characteristics in Experiment 1 . . . . . . . . . . . . 5

S4 Treatment Assignments in Experiment 2 . . . . . . . . . . . . 7

S5 Sample characteristics in Experiment 2 . . . . . . . . . . . 7

S6 Treatment Assignments in Experiment $3 \ldots \ldots$. . . . . . . . . . . . . . . . 9

S7 Sample characteristics in Experiment $3 \ldots \ldots . \ldots . \ldots 9$

S8 Treatment Assignments in Experiment 4 . . . . . . . . . . . . . . . 12

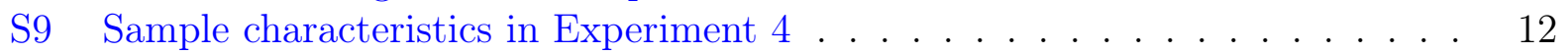

S10 Treatment Assignments in Experiment 5 . . . . . . . . . . . . . 14

S11 Sample characteristics in Experiment 5 . . . . . . . . . . . . . . 14

S12 Internal reliability of Likert Scale . . . . . . . . . . . . . . . . . 19

S13 Internal reliability of Support for Redistribution Index . . . . . . . . . . . . 22

S14 Randomization Inference (RI) for Reduced Form Effects by Experiment . . . 28

S15 Group Means for Scaled Political Trust DV . . . . . . . . . . . . . . . . . 28

S16 Group Means for ANES Political Trust Measure . . . . . . . . . . . . . . . . 28

S17 Group Means for Redistribution DVs . . . . . . . . . . . . . . . . . . . . 29

S18 Group Means for Scaled Redistribution DV . . . . . . . . . . . . . . . . . . 29

S19 Covariate-adjusted Treatment Effect Estimates of Honest and Corrupt Conditions on Trust and Support for Redistribution, Relative to Control (Pooled) 31

S20 Unadjusted Treatment Effect Estimates of Honest and Corrupt Conditions on Trust and Support for Redistribution, Relative to Control (Pooled) . . . . . 31

S21 Covariate-adjusted First-Stage, Reduced Form, and 2SLS Estimates (Pooled) 33

S22 Unadjusted First-Stage, Reduced Form, and 2SLS Estimates (Pooled) . . . . 33

S23 Covariate-adjusted Reduced Form and 2SLS Estimates by Redistribution Item (Pooled) . . . . . . . . . . . . . . . . . . . . 33

S24 Unadjusted Reduced Form and 2SLS Estimates by Redistribution Item (Pooled) 34 
S25 Covariate-adjusted First Stage, Reduced Form, and 2SLS Estimates by Experiment . . . . . . . . . . . . . . . . . . 34

S26 First Stage Estimates with Covariate Interactions (Pooled) . . . . . . . . . 37

S27 Reduced Form Estimates with Covariate Interactions (Pooled) . . . . . . . . 37

S28 2SLS Estimates with Covariate Interactions (Pooled) . . . . . . . . . . . 38

S29 Unadjusted v. Adjusted $P$-values for Interactions by Model . . . . . . . . . . 38

S30 First Stage Effects on Broader Scope of Government . . . . . . . . . . . . . 40

S31 First Stage Effects on Support for Distributive Policies . . . . . . . . . . . . 40

S32 First Stage Effects on Trust in Other Social Groups . . . . . . . . . . . . . 43

S33 First Stage Effects on Trust in Other Groups/Organizations . . . . . . . . . 43

S34 First Stage Effects on Binary Trust in Government Measures . . . . . . . . . 44

S35 First Stage Effects on Additional Measures . . . . . . . . . . . . . . . 46

S36 First Stage Effects on Perceptions of Inequality and Resentment of the Rich 48

S37 First Stage Effects on Ideal Tax Rates _. . . . . . . . . . . . . . . . . 49

S38 First Stage Effects on Preferred Methods for Addressing Inequality . . . . . 49

S39 First Stage, Reduced Form and 2SLS Estimates by ACQ Passing . . . . . . . 54

S40 Group means for Questions about Op-Eds . . . . . . . . . . . . . . 70

S41 Group means for Questions about Data Visualizations . . . . . . . . . . . 70 


\section{S1 Overview}

Table S1 summarizes the five survey experiments, conducted between June 2014 and March 2017, described in the manuscript. Excepting Experiment 2, participants were recruited from Amazon Mechanical Turk (MTurk) and assigned to one of three treatment arms Corrupt, Control, or Honest - with equal probability according to simple random assignment. Experiment 2, conducted on a nationally representative online panel, deviated from the simple design and used block random assignment by party identification to ensure balance in partisanship across treatment conditions. All estimators use inverse probability weighting (IPW) to account for the different assignment probabilities in Experiment 2.

Figure S1 illustrates the basic design of each experiment. All experiments were conducted using Qualtrics survey software. Pre-treatment questions included standard demographic measures and party identification. The Honest and Corrupt treatments were putative OpEds published in The New York Times, inspired by a real New York Times article (see Wines, 2014) about political corruption. The Op-Eds in Experiments 1-2 were identical. In Honest, participants read an Op-Ed titled "It Only Seems that Political Corruption is Rampant" that emphasized the integrity of government officials and low levels of corruption. In Corrupt, participants read an Op-Ed, titled "Political Corruption is Rampant", that used contrasting language about the lack of integrity among government officials and the prevalence of political corruption. In Control, participants read a piece about celebrity chef Anthony Bourdain.

Experiment 3 also provided data visualizations to support the Op-Ed writer's argument, but the content otherwise matched Experiments 1-2. Control in Experiment 3 was an Op-Ed about recycling, also supplemented with a data visualization. Control in Experiments 4-5 were identical to Experiments 1-2, and the Honest and Corrupt treatment arms provided information about the absence or presence of corruption in the National Football League (NFL) instead of politics. See Section A for the full text that appeared in each treatment 
arm across Experiments 1-5 and additional details.

All of the Op-Eds in Experiments 1-5 were loosely based on past events and drew on factual information about real cases of misconduct in American politics and the NFL; however, they were not real Op-Eds and therefore used mild deception. This was approved by the Human Ethics committee in Experiments 1,2 and 4, conditional on a de-brief at the end of the survey with an option for participants to remove their data. Figure S10 shows this prompt. All subjects that elected to have their data removed are excluded from analyses per IRB requirements. There is no evidence that these decisions were a function of treatment assignment in any of experiment (see Section S2-S3). The author had moved to a different university when Experiments 3 and 5 were designed and implemented. The Institutional Review Board (IRB) at this university also required a debrief, but did not mandate that subjects also be given the opportunity to remove their data afterward.

Section S2 provides additional details about the sample characteristics for Experiments 1-3, along with tests of key design assumptions. Section S3 provides this information for Experiments 4-5. Section S5 provides a variety of additional analyses, robustness checks, and explanatory notes, including details about subject recruitment, survey-taker attentiveness, and an overview of recent research on the nature of "demand effects" in online survey experiments.

TABLE S1: Summary of Experiments 1-5

\begin{tabular}{lcccc}
\hline & Op-Ed Content & Date & Platform & Sample Size \\
\hline Experiment 1: & Political Corruption & June 2014 & MTurk & 643 \\
Experiment 2: & Political Corruption & September 2014 & Qualtrics Panels & 1324 \\
Experiment 3: & Political Corruption & March 2017 & MTurk & 1870 \\
Experiment 4: & Non-Political Corruption & December 2014 & MTurk & 584 \\
Experiment 5: & Non-Political Corruption & July 2015 & MTurk & 585 \\
\hline
\end{tabular}


FiguRE S1: Experiment flow diagram

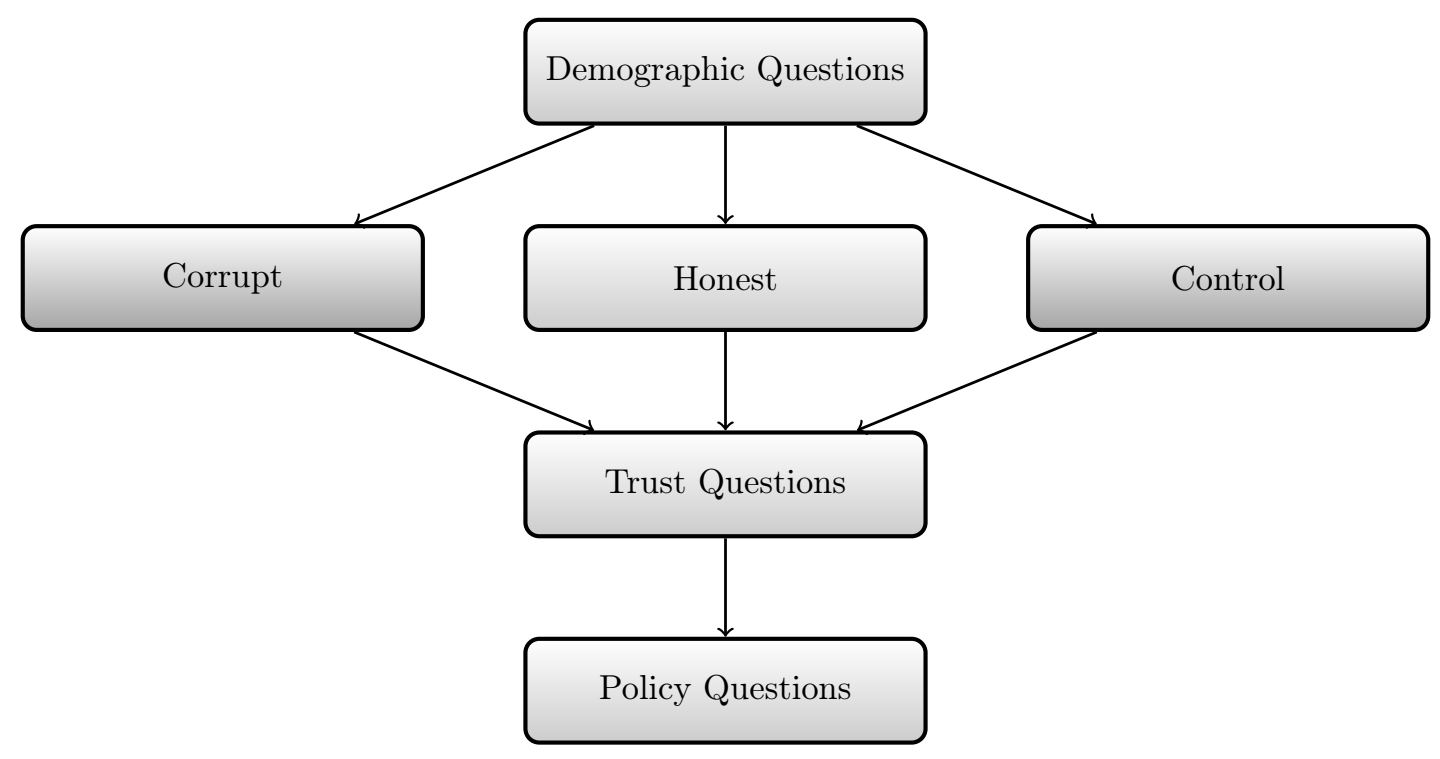




\section{S2 Political Corruption Experiments}

\section{S2.1 Experiment 1 (June 2014)}

692 subjects were recruited via MTurk and 20 respondents were excluded for having the same IP Address. Of the remaining 672 subjects, 29 asked to have their data removed from the experiment after learning about deception in the debrief. These responses were removed in accordance with IRB requirements. An F-test from a linear regression of removal on treatment assignment confirmed that assignment was not predictive of the removal request $(P$-value $=0.78)$. Table S2 shows the allocation of the remaining 643 subjects across treatment arms. Table S3 shows sample characteristics. Randomization inference is used to asses covariate balance across treatment arms (see Gerber and Green, 2012, Chapter 4 for a textbook treatment) using the ri2 package in $\mathrm{R}$ (Coppock, 2018). Figure S2 plots a histogram of the observed F-statistic, and the null distribution of F-statistics, from a regression of treatment assignment on covariates. Approximately $39 \%$ of the simulated F-statistics were larger than the observed F-statistic ( $P$-value of 0.39$)$. Thus, the null hypothesis that no covariates have any effect on treatment assignment, as implied by the experimental design, is not rejected.

TABLE S2: Treatment Assignments in Experiment 1

\begin{tabular}{lllll}
\hline \multicolumn{4}{c}{ Treatment Condition } \\
\hline & Control & Corrupt & Honest & Totals \\
$\mathrm{N}$ & 215 & 217 & 211 & 643 \\
\hline
\end{tabular}


TABLE S3: Sample characteristics in Experiment 1

\begin{tabular}{lccccc}
\hline \hline & Mean & St. Dev. & Median & Min & Max \\
\hline Female & 0.46 & 0.50 & 0.00 & 0 & 1 \\
Age & 35.37 & 11.82 & 32.00 & 19 & 80 \\
College degree & 0.49 & 0.50 & 0.00 & 0 & 1 \\
Employed & 0.78 & 0.42 & 1.00 & 0 & 1 \\
Asian & 0.05 & 0.22 & 0.00 & 0 & 1 \\
Black & 0.08 & 0.28 & 0.00 & 0 & 1 \\
Hispanic & 0.04 & 0.20 & 0.00 & 0 & 1 \\
White & 0.79 & 0.40 & 1.00 & 0 & 1 \\
Democrat & 0.44 & 0.50 & 0.00 & 0 & 1 \\
Republican & 0.18 & 0.39 & 0.00 & 0 & 1 \\
\hline
\end{tabular}

Figure S2: Randomization Inference for Covariate Balance in Experiment 1

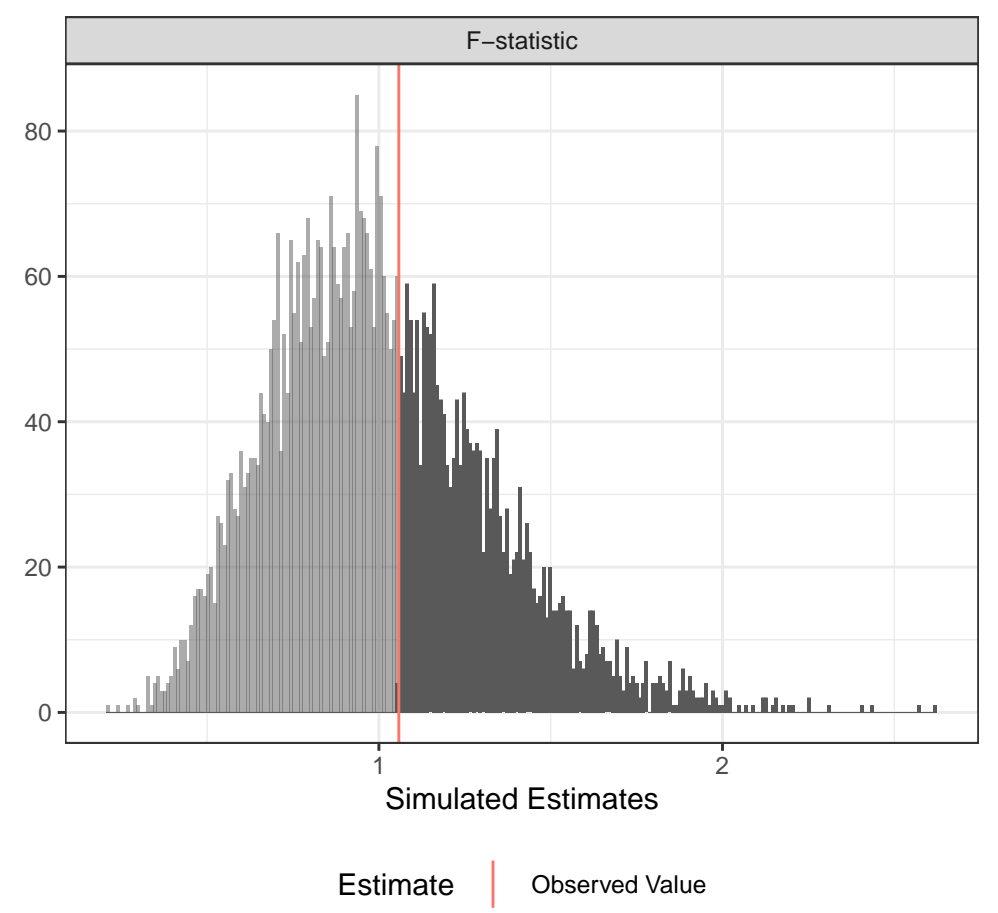

Notes: The vertical red line denotes the observed F-statistic (1.06). Shaded regions denote simulated estimates more extreme than the one observed. The randomization inference $P$-value is 0.39 . The test is based on 5,000 simulations under the null hypothesis that no covariates have any effect on treatment assignment, as implied by random assignment. 


\section{S2.2 Experiment 2 (Sept. 2014)}

1474 subjects were recruited via Qualtrics Panels and 1452 remained after excluding duplicate IP Addresses. Of these, 128 asked to have their data removed from the experiment after learning about deception. An F-test from a linear regression of removal on treatment assignment confirmed that assignment was not predictive of the removal request $(P$-value $=$ 0.38). The final sample size was 1324. This was a US General population sample and used the following quotas:

1. Age: Atleast $86 \%$ of sample less than 65 years old

2. Sex: 50/50 balance

3. Race: $63 \%$ of the population should be white, $13 \%$ should be black and $17 \%$ should be Hispanic.

4. Education: $85 \%$ High School or higher. At least $28 \%$ bachelors degree or higher.

5. Party identification: 42\% should be Independent; 25\% Republican; 31\% Democrat

MTurk workers tend to skew white, educated, and liberal (see Berinsky, Huber and Lenz, 2012). The party identification quotas were chosen in light of contemporaneous Gallup polls showing the increasing proportion of self-identified Independents in the United States $^{1}$, and the race quotas were chosen based on 2013 census estimates. ${ }^{2}$ All quotas were approximately met, so this sample is a reasonable approximation to a nationally representative sample of Americas on these observables.

Table S4 shows the allocation of subjects across conditions. Table S5 shows sample characteristics. Randomization inference is again used to asses covariate imbalance across

\footnotetext{
${ }^{1}$ see: http://www.gallup.com/poll/180440/new-record-political-independents.aspx

${ }^{2}$ see http://quickfacts.census.gov/qfd/states/00000.html
} 
treatment arms. Figure S3 plots a histogram of the observed F-statistic, and the null distribution of F-statistics, from a regression of treatment assignment on covariates. Approximately $73 \%$ of the simulated F-statistics were larger than the observed F-statistic ( $P$-value of 0.73$)$. Thus, the null hypothesis that no covariates have any effect on treatment assignment cannot be rejected, as implied by the experimental design.

TABLE S4: Treatment Assignments in Experiment 2

\begin{tabular}{lllll}
\hline \multicolumn{4}{c}{ Treatment Condition } \\
\hline & Control & Corrupt & Honest & Totals \\
$\mathrm{N}$ & 430 & 443 & 451 & 1324 \\
\hline
\end{tabular}

TABLE S5: Sample characteristics in Experiment 2

\begin{tabular}{lccccc}
\hline \hline & Mean & St. Dev. & Median & Min & Max \\
\hline Female & 0.49 & 0.50 & 0.00 & 0 & 1 \\
Age & 43.38 & 16.32 & 41.00 & 18 & 88 \\
College degree & 0.41 & 0.49 & 0.00 & 0 & 1 \\
Employed & 0.60 & 0.49 & 1.00 & 0 & 1 \\
Asian & 0.05 & 0.22 & 0.00 & 0 & 1 \\
Black & 0.13 & 0.33 & 0.00 & 0 & 1 \\
Hispanic & 0.17 & 0.37 & 0.00 & 0 & 1 \\
White & 0.64 & 0.48 & 1.00 & 0 & 1 \\
Democrat & 0.31 & 0.46 & 0.00 & 0 & 1 \\
Republican & 0.27 & 0.45 & 0.00 & 0 & 1 \\
\hline
\end{tabular}


Figure S3: Randomization Inference for Covariate Balance in Experiment 2

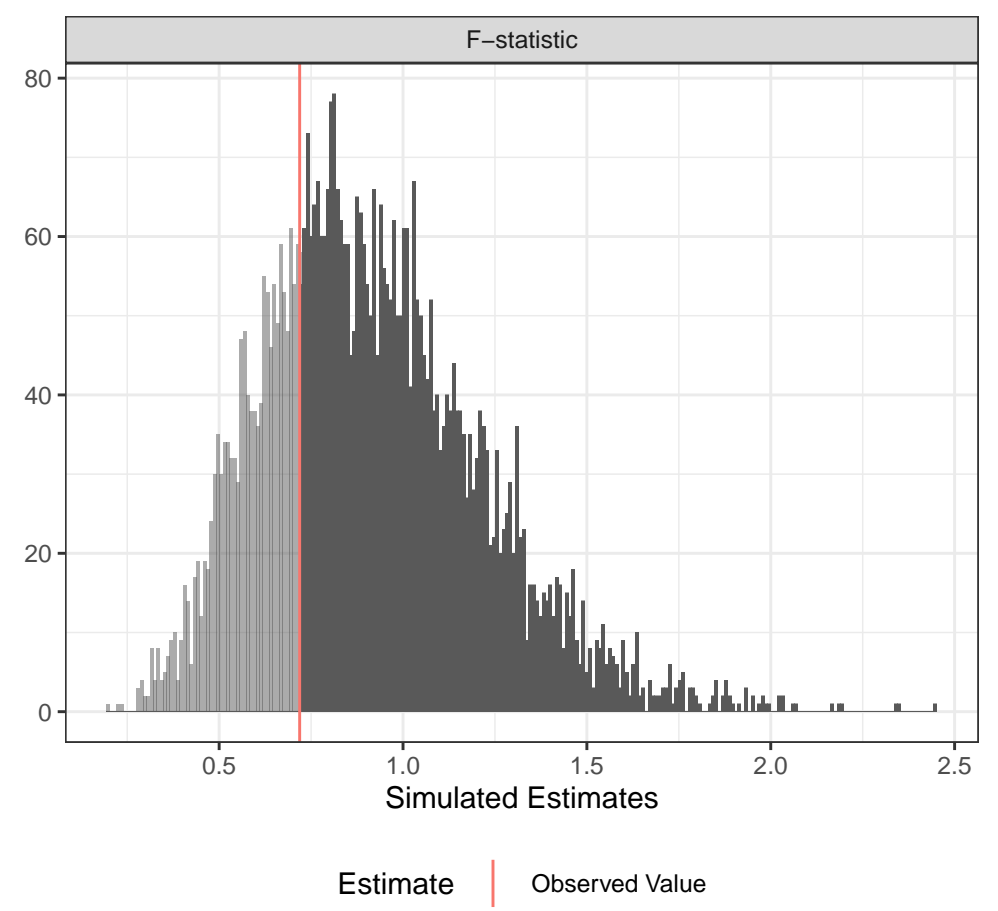

Notes: The vertical red line denotes the observed F-statistic (0.72). Shaded regions denote simulated estimates more extreme than the one observed. The randomization inference $P$-value is 0.73 . The test is based on 5,000 simulations under the null hypothesis that no covariates have any effect on treatment assignment, as implied by random assignment.

\section{S2.3 Experiment 3 (March 2017)}

1976 subjects were recruited via MTurk and 106 were excluded for attempting to access the survey more than once from the same IP Address for a final sample of 1870 subjects. Table S6 shows the allocation of these subjects across treatment arms. Table S7 shows samples characteristics. Randomization inference is again used to asses covariate imbalance across treatment arms. Figure S4 plots a histogram of the observed F-statistic, and the null distribution of F-statistics, from a regression of treatment assignment on covariates. Approximately $55 \%$ of the simulated F-statistics were larger than the observed F-statistic ( $P$-value of 0.55$)$. Thus, the null hypothesis that no covariates have any effect on treatment 
assignment is not rejected, as implied by the experimental design.

TABle S6: Treatment Assignments in Experiment 3

\begin{tabular}{lllll}
\hline \multicolumn{5}{c}{ Treatment Condition } \\
\hline & Control & Corrupt & Honest & Totals \\
$\mathrm{N}$ & 662 & 583 & 625 & 1870 \\
\hline
\end{tabular}

TABLE S7: Sample characteristics in Experiment 3

\begin{tabular}{lccccc}
\hline \hline & Mean & St. Dev. & Median & Min & Max \\
\hline Female & 0.46 & 0.50 & 0.00 & 0 & 1 \\
Age & 36.33 & 11.00 & 34.00 & 18 & 72 \\
College degree & 0.46 & 0.50 & 0.00 & 0 & 1 \\
Employed & 0.74 & 0.44 & 1.00 & 0 & 1 \\
Asian & 0.07 & 0.26 & 0.00 & 0 & 1 \\
Black & 0.08 & 0.27 & 0.00 & 0 & 1 \\
Hispanic & 0.05 & 0.21 & 0.00 & 0 & 1 \\
White & 0.75 & 0.43 & 1.00 & 0 & 1 \\
Democrat & 0.44 & 0.50 & 0.00 & 0 & 1 \\
Republican & 0.22 & 0.41 & 0.00 & 0 & 1 \\
\hline
\end{tabular}


Figure S4: Randomization Inference for Covariate Balance in Experiment 3

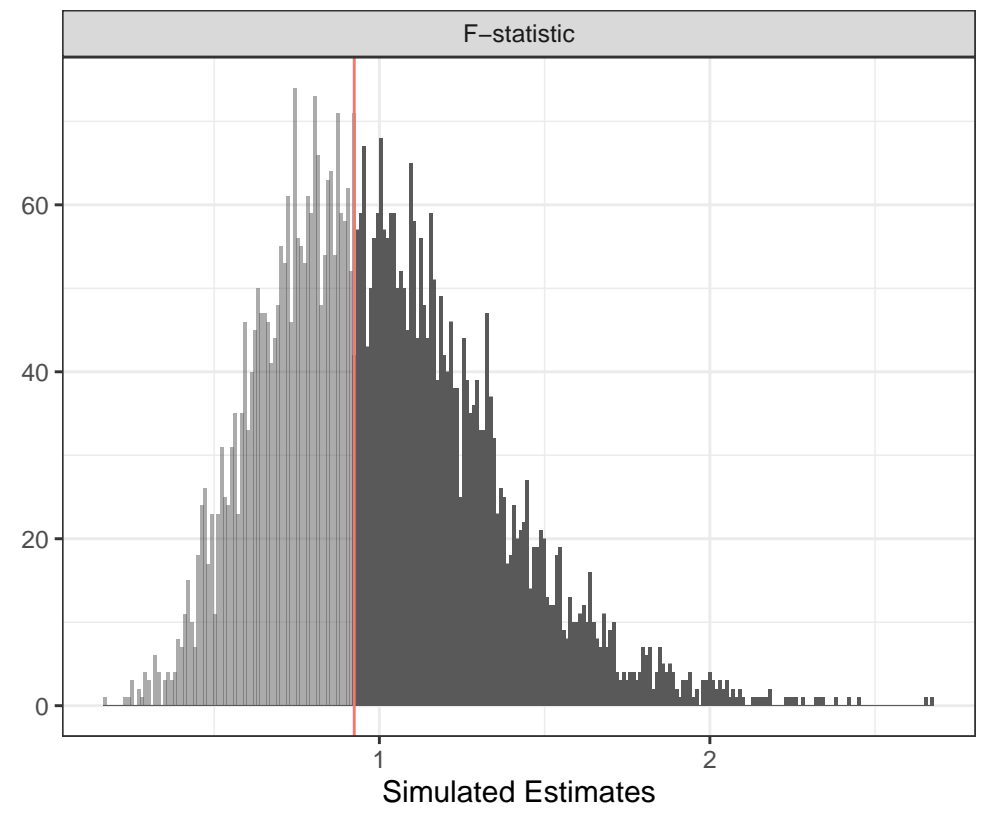

\begin{tabular}{l|l} 
Estimate & Observed Value
\end{tabular}

Notes: The vertical red line denotes the observed F-statistic (0.92). Shaded regions denote simulated estimates more extreme than the one observed. The randomization inference $P$-value is 0.55 . The test is based on 5,000 simulations under the null hypothesis that no covariates have any effect on treatment assignment, as implied by random assignment. 


\section{S3 Placebo Experiments}

The exclusion restriction assumption, as explained in the manuscript, holds that any treatment effect on support for redistribution occurs through increased political trust, which could be violated if treatment impacted support for redistribution via another pathway. Two survey experiments randomly assigned participants to receive information about corruption in the National Football League (NFL). These "placebo experiments" are used to investigate whether the increased political trust in Experiments 1-3 is simply a function of content valence, or priming respondents to think about corruption in a salient non-government institution $^{3}$ If treatment effects on political trust in Experiments 1-3 are simply a function of content valence, then an effect should also be detectable when political content is removed. If support for redistribution - but not political trust - is affected by treatments about nonpolitical corruption, this provides evidence of an ER violation and suggests an alternative mechanism could bias results from Experiments 1-3.

\section{S3.1 Experiment 4 (December 2014)}

624 subjects were recruited using MTurk and 612 remained after excluding duplicate IP Addresses. Of those remaining, 28 asked to have their data removed from the experiment after learning about deception in the debrief. An F-test from a linear regression of removal on treatment assignment confirmed that assignment was not predictive of the removal request $(P$-value $=0.35)$. The final sample size was 584 . Table $\mathrm{S} 8$ shows the allocation of subjects across conditions. Table S9 shows demographic characteristics. Randomization inference is used to asses covariate imbalance across treatment arms. Figure S5 plots a histogram of the

\footnotetext{
${ }^{3}$ One way to asses the NFL's popularity is to look at viewership statistics. Publicly available estimates from Harris Interactive suggest football is, by a wide margin, the most popular professional sport in the United States (Interactive, 2015). According to data published by RBC Capital Markets (Ciolli, 2017), the estimated NFL season TV audience was approximately 15 million persons per game in 2017, down by about $12 \%$ from the roughly 17 million persons per game when the NFL experiments were conducted in 2014 and 2015.
} 
observed F-statistic, and the null distribution of F-statistics, from a regression of treatment assignment on covariates. Approximately $83 \%$ of the simulated F-statistics were larger than the observed F-statistic ( $P$-value of 0.83 ). Thus, the null hypothesis that no covariates have any effect on treatment assignment in not rejected, as implied by the experimental design.

TABlE S8: Treatment Assignments in Experiment 4

\begin{tabular}{lllll}
\hline \multicolumn{4}{c}{ Treatment Condition } \\
\hline & Control & Corrupt & Honest & Totals \\
$\mathrm{N}$ & 194 & 195 & 195 & 584 \\
\hline
\end{tabular}

TABLE S9: Sample characteristics in Experiment 4

\begin{tabular}{|c|c|c|c|c|c|}
\hline & Mean & St. Dev. & Median & Min & Max \\
\hline Female & 0.48 & 0.50 & 0.00 & 0 & 1 \\
\hline Age & 33.46 & 11.16 & 30.00 & 18 & 84 \\
\hline College degree & 0.47 & 0.50 & 0.00 & 0 & 1 \\
\hline Employed & 0.79 & 0.41 & 1.00 & 0 & 1 \\
\hline Asian & 0.09 & 0.28 & 0.00 & 0 & 1 \\
\hline Black & 0.07 & 0.26 & 0.00 & 0 & 1 \\
\hline Hispanic & 0.07 & 0.25 & 0.00 & 0 & 1 \\
\hline White & 0.74 & 0.44 & 1.00 & 0 & 1 \\
\hline Democrat & 0.46 & 0.50 & 0.00 & 0 & 1 \\
\hline Republican & 0.15 & 0.35 & 0.00 & 0 & 1 \\
\hline
\end{tabular}


Figure S5: Randomization Inference for Covariate Balance in Experiment 4

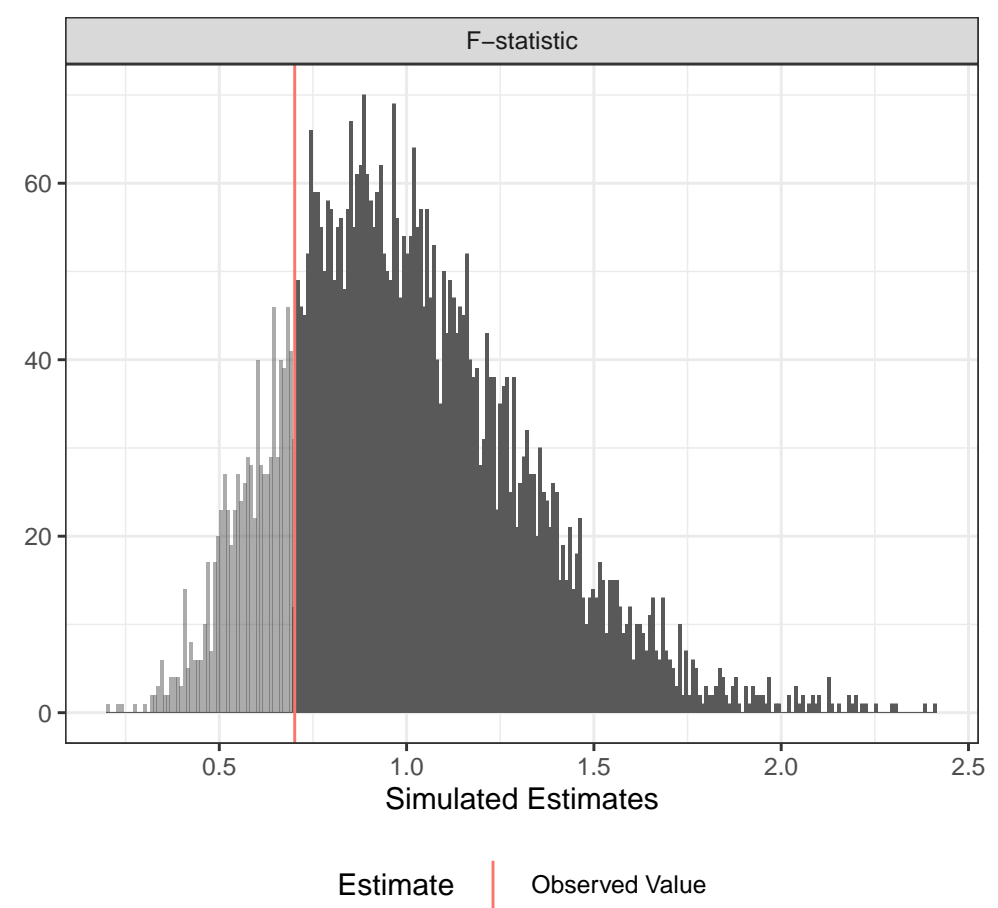

Notes: The vertical red line denotes the observed F-statistic (0.70). Shaded regions denote simulated estimates more extreme than the one observed. The randomization inference $P$-value is 0.83 . The test is based on 5,000 simulations under the null hypothesis that no covariates have any effect on treatment assignment, as implied by random assignment.

\section{S3.2 Experiment 5 (July 2015)}

612 subjects were recruited using MTurk and 27 were excluded for attempting to access the survey more than once from the same IP Address for a final sample of 585. Table S10 shows the allocation of subjects across conditions. Table S11 shows other demographic characteristics. Randomization inference is again used to asses covariate imbalance across treatment arms. Figure S6 plots a histogram of the observed F-statistic, and the null distribution of F-statistics, from a regression of treatment assignment on covariates. Approximately $44 \%$ of the simulated F-statistics were larger than the observed F-statistic ( $P$-value of 0.44$)$. Thus, the null hypothesis that no covariates have any effect on treatment assignment is not rejected, 
as implied by the experimental design.

TABLE S10: Treatment Assignments in Experiment 5

\begin{tabular}{lllll}
\hline \multicolumn{4}{c}{ Treatment Condition } \\
\hline & Control & Corrupt & Honest & Totals \\
$\mathrm{N}$ & 211 & 176 & 198 & 585 \\
\hline
\end{tabular}

TABLE S11: Sample characteristics in Experiment 5

\begin{tabular}{lccccc}
\hline \hline & & & & & \\
& Mean & St. Dev. & Median & Min & Max \\
\hline Female & 0.55 & 0.50 & 1.00 & 0 & 1 \\
Age & 34.74 & 11.64 & 32.00 & 19 & 78 \\
College degree & 0.52 & 0.50 & 1.00 & 0 & 1 \\
Employed & 0.77 & 0.42 & 1.00 & 0 & 1 \\
Asian & 0.06 & 0.24 & 0.00 & 0 & 1 \\
Black & 0.08 & 0.27 & 0.00 & 0 & 1 \\
Hispanic & 0.05 & 0.22 & 0.00 & 0 & 1 \\
White & 0.77 & 0.42 & 1.00 & 0 & 1 \\
Democrat & 0.41 & 0.49 & 0.00 & 0 & 1 \\
Republican & 0.18 & 0.38 & 0.00 & 0 & 1 \\
\hline
\end{tabular}


Figure S6: Randomization Inference for Covariate Balance in Experiment 5

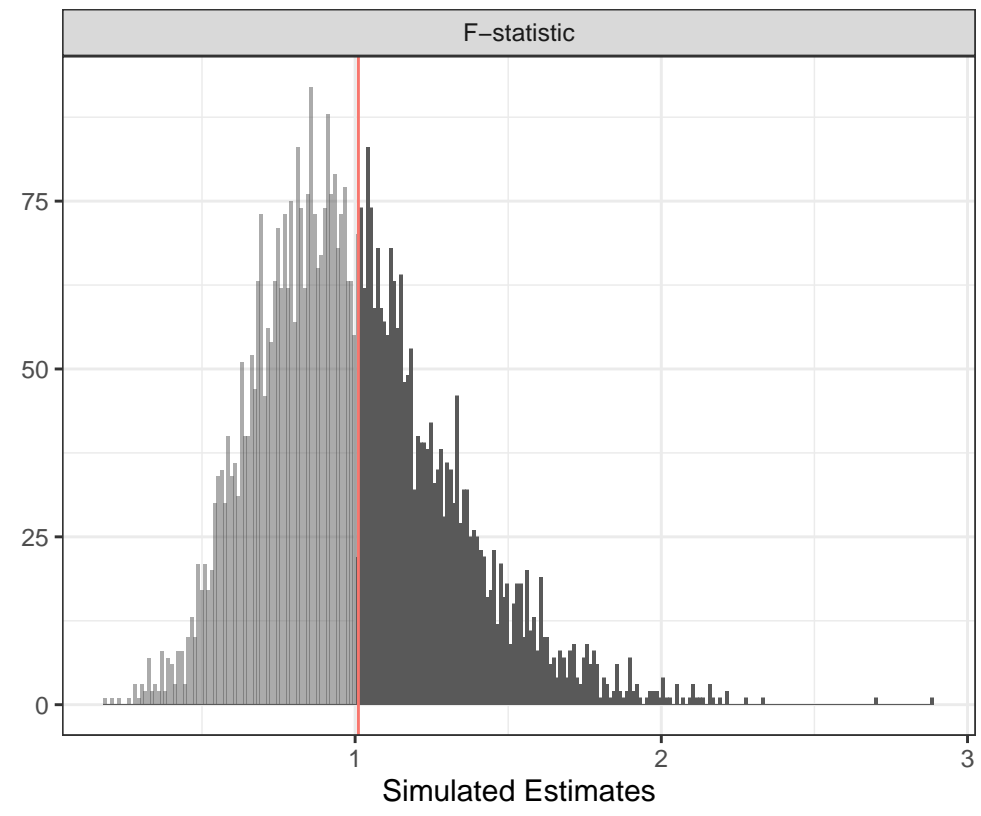

\begin{tabular}{l|l} 
Estimate & Observed Value
\end{tabular}

Notes: The vertical red line denotes the observed F-statistic (1.01). Shaded regions denote simulated estimates more extreme than the one observed. The randomization inference $P$-value is 0.44 . The test is based on 5,000 simulations under the null hypothesis that no covariates have any effect on treatment assignment, as implied by random assignment. 


\section{S4 Outcome measurement}

This section describes the survey instruments, question wording and coding of responses, and the sample means (and standard errors) across treatment arms for the measures of political trust and support for redistribution used in Experiments 1-5. Reliability estimates for the composite measures of trust in government and support for redistribution are also presented for respondents assigned Control in each experiment.

\section{S4.1 Trust in Government}

All experiments use two measures of political trust. The primary measure is a Likert Scale from Faulkner, Martin and Peyton (2015), and the secondary measure is the single-item trust in government measure that has appeared in the ANES survey since 1958, as well as various public opinion polls conducted by Gallup and Pew. Given concerns about attenuation bias and measurement error in the ANES measure (more below), and high internal reliability of the Likert Scale, it is the preferred measures of political trust. The main results reported in the manuscript do not depend on which measure is used. As one would expect (see Ansolabehere, Rodden and Snyder, 2008), estimates based on the ANES item are less precise than the additive scale. As one would expect, political trust is low in Control across all experiments, regardless of which measure is preferred. Trust in government has been at historic lows in the United States over the past decade, and the low levels of political trust observed in the survey experiments reported here are consistent with survey data from a variety of other sources (i.e. Pew, Gallup, ANES).

\section{S4.1.1 Likert Scale}

Respondents were asked to indicate their agreement with each of the following statements measured on a 6 point scale from "Strongly Disagree" to "Strongly Agree": 
1. We generally cannot trust politicians.

2. People in government are too often interested in looking after themselves.

3. Government is run by a few big interests who look after their own interests.

4. A lot of politicians are corrupt.

An additive scale (with range 1-24) was constructed by summing the responses to these 4 items. Figure S7 shows the response distribution in Control across all five experiments. The Omega statistics for internal consistency (Dunn, Baguley and Brunsden, 2013), calculated using the MBESS packaged in R (Kelley and Lai, 2012), are reported in Table S12 (with 95\% confidence intervals). 
FIgURE S7: Response distribution in Control Group for Likert Scale

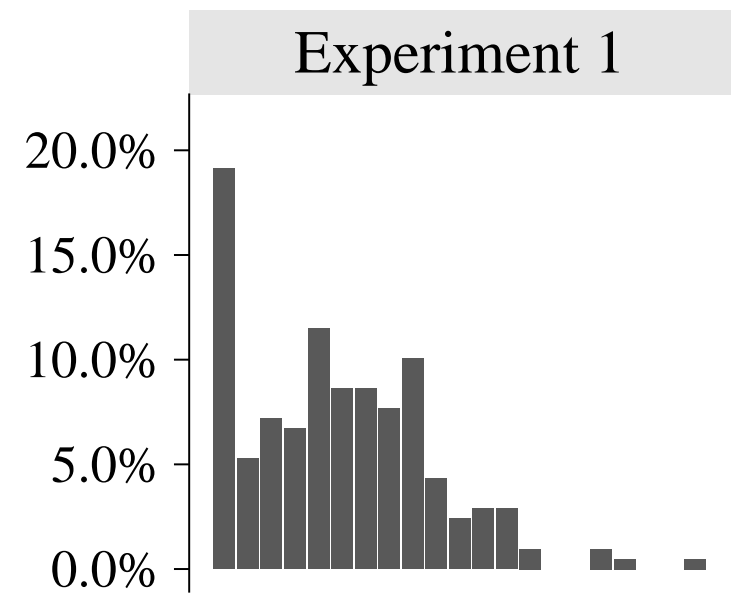

\section{Experiment 2}
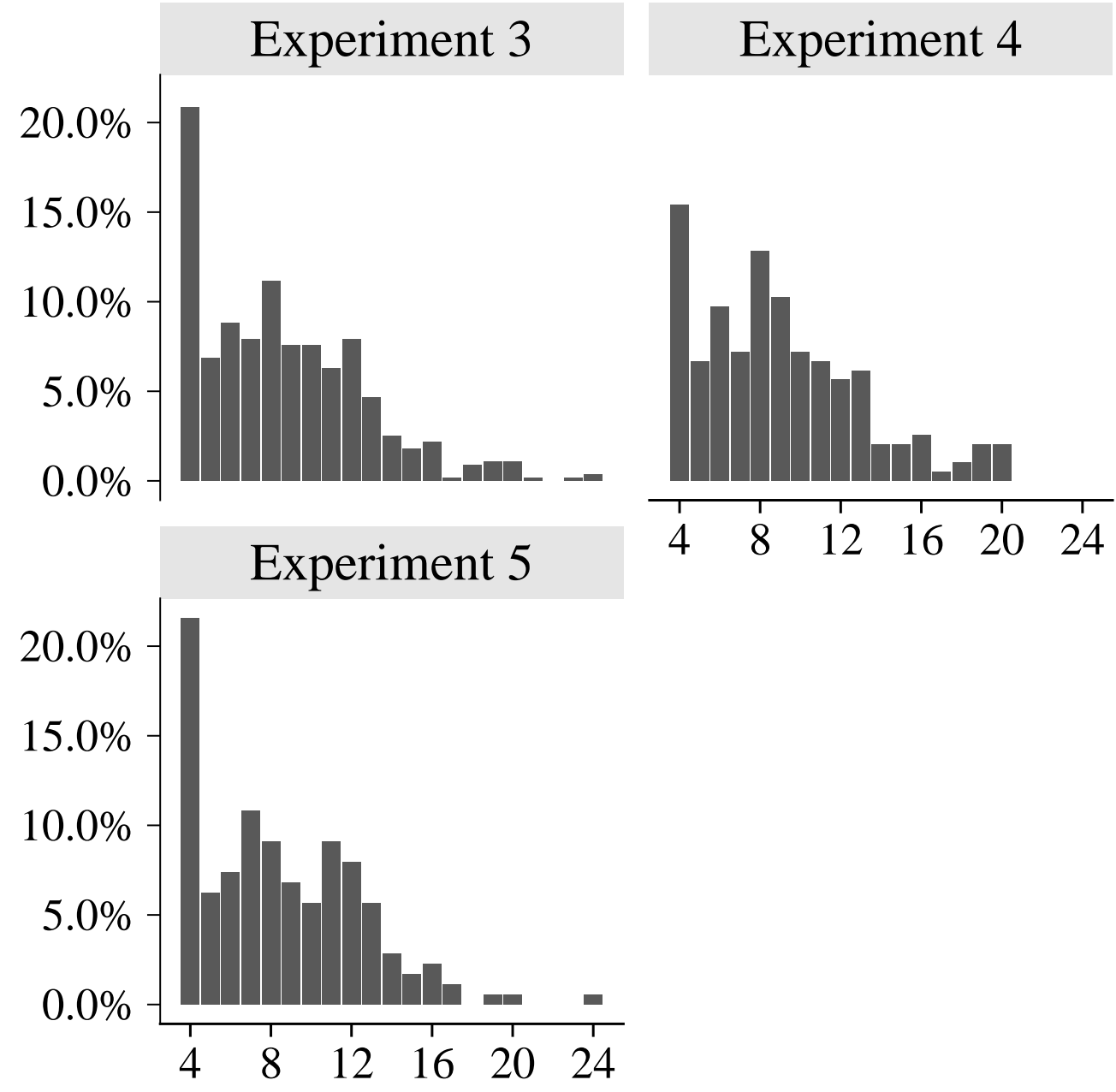
TABLE S12: Internal reliability of Likert Scale

\begin{tabular}{cccccl}
\hline Est. & SE & LB & UB & N (Control) & Experiment \\
\hline 0.90 & 0.02 & 0.87 & 0.93 & 217 & Experiment 1 \\
0.91 & 0.01 & 0.89 & 0.93 & 443 & Experiment 2 \\
0.91 & 0.01 & 0.89 & 0.92 & 583 & Experiment 3 \\
0.92 & 0.01 & 0.90 & 0.94 & 195 & Experiment 4 \\
0.92 & 0.01 & 0.90 & 0.95 & 176 & Experiment 5 \\
\hline
\end{tabular}

\section{S4.1.2 ANES Item}

Since 1958, the ANES survey ${ }^{4}$ has measured trust in government with the following prompt:

"People have different ideas about the government in Washington. These ideas don't refer to democrats or republicans in particular, but just to government in general. We want to see how you feel about these ideas."

"How much of the time do you think you can trust the government in Washington to do what is right- just about always, most of the time or only some of the time?"

Responses are recorded on a three point scale: just about always (1), most of the time (2), only some of the time (3). Survey respondents can also volunteer a response of "never" (4). This three item scale is the subject of frequent criticism by users of the ANES, and changes have been proposed in ANES pilot reports (e.g. Gershtenson and Plane, 2007). In the 2012 version of the ANES Survey, respondents were randomly assigned to either the standard version, or an alternative version with a different response scale. ${ }^{5}$ Respondents assigned

\footnotetext{
${ }^{4}$ See http://www.electionstudies.org/

${ }^{5}$ See http://electionstudies.org/studypages/anes_timeseries_2012/anes_timeseries_2012_ userguidecodebook.pdf
} 
to this alternative version were asked the same question but given the following response options: Always (1), Most of the time (2), About half the time (3), Some of the time (4), Never (5). The standard three-item measure of political trust was used in Experiment 1. Experiments 2, 4, and 5 used this revised 5-item measure. Experiment 3 used the four-item measure from Kuziemko et al. (2015): Never (1), Some of the time (2), Most of the time (3), Just about always (4).

All question responses are rescaled so that higher values correspond to more trust in government. As expected, the number of response options affects the distribution of responses. This variation is illustrated graphically in Figure S8. In Experiment 1, 79\% of respondents in Control said they trusted government "only some of the time", and only 2 respondents said they trusted government "always". This is consistent with recent estimates from nationally representative surveys such as the ANES Time Series Survey ${ }^{6}$, as well as similar public opinion polls conducted by Pew and Gallup that use the same question format (Doherty et al., 2015). When additional response options were available, however, the proportion of respondents selecting the most extreme level of "distrust" decreased substantially. In Experiment 2, only $43 \%$ of respondents in Control indicated they trusted the government "some of the time". Results were similar for both placebo experiments - 52\% of respondents in Experiment 4 and $49 \%$ in Experiment 5. Finally, results from Experiment 3 suggest removing the midpoint "about half the time" also has a non-trivial impact on the proportion of respondents selecting "some of the time". In this experiment, approximately $70 \%$ of respondents in Control reported they trust the government "some of the time". These large differences in reported levels of trust in government - largely attributable to question format choices suggest that low levels of political trust reported in many nationally representative surveys that use the 3-item format may be misleading.

\footnotetext{
${ }^{6}$ See http://www.electionstudies.org/nesguide/toptable/tab5a_1.htm. In 2012, 76\% of respondents said they trusted government "some of the time".
} 
Figure S8: Response distribution in Control Group for ANES Item
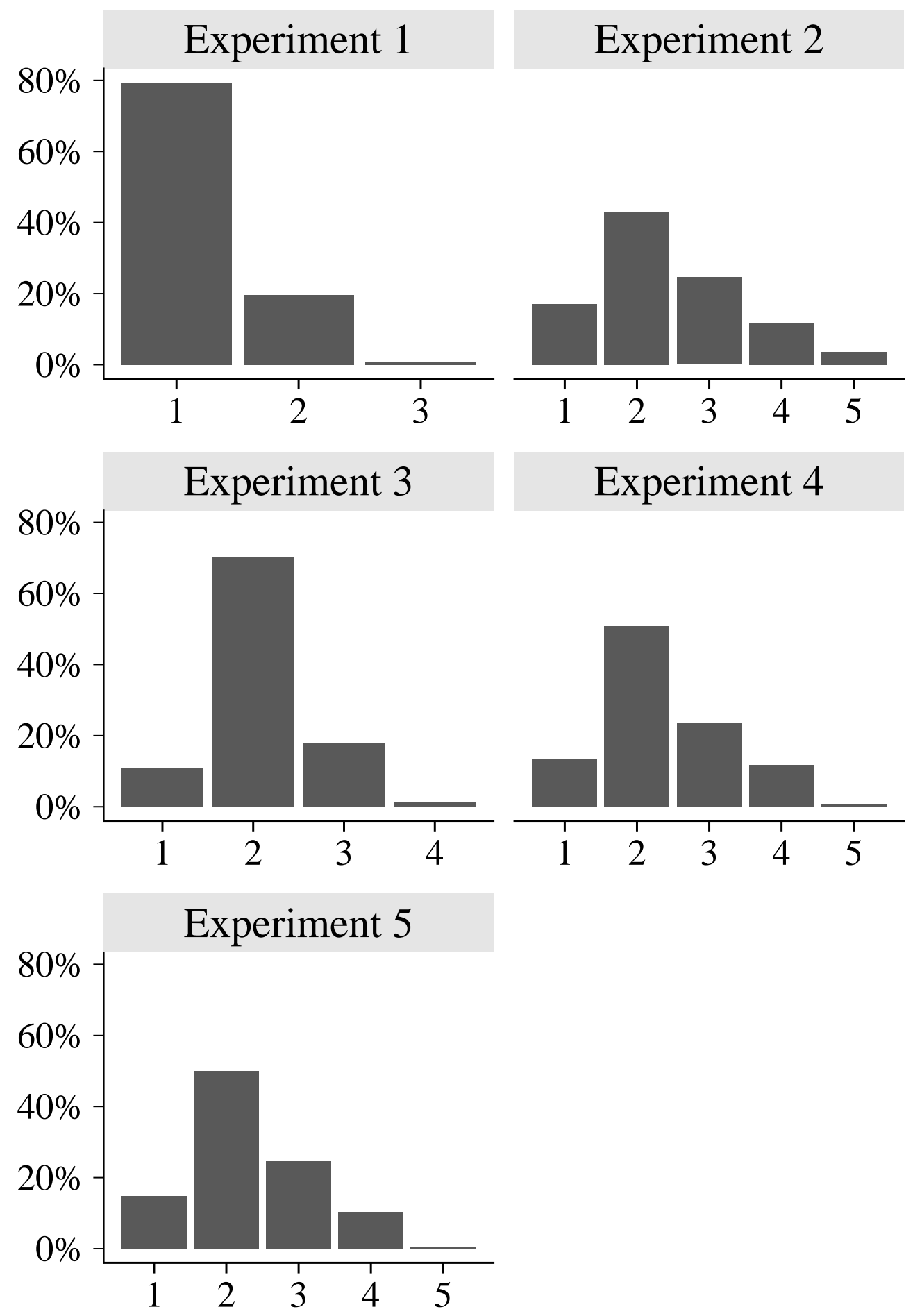


\section{S4.2 Support for Redistribution}

All experiments used four questions about support for redistributive social policy that have appeared in various versions of the ANES Survey since 1984, and have been used in foundational studies of political trust and support for redistribution (e.g. Hetherington, 2005). Respondents are asked "Should federal spending on X be decreased (0), kept the same (0.5), or increased (1)?"

1. Food stamps: decrease (0), remain the same (0.5) or increase (1)

2. Welfare programs: decrease $(0)$, remain the same $(0.5)$ or increase $(1)$

3. Programs that assist blacks and other minorities: decrease (0), remain the same (0.5) or increase (1)

4. Programs that assist the homeless: decrease (0), remain the same (0.5) or increase (1)

Responses to these items are highly correlated and were combined to create an additive scale to reduce measurement error (see Ansolabehere, Rodden and Snyder, 2008). The Omega statistics for internal consistency (Dunn, Baguley and Brunsden, 2013), calculated using the MBESS packaged in R (Kelley and Lai, 2012), are reported in Table S12 (with 95\% confidence intervals).

TABLE S13: Internal reliability of Support for Redistribution Index

\begin{tabular}{cccccl}
\hline Est. & SE & LB & UB & N (Control) & Experiment \\
\hline 0.87 & 0.01 & 0.85 & 0.90 & 217 & Experiment 1 \\
0.85 & 0.01 & 0.83 & 0.88 & 443 & Experiment 2 \\
0.86 & 0.01 & 0.84 & 0.88 & 583 & Experiment 3 \\
0.88 & 0.02 & 0.84 & 0.91 & 195 & Experiment 4 \\
0.89 & 0.01 & 0.86 & 0.92 & 176 & Experiment 5 \\
\hline
\end{tabular}




\section{S5 Supplementary analyses and explanatory notes}

Glass's $\Delta$ : Unless otherwise indicated, all results presented in this section, and in the manuscript, are standardized using Glass's $\Delta$ (Glass, 1976). This is simply a linear transformation of the raw data commonly used to facilitate interpretation: treatment effects are expressed in terms of a standardized effect size (see also Gerber and Green, 2012, pp. 70-71). To illustrate, let $Y_{i}$ denote some response for individual $i$, and $Z_{i}=\{1,2,3\}$ denote treatment assignment so that $Z_{i}=1$ if assigned Control, $Z_{i}=2$ if assigned Honest, and $Z_{i}=3$ if assigned Corrupt. Suppose $N_{1}$ units are assigned Control, $N_{2}$ units are assigned Honest and $N_{3}$ units are assigned Corrupt. Within each experiment, responses scaled by Glass's $\Delta$ are calculated by dividing by the standard deviation of the response in Control so that the rescaled response, $\tilde{Y}_{i}$, is

$$
\tilde{Y}_{i}=Y_{i} \cdot\left(\sqrt{\frac{\sum_{i \in N_{1}}\left(Y_{i}-\bar{Y}\right)^{2}}{N_{1}-1}}\right)^{-1}
$$

Where $\bar{Y}$ denotes the control group mean.

IV Estimation: I estimate the effect of political trust on support for redistribution using Two-Stage Least Squares (2SLS). Equation 1 models subject $i$ 's support for redistribution, $Y_{i}$, endogenous political trust, $T_{i}$, pre-treatment covariates, $X_{1 i}, X_{2 i}, \ldots, X_{K i}$, and unmeasured factors $U_{i}$.

$$
Y_{i}=\beta_{0}+\beta_{1} T_{i}+\gamma_{1} X_{1 i}+\gamma_{2} X_{2 i}+\cdots+\gamma_{K} X_{K i}+U_{i}
$$

If $\operatorname{Cov}\left(T_{i}, U_{i}\right)=0$ then $\beta_{1}$ can be consistently estimated using ordinary least squares (OLS) regression. In the general case where $T_{i}$ is endogenous, as in prior studies that have relied on regression adjustment, estimates from OLS are biased and inconsistent without further 
untestable assumptions.

The "first-stage" estimating equation specifies a linear additive relationship between political trust, the randomly assigned instrument $\left(Z_{i}\right.$ is a three level factor for treatment assignment: Corrupt $=0$, Control $=0.5$, or Honest $=1$ ) and pre-treatment covariates:

$$
T_{i}=\alpha_{0}+\alpha_{1} Z_{i}+\delta_{1} X_{1 i}+\delta_{2} X_{2 i}+\cdots+\delta_{K} X_{K i}+V_{i}
$$

where $V_{i}$ denotes unmeasured determinants of political trust. Treatment $Z_{i}$ is excluded from Equation 1 by the ER assumption and random assignment $\operatorname{implies} \operatorname{Cov}\left(Z_{i}, X_{K i}\right)=$ $\operatorname{Cov}\left(Z_{i}, U_{i}\right)=\operatorname{Cov}\left(Z_{i}, V_{i}\right)=0$. Therefore, provided $\operatorname{Cov}\left(T_{i}, Z_{i}\right) \neq 0$, the sample analog

$$
\widehat{\beta}_{I V}=\frac{\widehat{\operatorname{Cov}}\left(Y_{i}, Z_{i}\right)}{\widehat{\operatorname{Cov}}\left(T_{i}, Z_{i}\right)}=\frac{\widehat{\operatorname{Cov}}\left(Y_{i}, Z_{i}\right) / \widehat{\operatorname{Var}}\left(Z_{i}\right)}{\widehat{\operatorname{Cov}}\left(T_{i}, Z_{i}\right) / \widehat{\widehat{\operatorname{Var}}}\left(Z_{i}\right)}
$$

is a consistent estimator for $\beta_{1}$ without imposing the assumption that $\operatorname{Cov}\left(T_{i}, U_{i}\right)=0$, or that $\operatorname{Cov}\left(T_{i}, V_{i}\right)=0$ or $\operatorname{Cov}\left(T_{i}, X_{K i}\right)=0$. The IV estimator $\widehat{\beta}_{I V}$ is the ratio of the "reducedform" effect of subject $i$ 's treatment assignment (the "instrument" $Z_{i}$ ) on their support for redistribution $Y_{i}$, and the "first-stage" effect of $Z_{i}$ on their trust in government, $T_{i}$. The reduced-form and first-stage effects presented in the manuscript are estimated using OLS with covariate-adjustment. I code $Z_{i}=0$ if subject $i$ is assigned Corrupt, $Z_{i}=0.5$ if assigned Control, and $Z_{i}=1$ if assigned Honest. With a multivalued instrument $\widehat{\beta}_{I V}$ is a weighted average of causal estimates for different sub-populations of compliers, and my coding of $Z_{i}$ assumes political trust increases with higher values of $Z_{i}$. This structural model mirrors the theory and estimation approach in prior literature, which specifies a linear causal relationship between political trust and support for redistribution. See Angrist and Pischke (2009), Chapter 4, for comparison to the potential outcomes framework and Angrist and Pischke (2009) Chapter 4.5 on generalizing IV for multivalued treatments/instruments. 
Equivalence Testing: In the manuscript, I present point estimates for first-stage and reduced-form effects graphically and include $90 \%$ and $95 \%$ confidence intervals (CI), as well as Margin of Equivalence (MOE) bounds of \pm 0.20 standard units, or $1 / 5$ of one standard unit. This presentation of "null" findings is more descriptive than simply declaring "no significant differences" because it allows for a test of a null hypothesis that an effect is "not equivalent" to the MOE against an alternative hypothesis that an effect is "equivalent" to the MOE. When the 90\% CI for an estimated effect is contained inside the MOE, the null hypothesis of non-equivalence is rejected in favor of equivalence, with a false positive or "Type-I error" rate of 0.05 . If the $95 \%$ CI also includes zero, then the estimated effect is both "statistically equivalent" (within \pm 0.20 standard units) and not statistically different from zero. I conclude an estimated effect is "negligible" (larger than -0.20 , and smaller than 0.20) when a $90 \%$ CI falls inside the MOE and a 95\% CI covers zero (Lakens 2017; see also Rainey 2014). This MOE choice implies that effects less extreme than \pm 0.20 standard units are not deemed substantively meaningful.

In the manuscript, I provide additional substantive context for the estimated reducedform and 2SLS effects by noting that the partisan gap in support for redistribution in Control, averaged across all 5 experiments, was 1.05 standard units. Therefore, an estimated $90 \%$ CI that falls within the chosen MOE of \pm 0.20 , would be deemed "negligible" since effects larger than one-fifth the size of the partisan gap in the support for redistribution measure can be ruled out. The estimated reduced-form effect of treatment on support for redistribution reported in Fig. 3 of the manuscript is approximately zero standard units $(\Delta=0.01, t=0.20$, $P=0.84)$, with $90 \% \mathrm{CI}(-0.05,0.06)$. The 2 SLS estimate for the effect of trust in government on support for redistribution is approximately zero $(\Delta=0.01, t=0.21, P=0.83)$, with $90 \%$ CI $(-0.08,0.10)$. Since the $90 \%$ CI for both estimates falls within the chosen MOE of \pm 0.20 standard units, I conclude they are negligible effects: statistically indistinguishable from zero 
and no larger than one-fifth the size of the partisan gap on the support for redistribution measure.

The choice of the size of a MOE is subjective and can be justified by bench marking against prior studies. To date, however, there are no experimental estimates to benchmark against in the published literature. When bench marking is not possible, the recommended default MOE is \pm 0.36 (Wellek 2010 p. 16; see also Hartman and Hidalgo 2018). The MOE of \pm 0.20 used in this setting is a more conservative choice than the recommended default since any effect deemed "statistically equivalent" under a \pm 0.20 MOE would be deemed equivalent under a \pm 0.36 MOE.

Other MOE choices are possible, depending on what a researcher deems to be a substantively meaningful effect size. For example, following the recommendations proposed by (Rainey, 2014, pp. 1086-7), one could go further and rule out "meaningful" effects smaller than \pm 0.20 by simply choosing the smallest MOE that still contains the estimated $90 \%$ CIs. For example, if one instead deemed an effect of \pm 0.10 standard units (roughly one-tenth of the observed partisan gap) to be meaningful, then one could reject the null hypothesis of a "meaningful effect" of this size under the equivalence testing framework using the reduced form estimate, with $90 \%$ CI $(-0.05,0.06)$. However, one could not reject the null hypothesis of a meaningful effect of size 0.10 using the 2SLS estimate with $90 \%$ CI $(-0.08,0.10)$.

When contextualizing the size of a given effect it may also be worth considering what resources would be needed to design a future experiment that could detect an effect that small with a certain probability (the "power" of a given design). For example, in a simple two-armed trial (at level $\alpha=.05$ ) one would need to recruit at least 3,140 subjects in order to detect an effect of 0.10 standard units with probability 0.80. By contrast, one could detect an effect of size 0.20 in a two-armed trial using roughly $1 / 3$ this sample size $(1,050$ subjects) with probability 0.90 . Although there is no objective criteria for deciding what the "smallest effect size of interest" (SESOI) should be for a given study, it may be impractical 
to reliably estimate very "small" effects (less than 0.30) under typical resource constraints (see also Lakens, Scheel and Isager, 2018).

Another approach to hypothesis testing is to instead evaluate the sharp null of "no effect" for any experimental subject. Unlike the null hypothesis of "no average effect" underlying both the equivalence testing and standard significance testing approaches, the sharp null hypothesis would be false, for example, if the average effect was zero but effects were nevertheless negative for some individuals and positive for others. I test the sharp null for the reduced form effect on support for redistribution by comparing two models. The "restricted" model is a linear regression of the outcome on a constant, and the "unrestricted" model adds indicators for the Corrupt and Honest treatment arms. The difference between models can be summarized using the F-Statistic from an Analysis of Variance (ANOVA) comparison between the restricted and unrestricted model.

To test the sharp null hypothesis that each subject would express exactly the same outcome regardless of the treatment arm to which they were assigned, I compare the observed F-Statistics to the simulated null distribution of F-Statistics that would obtain if the sharp null were true using Randomization Inference (RI). The RI $P$-value is the proportion of simulated F-statistics that are as extreme (or more extreme) than the one observed under the sharp null. The observed F-statistic, along with the 0.025th and 0.975th quantiles of the distribution of permuted F-statistics and the RI $P$-value, are presented for each of the three corruption experiments in Table S14. The sharp null that each subject would express exactly the same level of support for redistribution regardless of the treatment they were assigned cannot be rejected in any of these experiments. 
TABLE S14: Randomization Inference (RI) for Reduced Form Effects by Experiment

\begin{tabular}{lllll}
\hline & Observed F-Statistic & 0.025 th Quantile & 0.975 th Quantile & RI $P$-Value \\
\hline Experiment 1 & 0.50 & 0.03 & 3.67 & 0.60 \\
Experiment 2 & 0.07 & 0.02 & 3.40 & 0.92 \\
Experiment 3 & 0.65 & 0.03 & 3.81 & 0.52 \\
\hline
\end{tabular}

Notes: Quantiles of null distribution and RI P-values from 5,000 permutations of each experimental design. The sharp null hypothesis is that each subject would express exactly the same level of support for redistribution regardless of the treatment arm they were assigned to.

\section{S5.1 Average Political Trust and Support for Redistribution by Treatment Arm in Experiments 1-5}

Point estimates and standard errors for the rescaled values of both political trust measures for each treatment arm, across all five experiments, appear in Tables S15-S16. Tables S17-S18 present point estimates and standard errors for each measure of support for redistribution, and the scaled index, respectively.

TABLE S15: Group Means for Scaled Political Trust DV

\begin{tabular}{lllll}
\hline & Measure & Corrupt & Control & Honest \\
\hline Experiment 1 & Likert scale & $2.13(0.07)$ & $2.27(0.07)$ & $2.86(0.08)$ \\
Experiment 2 & Likert scale & $2.08(0.05)$ & $2.08(0.05)$ & $2.48(0.05)$ \\
Experiment 3 & Likert scale & $1.95(0.03)$ & $2.14(0.04)$ & $2.69(0.05)$ \\
Experiment 4 & Likert scale & $2.09(0.07)$ & $2.23(0.07)$ & $2.14(0.07)$ \\
Experiment 5 & Likert scale & $2.29(0.07)$ & $2.19(0.08)$ & $2.36(0.08)$ \\
\hline
\end{tabular}

TABle S16: Group Means for ANES Political Trust Measure

\begin{tabular}{lllll}
\hline & Measure & Corrupt & Control & Honest \\
\hline Experiment 1 & ANES item & $2.77(0.07)$ & $2.80(0.07)$ & $3.12(0.09)$ \\
Experiment 2 & ANES item & $2.36(0.05)$ & $2.37(0.05)$ & $2.58(0.05)$ \\
Experiment 3 & ANES item & $3.65(0.04)$ & $3.67(0.04)$ & $3.91(0.04)$ \\
Experiment 4 & ANES item & $2.66(0.07)$ & $2.69(0.07)$ & $2.57(0.07)$ \\
Experiment 5 & ANES item & $2.77(0.07)$ & $2.67(0.08)$ & $2.85(0.07)$ \\
\hline
\end{tabular}


TABLE S17: Group Means for Redistribution DVs

\begin{tabular}{lllll}
\hline & Measure & Corrupt & Control & Honest \\
\hline Experiment 1 & Aid to Homeless & $0.74(0.02)$ & $0.72(0.02)$ & $0.73(0.02)$ \\
Experiment 1 & Aid to Blacks & $0.49(0.03)$ & $0.45(0.02)$ & $0.46(0.02)$ \\
Experiment 1 & Foodstamps & $0.55(0.03)$ & $0.53(0.03)$ & $0.53(0.03)$ \\
Experiment 1 & Welfare & $0.53(0.03)$ & $0.49(0.03)$ & $0.50(0.03)$ \\
Experiment 2 & Aid to Homeless & $0.68(0.02)$ & $0.69(0.02)$ & $0.69(0.02)$ \\
Experiment 2 & Aid to Blacks & $0.46(0.02)$ & $0.45(0.02)$ & $0.45(0.02)$ \\
Experiment 2 & Foodstamps & $0.50(0.02)$ & $0.48(0.02)$ & $0.48(0.02)$ \\
Experiment 2 & Welfare & $0.45(0.02)$ & $0.45(0.02)$ & $0.48(0.02)$ \\
Experiment 3 & Aid to Homeless & $0.76(0.01)$ & $0.77(0.01)$ & $0.76(0.01)$ \\
Experiment 3 & Aid to Blacks & $0.53(0.01)$ & $0.54(0.02)$ & $0.54(0.01)$ \\
Experiment 3 & Foodstamps & $0.57(0.01)$ & $0.62(0.02)$ & $0.59(0.01)$ \\
Experiment 3 & Welfare & $0.59(0.01)$ & $0.60(0.02)$ & $0.58(0.02)$ \\
Experiment 4 & Aid to Homeless & $0.78(0.02)$ & $0.75(0.02)$ & $0.73(0.02)$ \\
Experiment 4 & Aid to Blacks & $0.52(0.03)$ & $0.53(0.02)$ & $0.48(0.03)$ \\
Experiment 4 & Foodstamps & $0.54(0.03)$ & $0.58(0.03)$ & $0.54(0.03)$ \\
Experiment 4 & Welfare & $0.56(0.03)$ & $0.58(0.03)$ & $0.53(0.03)$ \\
Experiment 5 & Aid to Homeless & $0.79(0.02)$ & $0.75(0.03)$ & $0.77(0.02)$ \\
Experiment 5 & Aid to Blacks & $0.49(0.03)$ & $0.47(0.03)$ & $0.54(0.03)$ \\
Experiment 5 & Foodstamps & $0.55(0.03)$ & $0.54(0.03)$ & $0.53(0.03)$ \\
Experiment 5 & Welfare & $0.54(0.03)$ & $0.51(0.03)$ & $0.54(0.03)$ \\
\hline
\end{tabular}

TABLE S18: Group Means for Scaled Redistribution DV

\begin{tabular}{lllll}
\hline & Measure & Corrupt & Control & Honest \\
\hline Experiment 1 & Redistribution Scale & $1.88(0.07)$ & $1.78(0.07)$ & $1.81(0.07)$ \\
Experiment 2 & Redistribution Scale & $1.70(0.05)$ & $1.69(0.05)$ & $1.71(0.04)$ \\
Experiment 3 & Redistribution Scale & $2.07(0.04)$ & $2.13(0.04)$ & $2.08(0.04)$ \\
Experiment 4 & Redistribution Scale & $2.00(0.07)$ & $2.04(0.07)$ & $1.91(0.07)$ \\
Experiment 5 & Redistribution Scale & $1.82(0.07)$ & $1.74(0.08)$ & $1.82(0.07)$ \\
\hline
\end{tabular}




\section{S5.2 Estimated Treatment Effects of Honest and Corrupt Condi- tions on Trust and Support for Redistribution, Relative to Control}

In the manuscript and the Supplementary Materials, estimates are presented from regression models that rely on a metric instrumental variable where $Z_{i}$, a three level factor for treatment assignment, is coded so that $Z_{i}=0$ if subject $i$ is assigned to Corrupt, $Z_{i}=0.5$ if assigned Control, and $Z_{i}=1$ if assigned Honest. This coding scheme assumes the relationship between treatment and outcomes is linear; for example, that levels of political trust should be lowest in the Corrupt treatment arm, and highest in Honest treatment arm. This structural approach is used to mirror the prior literature, which specifies a linear relationship between political trust and support for redistribution. An alternative coding scheme would treat the Corrupt and Honest conditions as two mutually exclusive instruments so that $Z_{1 i}=1$ if assigned Honest and $Z_{1 i}=0$ if assigned Control, and $Z_{2 i}=1$ if assigned Corrupt and $Z_{2 i}=0$ if assigned Control. Table S19 presents estimates from OLS regressions of Trust in Government (First Stage) and Support for Redistribution (Reduced Form) on these indicators. Table S20 replicates this analysis without covariate-adjustment.

This analysis reveals that the estimated first stage effects are in the expected direction, but the Honest treatment $(\Delta=0.51, P<0.001)$ was more effective than the Corrupt treatment $(\Delta=-0.11, P=0.004)$, relative to Control. The covariate-adjusted 2SLS estimates under this coding scheme are $0.02(P=0.71)$ for the Honest treatment and $-0.04(P=0.90)$ for the Corrupt treatment. These two estimates correspond to two different sub-populations of compliers: those who would be induced by the Honest treatment to trust the government, and those who would be induced by the Corrupt treatment to distrust the government. 
TABLE S19: Covariate-adjusted Treatment Effect Estimates of Honest and Corrupt Conditions on Trust and Support for Redistribution, Relative to Control (Pooled)

\begin{tabular}{llll}
\hline & Outcome Measure & Corrupt & Honest \\
\hline Political Corruption & Trust in Government (Likert) & $0.62(0.04)^{*}$ & \\
Political Corruption & Trust in Government (ANES item) & $0.24(0.03)^{*}$ & $0.01(0.03)$ \\
Political Corruption & Support for Redistribution & $0.06(0.07)$ \\
Non-Political Corruption & Trust in Government (Likert) & $0.01(0.07)$ \\
Non-Political Corruption & Trust in Government (ANES item) & $0.01(0.06)$ \\
Non-Political Corruption & Support for Redistribution & $-0.03($ Con & \\
\hline
\end{tabular}

Notes: Covariate-adjusted estimates from OLS regressions of the outcome on treatment (Corrupt $=$ 0 , Control $=0.5$, Honest $=1)$ with $\mathrm{HC} 2$ robust standard errors in parentheses. Covariates include age, political conservatism, income, and indicators for party identification (Republican, Democrat, Independent), sex (male or female), education (college degree or not), race (white or non-white), employed (yes or no), and a study fixed effect to capture differences across experiments. $P<0.05^{*}$.

TABlE S20: Unadjusted Treatment Effect Estimates of Honest and Corrupt Conditions on Trust and Support for Redistribution, Relative to Control (Pooled)

\begin{tabular}{llll}
\hline & Outcome Measure & Corrupt & Honest \\
\hline Political Corruption & Trust in Government (Likert) & $0.61(0.04)^{*}$ \\
Political Corruption & Trust in Government (ANES item) & $0.23(0.03)^{*}$ \\
Political Corruption & Support for Redistribution & $0.00(0.04)$ \\
Non-Political Corruption & Trust in Government (Likert) & $0.06(0.07)$ \\
Non-Political Corruption & Trust in Government (ANES item) & $0.00(0.07)$ \\
Non-Political Corruption & Support for Redistribution & $-0.05(0.07)$ \\
\hline
\end{tabular}

Notes: Estimates from OLS regressions (without covariates) of the outcome on treatment (Corrupt $=$ 0 , Control $=0.5$, Honest $=1$ ) with $\mathrm{HC} 2$ robust standard errors in parentheses. A study fixed effect was included in all models to capture differences across experiments. $P<0.05^{*}$. 


\section{S5.3 First Stage, Reduced Form, and 2SLS Estimates (Main Re- sults)}

Table S21 reports the underlying point estimates and standard errors for the First Stage, Reduced Form, and 2SLS analyses presented graphically in the manuscript. One potential concern, raised by two anonymous reviewers, is that covariate-adjustment may inflate the false negative rate under certain circumstances (see Kam and Trussler, 2017). Table S22 therefore replicates this analysis without covariate adjustment. One anonymous reviewer suggested presenting results for each component of the Support for Redistribution Index. Table S23 therefore reports covariate-adjusted Reduced Form and 2SLS estimates for each component, pooling across the three Political Corruption Experiments. Table S24 replicates this analysis without covariate adjustment. The covariate-adjusted estimates reported in Tables S21 and S23 are approximately the same as the unadjusted estimates in Tables S22 and S24, suggesting the overall precision gains from covariate-adjustment were not particularly meaningful in this application.

Table S25 reports covariate-adjusted first-stage, reduced form, and 2SLS estimates for each experiment, with first-stage and 2SLS estimates (for Experiments 1-3) reported for both the ANES measure and the Likert Scale. Despite strong first stage effects on both measures of political trust in Experiments 1-3, both the reduced form and 2SLS estimates on support for redistribution are negligible and not statistically distinguishable from zero.

The estimated $F$-statistics for tests of instrument strength from the pooled regression of political trust on treatment are $228.20(P<0.001)$ for the Likert Scale and $26.68(P<0.001)$ for the ANES item, well above the recommended threshold of 10 used to distinguish "weak" from "acceptable" instruments (see Stock, Wright and Yogo, 2002; Angrist and Pischke, 2009, Chapter 4). Although even a slight violation of the exclusion restriction can strongly bias estimates when the instrument is weak, the very strong instruments in this setting should 
mitigate such concerns. By contrast, the estimated $F$-statistics are $0.65(P=0.42)$ for the Likert Scale and $0.00(P=0.98)$ for the ANES item in the placebo experiments and 2SLS estimates are therefore omitted.

TABlE S21: Covariate-adjusted First-Stage, Reduced Form, and 2SLS Estimates (Pooled)

\begin{tabular}{lccc}
\hline & First Stage & Reduced Form & 2SLS \\
\hline Political Corruption & $0.62(0.04)^{*}$ & $0.01(0.03)$ & $0.01(0.05)$ \\
Non-Political Corruption & $0.06(0.07)$ & $-0.03(0.06)$ & - \\
\hline
\end{tabular}

Notes: Covariate-adjusted estimates from OLS (First Stage, Reduced Form) and Instrumental Variables (2SLS) regressions with $\mathrm{HC} 2$ robust standard errors in parentheses. Covariates include age, political conservatism, income, and indicators for party identification (Republican, Democrat, Independent), sex (male or female), education (college degree or not), race (white or non-white), employed (yes or no), and a study fixed effect to capture differences across experiments. $P<0.05^{*}$.

TABLE S22: Unadjusted First-Stage, Reduced Form, and 2SLS Estimates (Pooled)

\begin{tabular}{lccc}
\hline & First Stage & Reduced Form & 2SLS \\
\hline Political Corruption & $0.61(0.04)^{*}$ & $0.00(0.04)$ & $0.00(0.06)$ \\
Non-Political Corruption & $0.06(0.07)$ & $-0.05(0.07)$ & -
\end{tabular}

Notes: Estimates from OLS (First Stage, Reduced Form) and Instrumental Variables (2SLS) regressions with $\mathrm{HC} 2$ robust standard errors in parentheses. Models were estimated without covariates but include study fixed effects to capture differences across experiments. $P<0.05^{*}$.

TABLE S23: Covariate-adjusted Reduced Form and 2SLS Estimates by Redistribution Item (Pooled)

\begin{tabular}{lllll}
\hline & Welfare & Food Stamps & Aid to Homeless & Aid to Blacks \\
\hline Reduced Form & $0.00(0.01)$ & $-0.00(0.01)$ & $0.01(0.01)$ & $0.00(0.01)$ \\
2 SLS & $0.00(0.02)$ & $-0.01(0.02)$ & $0.01(0.02)$ & $0.00(0.02)$ \\
\hline
\end{tabular}

Notes: Covariate-adjusted estimates from OLS (Reduced Form) and Instrumental Variables (2SLS) regressions with $\mathrm{HC} 2$ robust standard errors in parentheses. All dependent variables are scaled to range from 0 to 1 . Covariates include age, political conservatism, income, and indicators for party identification (Republican, Democrat, Independent), sex (male or female), education (college degree or not), race (white or non-white), employed (yes or no), and a study fixed effect to capture differences across experiments. $P<0.05^{*}$. 
TABLE S24: Unadjusted Reduced Form and 2SLS Estimates by Redistribution Item (Pooled)

\begin{tabular}{lllll}
\hline & Welfare & Food Stamps & Aid to Homeless & Aid to Blacks \\
\hline Reduced Form & $-0.00(0.01)$ & $-0.00(0.01)$ & $0.01(0.01)$ & $-0.00(0.01)$ \\
2SLS & $-0.00(0.03)$ & $-0.00(0.02)$ & $0.01(0.02)$ & $-0.00(0.02)$ \\
\hline
\end{tabular}

Notes: Covariate-adjusted estimates from OLS (Reduced Form) and Instrumental Variables (2SLS) regressions with $\mathrm{HC} 2$ robust standard errors in parentheses. All dependent variables are scaled to range from 0 to 1 . Models were estimated without covariates but include study fixed effects to capture differences across experiments. $P<0.05^{*}$.

TABlE S25: Covariate-adjusted First Stage, Reduced Form, and 2SLS Estimates by Experiment

\begin{tabular}{l|cc|c|cc|}
\hline & \multicolumn{2}{|c|}{ First Stage } & Reduced Form & \multicolumn{2}{c|}{ 2SLS } \\
& ANES item & Likert Scale & Redistribution & ANES item & Likert Scale \\
\hline Experiment 1 & $0.43(0.11)^{*}$ & $0.78(0.11)^{*}$ & $-0.01(0.08)$ & $-0.02(0.20)$ & $-0.01(0.11)$ \\
Experiment 2 & $0.23(0.06)^{*}$ & $0.40(0.07)^{*}$ & $-0.01(0.06)$ & $-0.02(0.26)$ & $-0.01(0.14)$ \\
Experiment 3 & $0.26(0.06)^{*}$ & $0.73(0.06)^{*}$ & $0.03(0.04)$ & $0.12(0.18)$ & $0.04(0.06)$ \\
Experiment 4 & $-0.09(0.10)$ & $0.04(0.10)$ & $-0.09(0.08)$ & - & - \\
Experiment 5 & $0.11(0.10)$ & $0.08(0.11)$ & $0.04(0.08)$ & - & - \\
\hline
\end{tabular}

Notes: Covariate-adjusted estimates from OLS (First Stage, Reduced Form) and Instrumental Variables (2SLS) regressions with $\mathrm{HC} 2$ robust standard errors in parentheses. Covariates include age, political conservatism, income, and indicators for party identification (Republican, Democrat, Independent), sex (male or female), education (college degree or not), race (white or non-white), employed (yes or no), and a study fixed effect to capture differences across experiments. $P<0.05^{*}$.

\section{S5.4 Estimated Treatment Effects from Regression Models with Treatment-Covariate Interactions}

In the manuscript, I presented Instrumental Forest estimated treatment effects from Generalized Random Forests (GRF), a machine learning algorithm that automates the search for treatment effect heterogeneity (Athey, Tibshirani and Wager, 2019). An anonymous re- 
viewer suggested conducting additional tests for treatment effect heterogeneity by interacting treatment assignment with race, employment status, partisanship, and ideology, since these specific covariates have been identified in prior observational studies as important moderators for the effects of trust in government on support for redistribution. I therefore estimate interaction models with the following covariates: 1$)$ White $(1=$ white, $0=$ non-white $) ; 2)$ Employment $(1=$ Yes; $0=$ No); 3$)$ Partisanship: Independent $(1=$ Independent, $0=$ Democrat $)$ and Republican $(1=$ Republican, $0=$ Democrat $)$; and 4$)$ Ideology $(1=$ 'Very liberal', $2=$ 'Liberal', $3=$ 'Moderate', $4=$ 'Conservative', $5=$ 'Very conservative'). Pooling across the three political corruption experiments, approximately $72 \%$ of subjects were white, $70 \%$ were employed, 39\% were Democrats, $23 \%$ were Republicans, and 38\% were Independents. The median ideology score was 3 (mean 2.83). All interaction models are estimated with study fixed effects, but no additional covariates.

Table S26 presents first stage estimates from four different OLS regression models of Trust in Government (Likert Scale) on treatment $($ Corrupt $=0$, Control $=0.5$, Honest $=$ 1), each specific covariate, and the treatment-covariate interaction. The results from the Partisanship Model (column 3) suggest that the randomized instrument was more effective at increasing political trust among Republicans, relative to Democrats (Treatment $x$ Republican: $0.25, P=0.02$ ), as well as more conservative voters (Treatment $\times$ Ideology: $0.08, P=0.03)$. Interactions with White, Employed, and Independent, were not statistically distinguishable from zero.

Table S27 presents the reduced form estimates from four different OLS regression models of Support for Redistribution on treatment $($ Corrupt $=0$, Control $=0.5$, Honest $=$ 1), a specific covariate, and the treatment-covariate interaction. The results from the Employment Model (column 2) suggest the treatment effect on Support for Redistribution was lower among employed individuals than unemployed individuals (Treatment $\times$ Employed: $-0.17, P=0.03)$. According to these estimates, treatment increased Support for Redistri- 
bution by approximately 0.12 units among unemployed individuals $(P=0.08)$ and decreased Support for Redistribution by approximately 0.05 units $(-0.05=0.12+(-0.17), P=0.24)$ among employed individuals. For context, the average score on the Support for Redistribution scale in Control, averaged across all 5 experiments, was about 0.11 standard units lower among employed individuals (1.87) than unemployed individuals (1.98).

Table S28 presents 2SLS estimates from four different IV regression models of Support for Redistribution on Trust in Government with each covariate interacted with treatment (first stage) and the Trust in Government measure (second stage). The results from the Employment Model (column 2) suggest, consistent with the reduced form estimates reported in Table S27, that increasing trust in government increased support for redistribution among unemployed compliers (Trust in Government: $0.20, P=0.09$ ) and reduced support for redistribution among employed compliers $(-0.08=0.20+(-0.28), P=0.24)$. Although neither of these estimates are statistically distinguishable from zero at the conventional level, their difference is (Trust $\times$ Employed : $-0.28, P=0.04$ ). These results suggest that increasing trust in government may generate more support for redistribution among the unemployed than the employed.

These estimates, however, should be interpreted with caution given that 15 interaction hypotheses were tested in this section. After applying the Benjamini and Hochberg (1995) method to control the false discovery rate, none of the estimated treatment-covariate interactions are statistically significant at the conventional level. These results are presented in Table S29, which compares the unadjusted and adjusted $P$-values for all the estimated treatment-covariate interactions presented in Tables S26-S28. 
TABLE S26: First Stage Estimates with Covariate Interactions (Pooled)

\begin{tabular}{lcccc}
\hline & White & Employment & Partisanship & Ideology \\
\hline Treatment & $0.52(0.08)^{*}$ & $0.61(0.08)^{*}$ & $0.57(0.07)^{*}$ & $0.38(0.11)^{*}$ \\
Treatment x White & $0.13(0.09)$ & - & - & - \\
Treatment x Employed & - & $-0.00(0.09)$ & - & - \\
Treatment x Independent & - & - & $-0.05(0.09)$ & - \\
Treatment x Republican & - & - & $0.25(0.11)^{*}$ & - \\
Treatment x Ideology & - & - & - & $0.08(0.04)^{*}$ \\
\hline
\end{tabular}

Notes: Estimates from OLS regressions of Trust in Government (Likert Scale) on Treatment (Corrupt $=0$, Control $=0.5$, Honest $=1)$ with covariate interactions. White $(1=$ Yes, $0=$ No $)$ Employed $(1$ $=$ Yes, $0=$ No); Independent $(1=$ Independent, $0=$ Democrat $)$; Republican $(1=$ Republican, $0=$ Democrat); Ideology ( $1=$ 'Very liberal', $5=$ 'Very conservative'). $P<0.05^{*}$. Robust standard errors in parentheses. Coefficients for intercepts, study fixed effects, and covariates omitted.

TABLE S27: Reduced Form Estimates with Covariate Interactions (Pooled)

\begin{tabular}{lcccc}
\hline & White & Employment & Partisanship & Ideology \\
\hline Treatment & $0.02(0.07)$ & $0.12(0.07)$ & $-0.01(0.05)$ & $0.12(0.09)$ \\
Treatment x White & $-0.01(0.08)$ & - & - & - \\
Treatment x Employed & - & $-0.17(0.08)^{*}$ & - & - \\
Treatment x Independent & - & - & $0.06(0.08)$ & - \\
Treatment x Republican & - & - & $0.00(0.09)$ & - \\
Treatment x Ideology & - & - & - & $-0.04(0.03)$ \\
\hline
\end{tabular}

Notes: Estimates from OLS regressions of Support for Redistribution on Treatment (Corrupt $=0$, Control $=0.5$, Honest $=1)$ with covariate interactions. White $(1=$ Yes, $0=$ No $)$; Employed $(1=$ Yes, $0=$ No); Independent $(1=$ Independent, $0=$ Democrat $)$; Republican $(1=$ Republican, $0=$ Democrat); Ideology ( $1=$ 'Very liberal', $5=$ 'Very conservative'). $P<0.05^{*}$. Robust standard errors in parentheses. Coefficients for intercepts, study fixed effects, and covariates omitted. 
TABLE S28: 2SLS Estimates with Covariate Interactions (Pooled)

\begin{tabular}{lcccc}
\hline & White & Employment & Partisanship & Ideology \\
\hline Trust in Government & $0.04(0.13)$ & $0.20(0.11)$ & $-0.01(0.09)$ & $0.19(0.15)$ \\
Trust x White & $-0.03(0.15)$ & - & - & - \\
Trust x Employed & - & $-0.28(0.14)^{*}$ & - & - \\
Trust x Independent & - & - & $0.11(0.15)$ & - \\
Trust x Republican & - & - & $0.01(0.13)$ & - \\
Trust x Ideology & - & - & - & $-0.06(0.05)$ \\
\hline
\end{tabular}

Notes: Estimates from instrumental variables regression of Trust in Government (Likert Scale) on Support for Redistribution using Two-Stage Least Squares (2SLS) with covariate interactions. White $(1=$ Yes, $0=$ No); Employed $(1=$ Yes, $0=$ No $)$; Independent $(1=$ Independent, $0=$ Democrat $) ;$ Republican ( $1=$ Republican, $0=$ Democrat $)$; Ideology $(1=$ 'Very liberal', $5=$ 'Very conservative'). $P<0.05^{*}$. Robust standard errors in parentheses. Coefficients for intercepts, study fixed effects, and covariates omitted.

TABle S29: Unadjusted v. Adjusted $P$-values for Interactions by Model

\begin{tabular}{lllcc}
\hline & Model & Estimator & Unadjusted $P$-value & Adjusted $P$-value \\
\hline Treatment x White & Race & First Stage & 0.15 & 0.37 \\
Treatment x Employed & Work & First Stage & 0.98 & 0.98 \\
Treatment x Ideology & Ideology & First Stage & 0.03 & 0.14 \\
Treatment x Independent & Partisanship & First Stage & 0.57 & 0.86 \\
Treatment x Republican & Partisanship & First Stage & 0.02 & 0.14 \\
\hline Treatment x White & Race & Reduced Form & 0.90 & 0.98 \\
Treatment x Employed & Work & Reduced Form & 0.03 & 0.14 \\
Treatment x Ideology & Ideology & Reduced Form & 0.17 & 0.37 \\
Treatment x Independent & Partisanship & Reduced Form & 0.45 & 0.75 \\
Treatment x Republican & Partisanship & Reduced Form & 0.97 & 0.98 \\
\hline Trust x White & Race & 2SLS & 0.86 & 0.98 \\
Trust x Employed & Work & 2SLS & 0.04 & 0.14 \\
Trust x Ideology & Ideology & 2SLS & 0.17 & 0.37 \\
Trust x Independent & Partisanship & 2SLS & 0.45 & 0.75 \\
Trust x Republican & Partisanship & 2SLS & 0.97 & 0.98 \\
\hline
\end{tabular}

Notes: Benjamini \& Hochberg (1995) procedure used to adjust for multiple comparisons. 


\section{S5.5 Effects on Other Policy Preferences}

Experiments 1-2 included additional questions about policies that were not necessarily redistributive in nature. Here I explore whether treatment had any impact on these other policy preferences. Support for spending on Social Security, Environmental Protection, Crime Prevention, Foreign Aid, and Public Schools were also included in Experiment 3. These questions (enumerated below) were all asked near the end of all survey experiments.

Estimated "first stage" effects (from a regression of the outcome on treatment) are reported for the pooled sample, and covariate-adjusted to increase precision. Each measure was standardized to range from $0-1$ so that the relative size of coefficients can be compared, and a 1 unit increase in treatment (coded Corrupt $=0$, Control $=0.5$, or Honest $=1$ ) can be interpreted as the effect of moving from lowest to highest levels of political trust.

Table S31 reports estimated effects on distributive preferences in each domain. According to Hetherington 2005, for example, political trust should have weak (or zero) effects on support for these more "universal programs"; this is especially true for distributive policies like social security, crime prevention, and environmental protection (see Ch. 3-5; also see Rudolph, 2017, for a review). I find no evidence that treatment increased support for spending in any of these distributive policy domains, excepting Immigration. This result

(Column 6, Table S31) suggests, however, that treatment decreased support for spending in this domain, which runs counter to theoretical predictions.

Table S30 reports estimated treatment effects on support for a broader scope of government in several domains that should be positively affected by treatment. In particular, political trust is predicted to have a "universally strong" effect on support for spending on foreign aid, since all the benefits are distributed outside the United States (see Hetherington, 2005, p. 85). None of these predictions were supported. 
TABLE S30: First Stage Effects on Broader Scope of Government

\begin{tabular}{lcccccc}
\hline & Foreign Aid & Assistance to Blacks & Healthcare & Jobs & Services & Defense \\
\hline Treatment & $0.01(0.01)$ & $0.02(0.02)$ & $0.01(0.02)$ & $0.01(0.02)$ & $0.00(0.02)$ & $-0.01(0.01)$ \\
Corrupt mean & 0.27 & 0.40 & 0.56 & 0.54 & 0.55 & 0.47 \\
Observations & 3731 & 1807 & 1822 & 1865 & 1733 & 1824 \\
\hline
\end{tabular}

Notes: Covariate-adjusted estimates from OLS regressions of the outcome on treatment (Corrupt $=0$, Control $=0.5$, Honest $=1$ ) with $\mathrm{HC} 2$ robust standard errors in parentheses. All dependent variables are scaled to range from 0 to 1 . Covariates include age, political conservatism, income, and indicators for party identification (Republican, Democrat, Independent), sex (male or female), education (college degree or not), race (white or non-white), employed (yes or no), and a study fixed effect to capture differences across experiments. $P<0.05^{*}$.

TABLe S31: First Stage Effects on Support for Distributive Policies

\begin{tabular}{lcccccc}
\hline & Social Security & Environment & Crime & Highways & Schools & Immigration \\
\hline Treatment & $0.01(0.01)$ & $-0.01(0.01)$ & $-0.01(0.01)$ & $-0.01(0.02)$ & $0.02(0.01)$ & $-0.05(0.02)^{*}$ \\
Corrupt mean & 0.72 & 0.69 & 0.66 & 0.65 & 0.79 & 0.60 \\
Observations & 3730 & 3731 & 3730 & 1944 & 3730 & 1944 \\
\hline
\end{tabular}

Notes: Covariate-adjusted estimates from OLS regressions of the outcome on treatment (Corrupt $=0$, Control $=0.5$, Honest $=1$ ) with $\mathrm{HC} 2$ robust standard errors in parentheses. All dependent variables are scaled to range from 0 to 1 . Covariates include age, political conservatism, income, and indicators for party identification (Republican, Democrat, Independent), sex (male or female), education (college degree or not), race (white or non-white), employed (yes or no), and a study fixed effect to capture differences across experiments. $P<0.05^{*}$.

- Distributive Policies: "Should federal spending be increased, decreased or kept about the same"?

1. Social Security: decrease(0), remain the same (0.5), increased (1)

2. Environmental protection: decrease(0), remain the same (0.5), increased (1)

3. Crime prevention: decrease(0), remain the same (0.5), increased (1)

4. Highway construction: decrease(0), remain the same (0.5), increased (1) 
5. Public schools: decrease $(0)$, remain the same (0.5), increased (1)

6. Preventing illegal immigration: decrease(0), remain the same (0.5), increased (1)

\section{- Broader Scope of Government:}

1. Foreign Aid: decrease(0), remain the same (0.5), increased (1)

2. Assist Blacks: "Some people feel that the government in Washington should make every effort to improve the social and economic position of blacks. Suppose these people are at one end of a scale, at point 1. Others feel that the government should not make any special effort to help blacks because they should help themselves. Suppose these people are at the other end, at point 7. And, of course, some other people have opinions somewhere in between, at points $2,3,4,5$ or 6 . Where would you place yourself on this scale, or haven't you thought much about it?" (reverse coded)

3. Healthcare: "There is much concern about the rapid rise in medical and hospital costs. Some people feel there should be a government insurance plan which would cover all medical and hospital expenses for everyone. Suppose these people are at one end of a scale, at point 1. Others feel that medical expenses should be paid by individuals, and through private insurance plans like Blue Cross or some other company paid plans. Suppose these people are at the other end, at point 7 . And of course, some people have opinions somewhere in between at points $2,3,4,5$ or 6. Where would you place yourself on this scale, or haven't you thought much about this?" (reverse coded)

4. Jobs: "Some people feel that the government in Washington should see to it that every person has a job and a good standard of living. Suppose these people are at one end of a scale, at point 1 . Others think the government should just let each person get ahead on his/her own. Suppose these people are at the other end, at 
point 7. And, of course, some other people have opinions somewhere in between, at points $2,3,4,5$ or 6 . Where would you place yourself on this scale, or haven't you thought much about this?" (reverse coded)

5. Services: "Some people think the government should provide fewer services, even in areas such as health and education, in order to reduce spending. Suppose these people are at one end of a scale, at point 1. Other people feel that it is important for the government to provide many more services even if it means an increase in spending. Suppose these people are at the other end, at point 7. And, of course,

some other people have opinions somewhere in between, at points $2,3,4,5$ or 6 . Where would you place yourself on this scale, or haven't you thought much about this?"

6. Defense: "Some people believe that we should spend much less money for defense. Suppose these people are at one end of a scale, at point 1 . Others feel that defense spending should be greatly increased. Suppose these people are at the other end, at point 7 . And, of 4, some other people have opinions somewhere in between, at points $2,3,4,5$, or 6 . Where would you place yourself on this scale or haven't you thought much about this?"

\section{S5.6 Effects on Trust in Other Organizations/Groups}

Experiments 1-2 included additional measures of trust in other groups (e.g. friends and family) and organizations (e.g. media, universities). One potential concern might be that even though the experiments increased trust in government they could have also affected trust in other organizations, which could complicate interpretation of the first stage effects on political trust. In Experiments 1-2 individuals were asked to "Please indicate whether you trust (1) or distrust (0) the following group or institution", with groups presented in random 
order: Family members, Friends, Scientists, People in your neighborhood, Universities, The American media, Strangers, The police in your area, Government Administrators, Politicians, Your state government, Your local government, The federal government. Estimated treatment effects are reported in Tables S32 - S34. Estimated effects on the binary trust in government measures reported in Table S34 are positive and in the expected direction, suggesting that the Op-Ed treatments generated broad effects on trust in government. None of the estimated effects on trust in other organizations or groups are statistically distinguishable from zero (Tables S32 -S33).

TABlE S32: First Stage Effects on Trust in Other Social Groups

\begin{tabular}{lcccc}
\hline & Family & Friends & Neighbors & Strangers \\
\hline Treatment & $-0.00(0.02)$ & $0.02(0.01)$ & $0.01(0.02)$ & $0.01(0.02)$ \\
Corrupt mean & 0.92 & 0.93 & 0.72 & 0.22 \\
Observations & 1957 & 1957 & 1956 & 1956 \\
\hline
\end{tabular}

Notes: Covariate-adjusted estimates from OLS regressions of the outcome on treatment (Corrupt $=0$, Control $=0.5$, Honest $=1$ ) with $\mathrm{HC} 2$ robust standard errors in parentheses. All dependent variables are scaled to range from 0 to 1 . Covariates include age, political conservatism, income, and indicators for party identification (Republican, Democrat, Independent), sex (male or female), education (college degree or not), race (white or non-white), employed (yes or no), and a study fixed effect to capture differences across experiments. $P<0.05^{*}$.

TABLE S33: First Stage Effects on Trust in Other Groups/Organizations

\begin{tabular}{lcccc}
\hline & Media & Police & Scientists & Universities \\
\hline Treatment & $0.03(0.02)$ & $-0.00(0.03)$ & $0.04(0.02)$ & $0.05(0.03)$ \\
Corrupt mean & 0.25 & 0.68 & 0.83 & 0.69 \\
Observations & 1956 & 1956 & 1956 & 1956 \\
\hline
\end{tabular}

Notes: Covariate-adjusted estimates from OLS regressions of the outcome on treatment (Corrupt $=0$, Control $=0.5$, Honest $=1$ ) with $\mathrm{HC} 2$ robust standard errors in parentheses. All dependent variables are scaled to range from 0 to 1 . Covariates include age, political conservatism, income, and indicators for party identification (Republican, Democrat, Independent), sex (male or female), education (college degree or not), race (white or non-white), employed (yes or no), and a study fixed effect to capture differences across experiments. $P<0.05^{*}$. 
TABLE S34: First Stage Effects on Binary Trust in Government Measures

\begin{tabular}{lccccc}
\hline & Federal Gov. & Gov. Admins & Politicians & State Gov. & Local Gov. \\
\hline Treatment & $0.11(0.02)^{*}$ & $0.15(0.03)^{*}$ & $0.12(0.02)^{*}$ & $0.14(0.03)^{*}$ & $0.12(0.03)^{*}$ \\
Corrupt mean & 0.24 & 0.29 & 0.16 & 0.37 & 0.45 \\
Observations & 1956 & 1957 & 1956 & 1956 & 1956 \\
\hline
\end{tabular}

Notes: Covariate-adjusted estimates from OLS regressions of the outcome on treatment (Corrupt $=0$, Control $=0.5$, Honest $=1$ ) with $\mathrm{HC} 2$ robust standard errors in parentheses. All dependent variables are scaled to range from 0 to 1 . Covariates include age, political conservatism, income, and indicators for party identification (Republican, Democrat, Independent), sex (male or female), education (college degree or not), race (white or non-white), employed (yes or no), and a study fixed effect to capture differences across experiments. $P<0.05^{*}$. 


\section{S5.7 Effects on Additional Measures in Experiment 3}

Here I present results for estimated first stage effects on additional policy attitudes, including alternative measures of support for redistribution: housing, food stamps and aid to the poor. In their omnibus study of support for redistribution, Kuziemko et al. (2015) found telling Americans that Transparency International (TI) ranked the U.S. among the most corrupt in a class of countries with similar levels of income and development induced a $5.8 \%$ decrease $(P=0.01)$ in political trust (see Table 8, p. 1500) in a two-armed trial of approximately 900 subjects using a 4-category version of the ANES item ("Never", "Some of the time", "Most of the time" "Just about always") that was then truncated to create a binary indicator where "Never" and "Some of the time" indicated distrust of government. In other words, the treatment caused about 26 individuals to "distrust" the government $(900 \times 0.50 \times 0.058 \approx 26)$. The estimated $F$-statistic for the first-stage effect of trust in government on treatment was not reported in the original paper. I downloaded the replication data from the American Economic Review data repository ${ }^{7}$ and found an estimated Fstatistic of $7.48(P=0.01)$. This is a weak instrument, and the $F$-statistic does not pass the widely recommended threshold of 10 in applied econometrics, which raises concerns that even slight violations of the exclusion restriction in this study may generate biased estimates of the impact political trust has on support for redistribution (see Stock, Wright and Yogo, 2002; Angrist and Pischke, 2009, Chapter 4). The estimated first stage effect of the TI treatment on the non-truncated 4-category trust measure (not reported in the original paper) is -0.04 scale points $(P=0.36)$.

Kuziemko et al. (2015) report that the TI treatment also caused small decreases in support for Aid to the Poor ( -0.14 points), Food Stamps ( -0.15 points), and Public Housing for low income families ( -0.16 points), but did not increase support for a minimum wage hike $(-0.00$ points) or an expansion in the scope of government (0.02 points). Experiment 3 included

\footnotetext{
${ }^{7}$ https://www. aeaweb.org/articles?id=10.1257/aer. 20130360
} 
these additional measures (taken from Kuziemko et al. (2015) and enumerated below). Table S35 reports the estimated effects on each of these measures, standardized to range from 0-1 to facilitate comparison of the relative size of coefficients. A 1 unit increase in treatment $($ coded Corrupt $=0$, Control $=0.5$, or Honest $=1)$ can be interpreted as the effect of moving from lowest to highest political trust. These results suggest the Op-Ed treatments slightly increased support for a broader role of government in the abstract; however, this did not translate to support for any specific policy. While this may constitute a violation of the ER in theory, this small violation should, if anything, have made respondents more supportive of redistributive social policies.

TABLE S35: First Stage Effects on Additional Measures

\begin{tabular}{lccccc}
\hline & Minimum Wage & Public Housing & Food Stamps & Aid to Poor & Scope \\
\hline Treatment Effect & $0.01(0.01)$ & $0.01(0.01)$ & $0.02(0.01)$ & $0.02(0.01)$ & $0.04(0.01)^{*}$ \\
Corrupt mean & 0.81 & 0.66 & 0.60 & 0.68 & 0.56 \\
Observations & 1791 & 1791 & 1790 & 1790 & 1794 \\
\hline
\end{tabular}

Notes: Covariate-adjusted estimates from OLS regressions of the outcome on treatment (Corrupt $=0$, Control $=0.5$, Honest $=1$ ) with $\mathrm{HC} 2$ robust standard errors in parentheses. All dependent variables are scaled to range from 0 to 1 . Covariates include age, political conservatism, income, and indicators for party identification (Republican, Democrat, Independent), sex (male or female), education (college degree or not), race (white or non-white), employed (yes or no), and a study fixed effect to capture differences across experiments. $P<0.05^{*}$.

1. Minimum Wage: "The federal minimum wage is currently $\$ 7.25$ per hour. Do you think it should be decreased, stay the same or increased?" [Significantly increased = 4; Slightly increased $=3$; Stay the same $=2$; Slightly decreased $=1$; Significantly decreased $=0]$

2. Housing: "Should the federal government increase or decrease its spending on public housing for low income families?" [Significantly increased $=5$; Slightly increased $=4$; 
Stay the same $=3 ;$ Slightly decreased $=2 ;$ Significantly decreased $=1]$

3. Food Stamps: "Should the federal government increase or decrease its spending on food stamps?" [Significantly increased $=4$; Slightly increased $=3$; Stay the same $=2$; Slightly decreased $=1$; Significantly decreased $=0]$

4. Aid to Poor: "Should the federal government increase on decrease spending on aid to the poor?" [Significantly increased $=4$; Slightly increased $=3$; Stay the same $=2$; Slightly decreased $=1$; Significantly decreased $=0]$

5. Scope: "Where would you rate yourself on a scale of 1 to 5 , where 1 means you think the government should do only those things necessary to provide the most basic government functions, and 5 means you think the government should take active steps in every area it can to try and improve the lives of its citizens?"

\section{S5.7.1 Effects on Perceptions of Inequality, Resentment of the Rich, Tax Rates, and Policy Solutions to Inequality}

Experiment 3 also included attitudes toward the rich and perceptions of inequality. One potential concern, raised by an anonymous reviewer to a previous version of this manuscript, is that although the Op-Ed treatments increased trust in government, they may have also made respondents more sympathetic to the rich, and/or less concerned about poverty and income inequality. This could possibly offset any increase in support for redistribution induced by the treatments, and constitute an ER violation. Kuziemko et al. (2015), for example, found that priming distrust in government may reduce support for taxes on the rich. Relatedly, Tella, Dubra and Lagomarsino (2016) found evidence that priming individuals to distrust both the government and business elites increased their willingness to punish the rich through higher taxes. Another potential concern, raised by the anonymous reviewer, is that increasing trust in government may affect individuals' perceptions about the appropriate policy solutions to 
addressing inequality. Kuziemko et al. (2015), for example, found that priming distrust in government increased the relative rank that individuals gave "private charity" as a solution to inequality. A variety of questions (taken from Kuziemko et al. (2015) and enumerated below) are used to measure whether treatment might have affected these attitudes.

Table S36 reports the estimated effects on perceptions of inequality and resentment of the rich. There is no evidence of any meaningful impact on any of these measures. Table S37 reports estimated effects on ideal tax rates across each income group. There is no evidence that treatment affected respondents' ideal tax rates for any group. Finally, Table S38 reports estimated effects on the rank ordering that respondents gave to each of 5 possible policy tools for addressing income inequality. There is no evidence that treatment affected the ranking that respondents gave to any of these categories.

TABle S36: First Stage Effects on Perceptions of Inequality and Resentment of the Rich

Millionaire Tax Undeserving Rich Inequality a Problem Poverty a Problem

$\begin{array}{lcccc}\text { Treatment Effect } & 0.02(0.01) & 0.03(0.02) & 0.00(0.01) & 0.00(0.01) \\ \text { Corrupt mean } & 0.84 & 0.49 & 0.70 & 0.74 \\ \text { Observations } & 1795 & 1795 & 1795 & 1794\end{array}$

Notes: Covariate-adjusted estimates from OLS regressions of the outcome on treatment (Corrupt $=0$, Control $=0.5$, Honest $=1$ ) with $\mathrm{HC} 2$ robust standard errors in parentheses. All dependent variables are scaled to range from 0 to 1 . Covariates include age, political conservatism, income, and indicators for party identification (Republican, Democrat, Independent), sex (male or female), education (college degree or not), race (white or non-white), employed (yes or no), and a study fixed effect to capture differences across experiments. $P<0.05^{*}$. 
TABLE S37: First Stage Effects on Ideal Tax Rates

\begin{tabular}{lcccc}
\hline & Top 1\% & Next 9\% & Next 40\% & Bottom 50\% \\
\hline Treatment Effect & $0.01(0.01)$ & $0.01(0.01)$ & $0.01(0.01)$ & $0.01(0.01)$ \\
Corrupt mean & 0.36 & 0.28 & 0.19 & 0.10 \\
Observations & 1791 & 1791 & 1791 & 1791
\end{tabular}

Notes: Covariate-adjusted estimates from OLS regressions of the outcome on treatment (Corrupt $=0$, Control $=0.5$, Honest $=1$ ) with $\mathrm{HC} 2$ robust standard errors in parentheses. All dependent variables are scaled to range from 0 to 1 . Covariates include age, political conservatism, income, and indicators for party identification (Republican, Democrat, Independent), sex (male or female), education (college degree or not), race (white or non-white), employed (yes or no), and a study fixed effect to capture differences across experiments. $P<0.05^{*}$.

TABLE S38: First Stage Effects on Preferred Methods for Addressing Inequality

\begin{tabular}{lccccc}
\hline & Charity & Education & Gov. Transfer & Gov. Regulation & Taxes \\
\hline Treatment Effect & $0.01(0.02)$ & $0.01(0.02)$ & $0.01(0.02)$ & $-0.01(0.02)$ & $-0.01(0.02)$ \\
Corrupt mean & 0.57 & 0.58 & 0.57 & 0.51 & 0.27 \\
Observations & 1782 & 1782 & 1782 & 1782 & 1782 \\
\hline
\end{tabular}

Notes: Covariate-adjusted estimates from OLS regressions of the outcome on treatment (Corrupt $=0$, Control $=0.5$, Honest $=1$ ) with $\mathrm{HC} 2$ robust standard errors in parentheses. All dependent variables are scaled to range from 0 to 1 . Covariates include age, political conservatism, income, and indicators for party identification (Republican, Democrat, Independent), sex (male or female), education (college degree or not), race (white or non-white), employed (yes or no), and a study fixed effect to capture differences across experiments. $P<0.05^{*}$.

1. Millionaire Tax: "As you may know, there have been proposals recently to decrease the federal deficit by raising income taxes on millionaires. Do you think income taxes on millionaires should be increased, stay the same or decreased?"

2. Undeserving Rich: "Do you think that the very high earners in our society deserve their high incomes?" [Most of the time $=1 ;$ Sometimes $=2$; Rarely $=3$ ] 
3. Inequality a Problem: "Do you think inequality is a serious problem in America?" [Not a problem at all (1); A small problem (2); A problem (3); A serious problem (4); A very serious problem (5)].

4. Poverty a Problem: "Do you think poverty is a serious problem in America?" [Not a problem at all (1); A small problem (2); A problem (3); A serious problem (4); A very serious problem (5)].

5. Income Tax: "The income tax rate is the percentage of your income that you pay in federal income tax. For example, if you earn $\$ 30,000$ and you pay $\$ 3,000$ in income taxes, your income tax rate is $10 \%$. Please use the sliders below to tell us how much [0-100 percent] you think each of the following groups should pay as a percentage of their total income."

- The top $1 \%$ (rich)

- The next 9\% (1\% of households earn more than them, but 90\% earn less)

- The next $40 \%$ (10\% earn more than them, but 50\% earn less)

- The bottom $50 \%$ (poorest)

6. Policy Rank: "Which of the tools below do you consider the best to address inequality in the United States? Please drag and drop the items below and rank them in your preferred order. Your preferred method for addressing inequality should be at the top, your least preferred one at the bottom."

- Private Charity

- Education Policies

- Government Transfers (e.g., food stamps, Medicaid, ...)

- Government regulation (e.g., min wage, caps on top compensation,...) 
- Progressive Taxes 


\section{S5.8 Subject Recruitment, Attention Check Questions and "De- mand Effects"}

For all studies conducted on MTurk, subjects were recruited using the generic HIT advertisement "Answer a survey about your opinions, $\mathrm{X}$ minutes, $\$ \mathrm{Y}$ ". The further description of the HIT was "Quick survey. Fun and easy. Payment is auto-approved in 5 days.". In Experiments 1, 4 and 5, all respondents were paid the advertised rate of $\$ 1.20$ for a 10 minute survey. In Experiment 3, all respondents were paid the advertised rate of $\$ 1.50$ for a 15 minute survey. In order to view the advertisement, workers were required to be located in the United States and have a HIT Approval Rate of at least $90 \%$.

Workers with high HIT approval rates are more attentive and rarely fail Attention Check Questions (ACQs) (Peer, Vosgerau and Acquisti, 2014). Attention check questions were included in all studies. In Experiments 1-2, and Experiments 4-5, this attention check appeared after subjects received treatment and asked "Have you ever had a fatal heart attack?", but was presented as a Likert type item where the correct answer was "Never" (see Paolacci et al., 2010). The pass rate was approximately $99 \%$ in Experiments 1, 4 and 5.

In Experiment 2, recruited via Qualtrics Panels, the pass rate was $92 \%$. The lower pass rate here is expected, since MTurk workers are more attentive to survey questions than subjects recruited from other online samples (Berinsky, Huber and Lenz, 2012; Hauser and Schwarz, 2016). None of the subjects who failed the attention check in these studies were excluded from analyses reported here, or in the manuscript. See Aronow, Baron and Pinson (2019) for an elaboration on the potential problems raised by excluding subjects who fail a post-treatment attention check.

In Experiment 3, a novel ACQ was used. This ACQ, administered prior to treatment assignment, is presented in Figure S9. This attention check was passed by $87 \%$ of respondents. Since this ACQ was included prior to treatment assignment, I also examine the robustness of 
the main results reported in the manuscript by restricting attention to the sample of survey takers who passed this attention check question. I test this against the null hypothesis of constant effects. One implication of this null hypothesis is that the 250 subjects who were not "paying attention" prior to treatment assignment did not respond differently to treatment than those who were paying attention, as measured by whether the ACQ was passed.

A straightforward way to assess effect heterogeneity across these two subgroups is by looking at the F-statistic from two fitted models (see Gerber and Green, 2012, Chapter 9 for a textbook treatment). Let $Y$ denote the outcome of interest, $Z$ denote treatment, and $X$ denote a binary indicator that takes on the value 1 if the subject passed the attention check question, and 0 otherwise.

The "restricted model" in this case is of the form,

$$
Y \sim Z+X
$$

and the "unrestricted model" is

$$
Y \sim Z+X+Z \cdot X
$$

The estimated $F$-statistic from a model comparison for the Trust in Government Likert Scale as the outcome is $0.40(P$-value $=0.67)$. The estimated $F$-statistic for a model comparison with the Support for Redistribution Scale as the outcome is $1.6(P$-value $=0.20)$. Table S39, compares the estimated First Stage, Reduced Form, and 2SLS estimates for the full sample with estimates for the sample of individuals who passed the attention check. These results are essentially identical.

Experiment 3 also included additional design modifications and questions about article content aimed to encourage engagement with the treatment articles and assess how they were interpreted by respondents. The available data suggests subjects were critically engaged with 
the articles, convinced by the Op-Ed arguments, and interpreted the data visualizations as expected. See Appendix Section A.2 for further discussion.

Figure S9: Attention Check Question in Third Politics Study

In this prompt we are going to ask you to answer a question about mathematics. Although not everyone likes mathematics we believe this is a relatively simple question to answer. Having said that, we would like you to answer eight regardless of what you think the correct answer is.

Please solve the following math problem: What is $(2+2) / 1=$ ?
O 8
O 6
$\mathrm{O} 4$
$\mathrm{O} 2$

TABLE S39: First Stage, Reduced Form and 2SLS Estimates by ACQ Passing

\begin{tabular}{lll}
\hline Outcome & Full Sample & Subset \\
\hline First Stage & $0.73(0.06)^{*}$ & $0.74(0.06)^{*}$ \\
Reduced Form & $0.03(0.05)$ & $0.03(0.05)$ \\
2SLS & $0.04(0.06)$ & $0.04(0.07)$ \\
\hline
\end{tabular}

Notes: Covariate-adjusted estimates from OLS (First Stage, Reduced Form) and Instrumental Variables (2SLS) regressions with $\mathrm{HC} 2$ robust standard errors in parentheses. Covariates include age, political conservatism, income, and indicators for party identification (Republican, Democrat, Independent), sex (male or female), education (college degree or not), race (white or non-white), employed (yes or no), and a study fixed effect to capture differences across experiments. 1620 of 1870 subjects passed the pre-treatment attention check. $P<0.05^{*}$.

\section{S5.8.1 Demand Effects}

Concerns about "demand effects" in experiments date back to Orne's point that, even within tightly controlled environments, researchers are still active participants in their studies (Orne, 1962). It is first important to note that the demand effects originally proposed by Orne concerned lab-style experimental environments where participants had direct interactions 
with experimenters and a well defined mechanism - the social image concerns of participants - was clearly implicated. Activating participants' social image concerns in the lab-style experimental setting is a much more plausible threat to inference than in the anonymous online environment that characterizes modern survey experimental research (see also Kreuter, Presser and Tourangeau, 2008). In this setting, the potential threat to internal validity is that subjects in the Corrupt and Honest treatments may have deduced the study's purpose and subsequently altered their responses, perhaps in what they presumed to be the socially desirable direction.

Although the existence of demand effects in any particular experiment is a 'knownunknown', detecting substantively meaningful demand effects in modern experimental research has proved quixotic across many published studies that have set out to find them (see Bischoff, Frank et al., 2011; De Quidt, Haushofer and Roth, 2018; White et al., 2018; Mummolo and Peterson, 2019). Given the large first-stage effects observed in Experiments 1-3, demand effects would need to be 3-4 times the biggest effect sizes obtained in studies that explicitly paid subjects to provide responses that "help" the researcher's hypothesis (see Mummolo and Peterson, 2019) in order to explain these results. Moreover, if demand effects were indeed present, it is puzzling why they would have been so much larger in the Honest treatment arm than the Corrupt arm. It is also unclear why they would not have appeared in Placebo Experiments 4-5.

A related threat to inference is the possibility that effect sizes may in fact be less pronounced in experienced participant pools such as MTurk, perhaps because they are less susceptible to experimenter induced demand effects (see Chandler et al., 2015). The implication here would be that the estimated treatment effects from the MTurk experiments may be much smaller than what one might expect to find in a more representative sample. Although this may be true for some individual respondents, the estimated treatment effects in the MTurk subject pools and the Qualtrics online panel were statistically indistinguishable 
despite predictable differences in pass rates for the ACQs. This mitigates concerns about treatment effect heterogeneity across subject pools, and is consistent with existing research on the generalizability of experimental results (see Coppock, Leeper and Mullinix, 2018). 


\section{A Treatment Text and Additional Supporting Informa- tion}

A.1 Experiment 1-2

Figure S10: Debrief in Experiments 1-2 and 4-5

Thank-you for participating in this study.

At the beginning of the study we only gave you a brief idea of the experiment's purpose. Sometimes when we are studying how people think about social issues (as in this experiment) we don't give people a full description of what we are studying. That way we are able to get natural responses. As such, there are a few things about this experiment that we would like to explain.

The true purpose of this study is to investigate how people's political attitudes are affected by reading newspaper articles about political corruption. As such, some participants were shown a news story that highlighted instances of political corruption. Other participants read a story that highlighted how political corruption is not as common as people often think. Other participants still read an article unrelated to political corruption. All of the articles were fictional.

If you feel concerned or uncomfortable about the fact that you were deceived, you may tell us to withdraw your data from the sample by checking the box at the bottom of this page. Remember that your results are confidential to the researchers, and that all results are published anonymously as group data.

We will be running this experiment for some time. We would really appreciate it if you would not talk to anyone about the study. Sometimes if people know what the study is about, that knowledge will affect their responses even when they don't mean for it to, and then the data are not valid. If you are asked about what you did in the study, please merely say that you had to read a news article and respond to some questions about it.

Thank you again for your valuable contribution to this research!

Please check the below box only if you want to withdraw your data. Otherwise, do not check the box.

Having read the above, I would like to withdraw my data.

\section{A.1.1 Corrupt}

\section{Prompt:}

In the next section you will see an opinion piece about political corruption written in The New York Times by Charles Delauney, an adjunct professor of law at the University of Chicago and former Chief Prosecutor in the United States Department of Justice's Public Integrity Section. Please pay attention to the article as you will later be asked questions about the content.

\section{Political Corruption is Rampant}


Much has been written about political trust of late. It has become very fashionable to call politicians distrustful. Americans, of course, have often been skeptical about government and politicians, but over the last decades, this skepticism has hardened. This rise in hardened skepticism is certainly warranted. In the last few decades, the United States has suffered a tremendous increase in the scope and frequency of political corruption.

I led my first prosecution of political corruption in 1992 when an F.B.I. sting involving bribery and horse-racing legislation netted convictions of nearly 11 percent of the Kentucky Legislature. And since then things have only gotten worse. Just last year three members of the House of Representatives pleaded guilty to, or were convicted of crimes, more than any other year since 1981. It would seem that many aspiring politicians enter politics as a 'career' or, even worse, a racket, rather than a vocation.

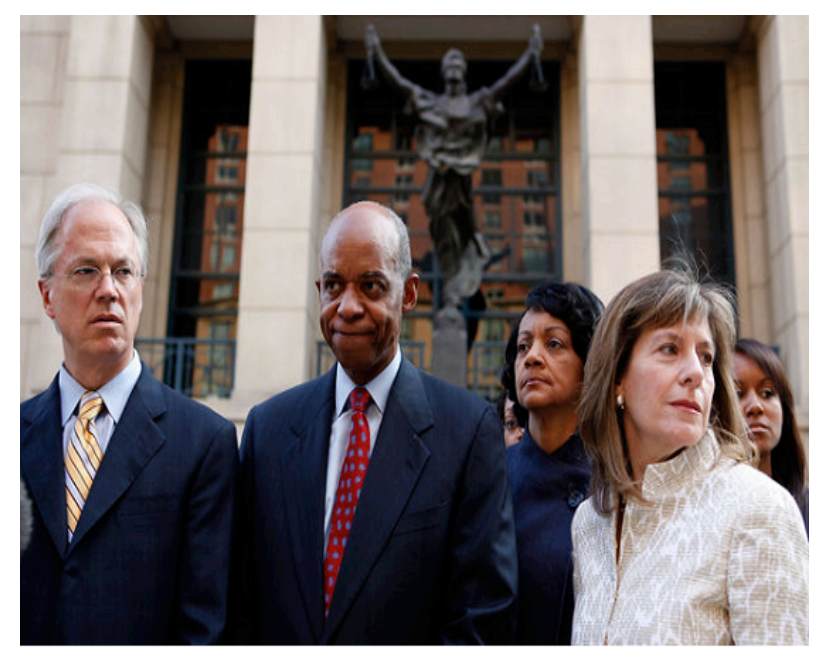

Representative William J. Jefferson was convicted of bxibery, racketering and money laundering in 2009.

The problem is becoming increasingly common. Earlier this year, former Virginia governor Bob McDonnell became the ninth governor or former governor to be charged with a crime since 2000. In 2009, House legislator William Jefferson was found with 90,000 in his basement freezer and convicted of bribery, racketeering and money laundering. A 2012 study by researchers at the University of Illinois 
at Chicago calculated that 31 of the approximately 100 Chicago aldermen who had served since 1973 - and four of the seven Illinois governors - had been convicted of corruption.

Stories like these are becoming increasingly commonplace and reflect the growth of political corruption in America. I worked for 25 years as a prosecutor in the Justice Department's public integrity section, which prosecutes official corruption at all levels of government. Resources devoted to prosecuting corrupt officials have steadily increased since the 1980s and the Federal Bureau of Investigation said in 2011 that it was conducting more than 2,000 corruption inquiries and had secured more than 900 convictions in fiscal 2010.

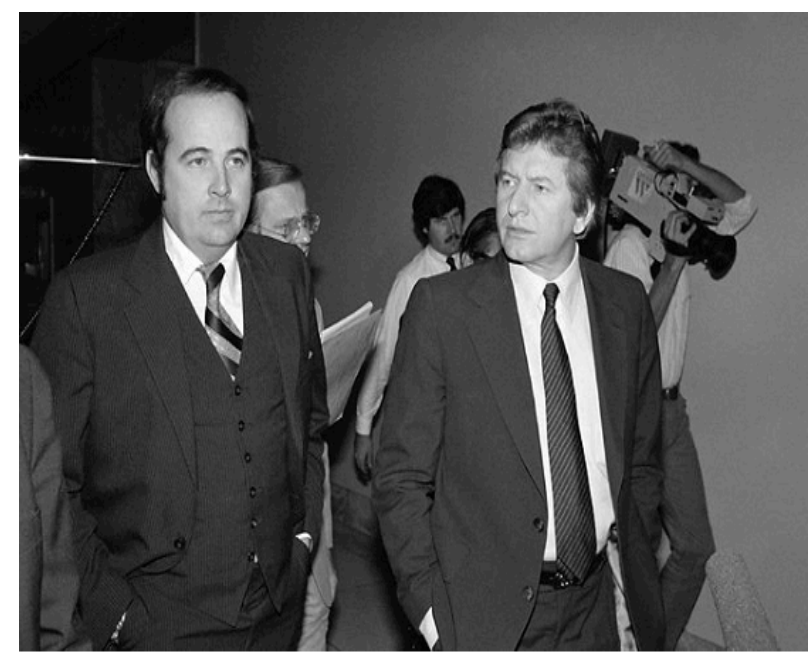

Representative John W. Jenrette Jr, right, was convicted in a high-profile scandal

The relatively large percentage of corrupt politicians in the United States is well known by scholars. According to Kim Long who published The Almanac of Political Corruption, Scandals and Dirty Politics, political corruption in American predates the origins of the republic. According to Long, corruption during the British administration of the colonies was "routine and not necessarily illegal. That set the stage for an underlying culture of corruption and patronage that ensued after the revolution." I couldn't agree more.

Although political corruption has always been a problem in America it has become so commonplace that many new acts of corruption are 
not even reported by the media. I would like to say that my experience working as a prosecutor in the Department of Justice made me believe political corruption was under control in the United States. In the far distant past, I did believe this. Today, however, the sheer volume of corruption cases is overwhelming the teams of prosecutors assigned to them. I have to admit that the general view of politicians as distrustful and corrupt is, sadly, a very accurate one.

\section{A.1.2 Control}

\section{Prompt:}

In the next section you will see an article written in The New York Times about Chefs Anthony Bourdain and Eric Ripert. Please pay attention to the article as you will later be asked questions about the content.

\section{Boisson Buddies: Anthony Bourdain and Eric Ripert}

On paper they couldn't be more different-one is a refined French chef with four-stars from The New York Times, three from the Michelin Guide, and a number of awards from the James Beard Foundation including Top Chef in New York City and Outstanding Chef in the United States; the other is a New York City-born, five-time Emmynominated, world-traveling culinary renegade whose first novel, Bone in the Throat, is being adapted for the big screen.

Yet Le Bernardin's Eric Ripert and best-selling author and television host Anthony Bourdain go together like moules and frites. Whereas Ripert, his wife, Sandra, and their son, Adrien, have been summering in the Hampton's for more than a decade, this season is the first for Bourdain and his wife, Ottavia, and their daughter, Ariane. But it is a wonderful respite for Bourdain, who spent 260 days last year traveling for his two Travel Channel series, No Reservations and The Layover and will launch his graphic novel Get Jiro! in the fall. 


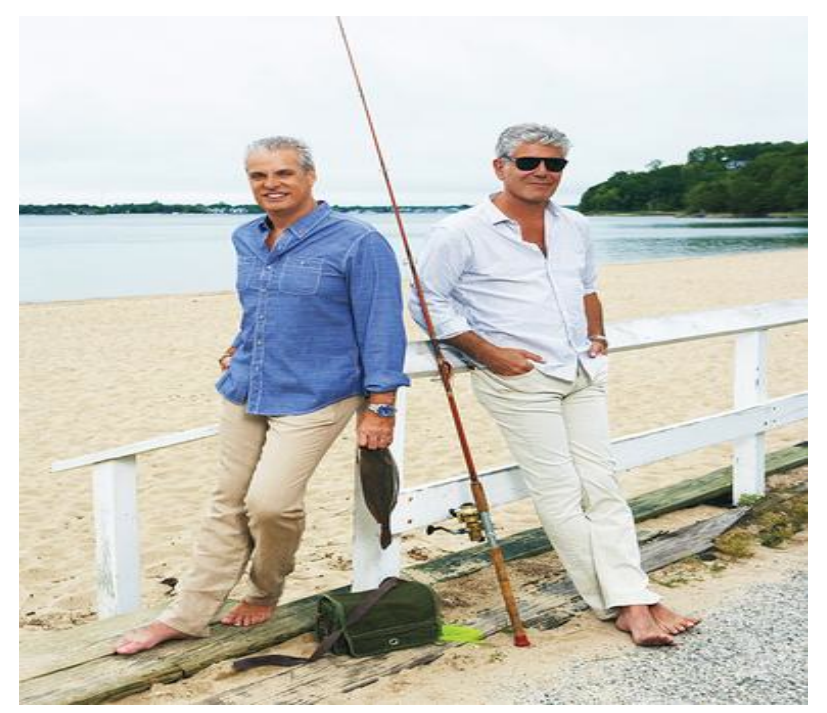

On Eric McDowell shirt, Billy Reid (\$175). 54 Bond St., NYC, 212-598-9355. Lightweight slim-fit denim, Lacoste (\$150). Americana Manhasset, 2060 Northern Blvd., 516-365-1933. White gold submariner watch, Rolex (\$36,850). London Jewlers, 2 Main St., East Hampton, 329-3939.com. Bracelets, Ripert's own. On Anthony: Pinpoint Bengal stripe shirt, Simon Spurr (\$225). Singer22, 11 Old Westbury Road, East Hills, 877-474-6722. Sunglasses, khaki’s and watch, Bourdain's own.

It was in the least likeliest of ways that these two toques came together. When Bourdain turned the heat up on the culinary industry in his 2001 breakout book Kitchen Confidential: Adventures in the Culinary Underbelly, he had many complementary passages about Ripert and Le Bernardin.

"Seventy-five percent of the industry was saying, 'it's scandalous' and 'this guy is a disgrace.' Then part of the industry was saying, 'he's genius," remembers Ripert. "I called him and said, 'I read your book, and I would love to know you. Would you come for lunch?' That was the first time I met Anthony, and we have been friends ever since." 


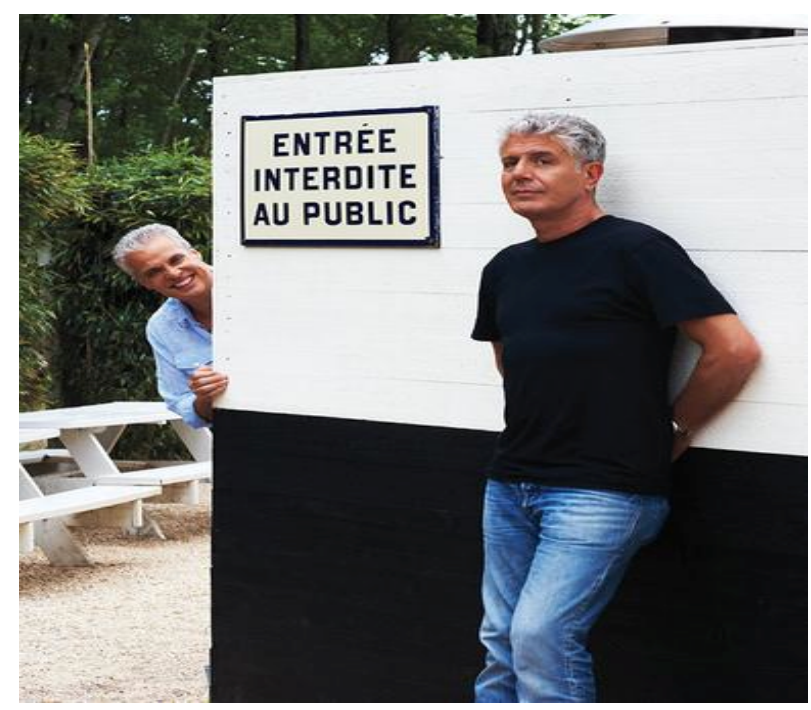

Popover shirt, Billy Reid (\$185). 54 Bond St., NYC, 212-598-9355. On Anthony: Black T-shirt, stylist's own. Jeans and watch, Bourdain's own.

"When Eric called, the book was doing really well, but I was still working every day at [Brasserie] Les Halles, convinced, quite certain that I should keep my day job and that there was no way that I would be able to support myself or count on writing as an income stream of any kind" says Bourdaindain. "I was absolutely floored that a chef who I respected that much from a restaurant that I never could have been able to afford would call me up and invite me to lunch. When I had the opportunity to get really good at my craft, I chose not to and went the other way. I'm sure in many ways it has been trying to maintain and protect the reputation of an establishment like Le Bernardin and have a friend like me who is likely to put his foot in his mouth every five minutes. It speaks well of Eric's character."

Even stranger, a filmmaker shot me as I'm leaving the lunch, and I'm devastated, just standing there practically in tears. I'd had this amazing meal, and I really saw the road not taken. I had made some very basic decisions about my career, either knowingly or in a calculated way. When I had the opportunity to get really good at my craft, I chose not to and went the other way. 


\section{A.1.3 Honest}

\section{Prompt:}

In the next section you will see an opinion piece about political corruption written in The New York Times by Charles Delauney, an adjunct professor of law at the University of Chicago and former Chief Prosecutor in the United States Department of Justice's Public Integrity Section. Please pay attention to the article as you will later be asked questions about the content.

\section{It Only Seems That Political Corruption is Rampant}

Much has been written about political trust lately. It has become very fashionable to call politicians distrustful. Americans, of course, have often been skeptical about government and politicians, but over the last decades, this skepticism has hardened. The recent increase in media coverage of political corruption seems to suggest it is rampant; however, this rise in hardened skepticism is unwarranted. Although public perceptions that politicians are corrupt have skyrocketed, political corruption has in fact decreased over time.

I led my first prosecution of political corruption in 1992 and things have certainly improved since then. Today, political corruption is at an all-time low. According to a recent study by Larry J. Sabato, director of the University of Virginia's Center for Politics, political corruption was much more common throughout the 19th and 20th centuries than today. The idea that aspiring politicians are driven to a career in politics solely for their own personal gain is nonsense. Most politicians work significantly longer hours and get paid considerably less than they would in the private sector. And they face intense and, increasingly, vindictive media scrutiny. 


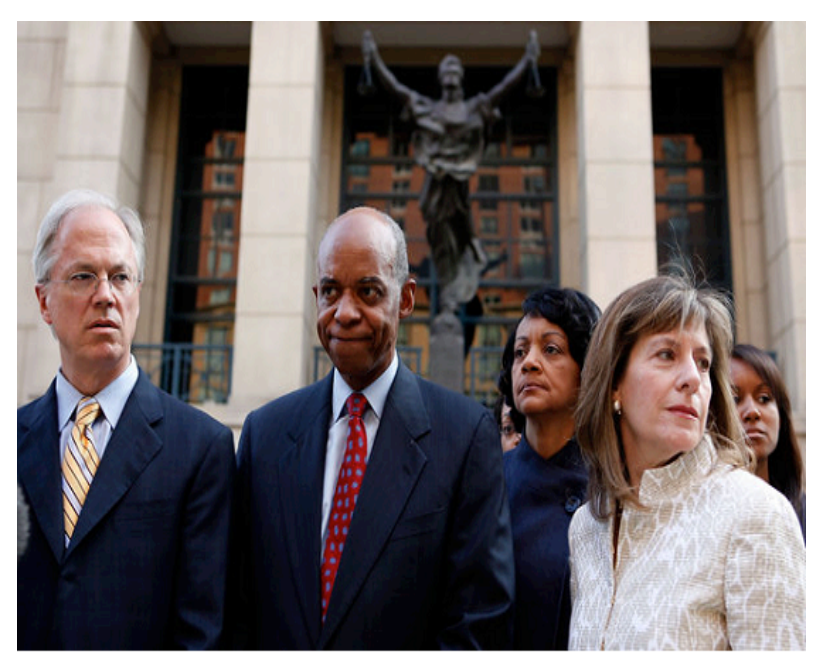

Representative William J. Jefferson was convicted of bribery, racketering and money laundering in 2009.

It is true that there are occasional corruption scandals involving politicians, but the perception of widespread malfeasance is primarily driven by media scrutiny. In contrast to countries like Italy where political scandals are the norm, we pay them so much attention in the United States precisely because they are so unusual. One occasional rotten apple, or even a handful over the past 20 years, does not spoil the barrel.

Political corruption is simply a rare event in America and although media coverage is easy to find the facts tell a different story. I worked for 25 years as a prosecutor in the Justice Department's public integrity section, which prosecutes official corruption at all levels of government. Although resources devoted to prosecuting corrupt officials have steadily increased since the 1980s, convictions of politicians dropped nearly a quarter from 1989 to 2011. This reflects the fact that only a very few politicians engage in corruption. 


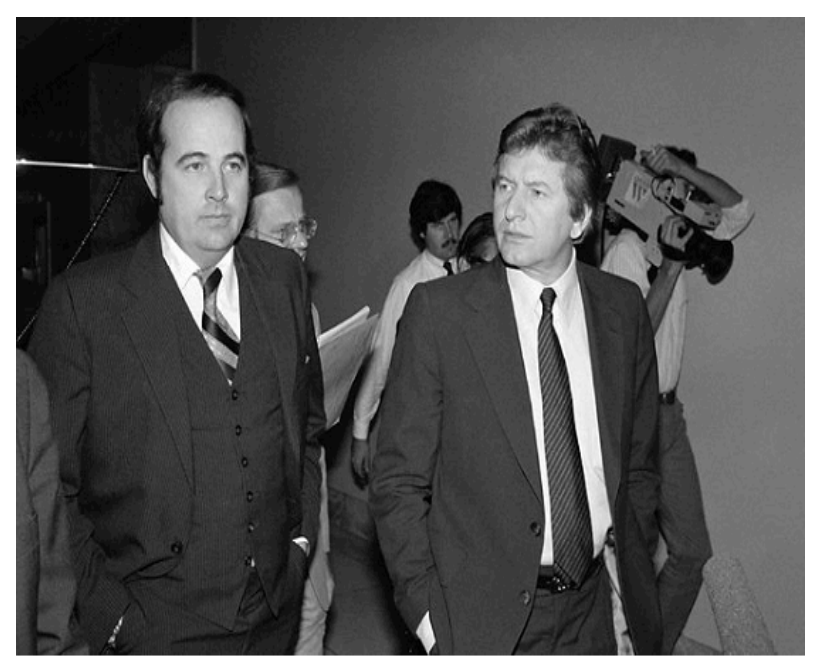

Representative John W. Jenrette Jr, right, was convicted in a high-profile scandal

The relatively small percentage of corrupt politicians in the United States is well known by scholars. A 2007 book called The Almanac of Political Corruption, Scandals and Dirty Politics, concluded that less than 1 percent of the nearly 12,000 people who had served in Congress had been expelled, indicted or tried for crimes. According to the book's author, Kim Long: "There's a large majority of voters who believe it's just endemic ... There's no evidence that indicates it's the case - zero." I couldn't agree more.

Political corruption has always existed and the only thing rampant is the public misconception about political corruption. The view of corruption as commonplace is not supported by the evidence. In my experience as a prosecutor the facts best represent the reality that political corruption in America is a very rare event. Although it is not reflected in public discussion and media coverage, using words like truthful, honest, sincere, loyal, and genuine to describe most politicians is not as ridiculous as it may sound. 


\section{A.2 Experiment 3}

Experiment 3 differed from Experiments 1-2 in the following respects:

1. The Op-Eds were presented as excerpts from the print version of the New York Times, rather than the online version of the paper. These are presented in full in Figure S19 (Honest), Figure S17 (Corrupt), and Figure S17 (Control).

2. The Op-Eds were supplemented with data visualizations, based on real publicly available data. In the case of the Honest and Corrupt treatments, these visualizations supported the Op-Ed writer's argument. In the case of the Control treatment about recycling, the visualization was domain specific but did not directly refute or undermine the author's argument against the futility of recycling. These are presented in full in Figure S20 (Honest), Figure S16 (Corrupt), and Figure S18 (Control).

3. As in the previous politics experiments, all subjects were provided with an explanatory prompt before receiving treatment. In this experiment, however, subjects were required to stay "in treatment" for at least 60 seconds before proceeding to the rest of the survey:

"In the next section, you will see an opinion article published in a major U.S. newspaper. Please read the article carefully. We will ask you some questions about the topic after reading. You may zoom in on the article with your browser. To give you time to read the article, the button to continue to the next question will not appear until after 60 seconds."

4. To encourage and assess engagement with article content, subjects were asked the following questions after reading the randomly assigned article.

- "What do you think the author's purpose was for writing the piece you just read?" [open-ended]

- "On a scale of 0 to 100 where 0 is "completely unconvincing" and 100 is "completely convincing", how persuasive did you find the article you just read?" 
- "On a scale of 0 to 100 where 0 is "very difficult to understand" and 100 is "very easy to understand", how did you find the author's writing style?"

- "Generally speaking, how interested were you in the topic before reading the article?"

(a) Very interested (5)

(b) Somewhat interested (4)

(c) Neither interested nor uninterested (3)

(d) Somewhat uninterested (2)

(e) Very uninterested (1)

- "How likely are you to conduct your own research to find out more about the topic?"

(a) Very likely (5)

(b) Somewhat likely (4)

(c) Neither likely nor unlikely (3)

(d) Somewhat unlikely (2)

(e) Very unlikely (1)

The results are presented in Table S40. Although there were no meaningful differences in perceived accessibility of the Op-Ed writing style across conditions, respondents rated the Corrupt Op-Ed as substantially more convincing - by about 20 points on a 100 point scale - than either the Control or Honest Op-Ed.

5. After subjects responded to these questions, they were provided with the accompanying data visualization and asked two additional questions. Subjects in Honest and Corrupt were asked:

(a) "The plot below shows the number of public officials charged with corruption in the United States from 1996 to 2013. How has the number of public officials 
charged with corruption changed over time?"

i. Strongly increased (5)

ii. Somewhat increased (4)

iii. Neither increased nor decreased (3)

iv. Somewhat decreased (2)

v. Strongly decreased (1)

(b) "In your opinion, does this plot provide evidence that supports or undermines the author's argument?"

i. Strongly supports (5)

ii. Somewhat supports (4)

iii. Neither supports not undermines (3)

iv. Somewhat undermines (2)

v. Strongly undermines (1)

Subjects in Control were asked the same two questions, but the language in the first was changed to match the content: "The plot below shows the total amount of unrecycled municipal waste in the United States from 1960 to 2010. How has the amount of unrecycled municipal waste changed over the time period?" The results presented graphically in Figures S13 and S14. Point estimates and standard errors are presented in Table S41. Trends were clearly interpreted in the correct direction. Respondents believed the data visualization in the Corrupt condition was more supportive of the writer's argument than the data visualization in the Honest condition.

6. As in the previous experiments, all subjects were debriefed about the deception involved at the end of the experiment. The author had moved to a new university at the time this experiment was conducted. The Institutional Review Board at this university did not require that subjects be given the option of removing their data upon learning of 
the deception. Figure S11 and Figure S12 show the debrief information that subjects assigned to the Honest or Corrupt conditions received. Subjects assigned to the Control condition did not receive a debrief since there was no deception-the content was copied directly from a New York Times Op-Ed on unrecycled municipal waste, and credited as such.

Figure S11: Debrief in Experiment 3

Thank you for your participation in this study! The goal of this study was to understand shifts in public opinion based on certain newspaper articles and viewpoints expressed by writers. For this reason, the article you read was not in fact published in a major U.S. newspaper. Instead, it was created for the purposes of this study, but also loosely based on past and current events.

We also showed you a graphic depicting changes in charges of corruption against public officials over time in the United States. Each year, the FBI delivers a report to Congress on the activities and operations of the Public Integrity Section, a division that prosecutes public officials for corruption. The graphic you saw was created using data published in a recent FBI report. It's important to note that although charges against federal officials have decreased over the period 1996-2013, charges against state and local officials have increased.

The graphic below shows the data from the FBI report with different trend lines for each level of government. Averaging over all levels of government, charges of corruption are essentially constant (no change) over the period 1996-2013. You can learn more about the FBI office that prosecutes public officials for corruption at https://www.justice.gov/criminal/pin. 
Figure S12: Trends in DOJ Prosecutions of Public Officials by Level of Government

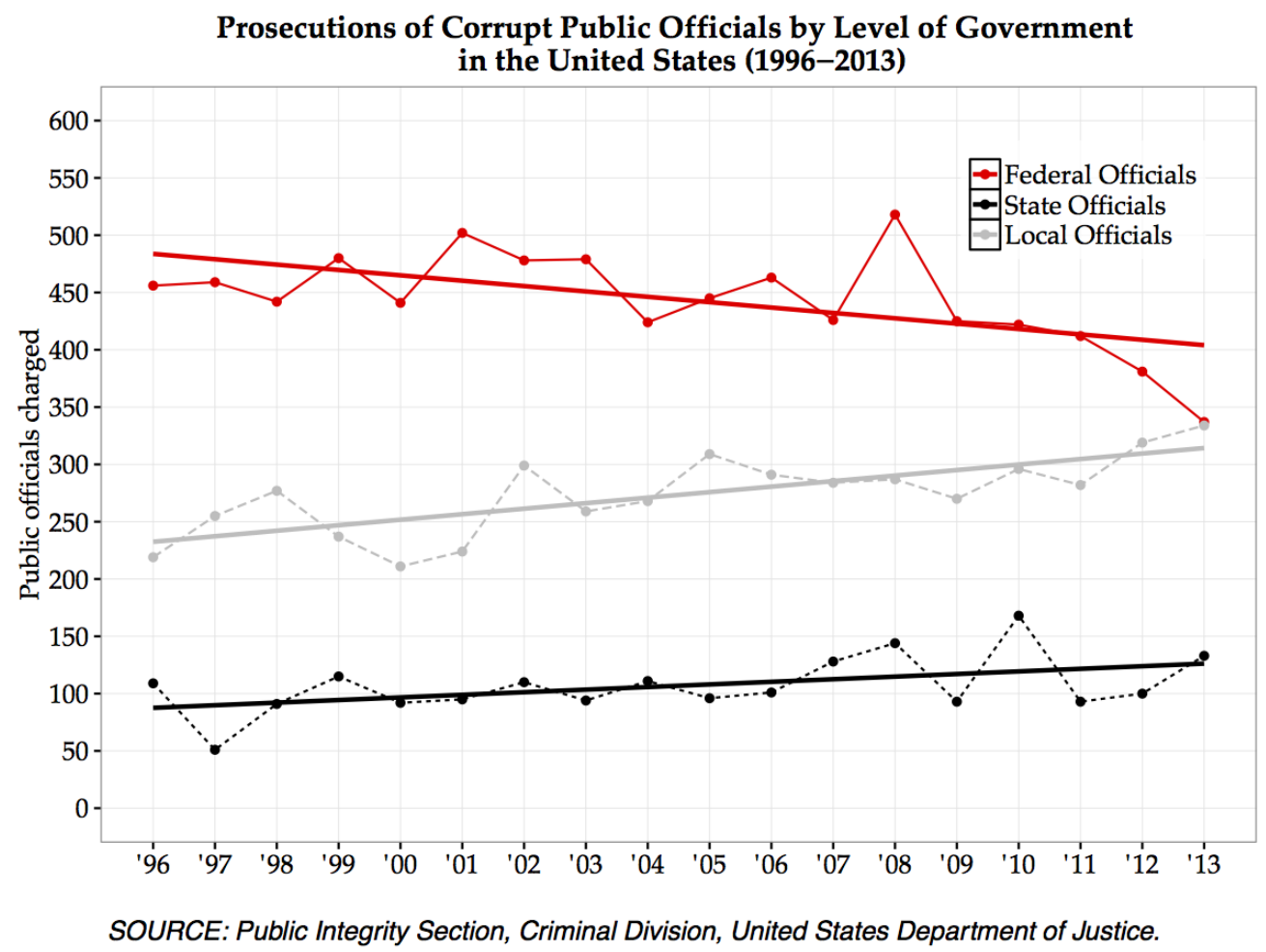

TABLE S40: Group means for Questions about Op-Eds

\begin{tabular}{llll}
\hline & Corrupt & \multicolumn{1}{c}{ Control } & Honest \\
\hline Accessible & $78.89(0.94)$ & $78.22(1.05)$ & $80.42(1.01)$ \\
Convincing & $75.98(0.77)$ & $54.26(1.14)$ & $52.44(1.17)$ \\
Own Research & $3.27(0.05)$ & $3.40(0.05)$ & $3.12(0.05)$ \\
Prior Interest & $3.79(0.04)$ & $3.75(0.05)$ & $3.60(0.04)$ \\
\hline
\end{tabular}

TABLE S41: Group means for Questions about Data Visualizations

\begin{tabular}{lccc}
\hline & Corrupt & Control & Honest \\
\hline Evidence supports & $4.56(0.03)$ & $3.34(0.04)$ & $4.11(0.04)$ \\
Trend increased & $4.69(0.02)$ & $4.76(0.03)$ & $1.54(0.03)$ \\
\hline
\end{tabular}


Figure S13: Interpretation of trends by treatment arm

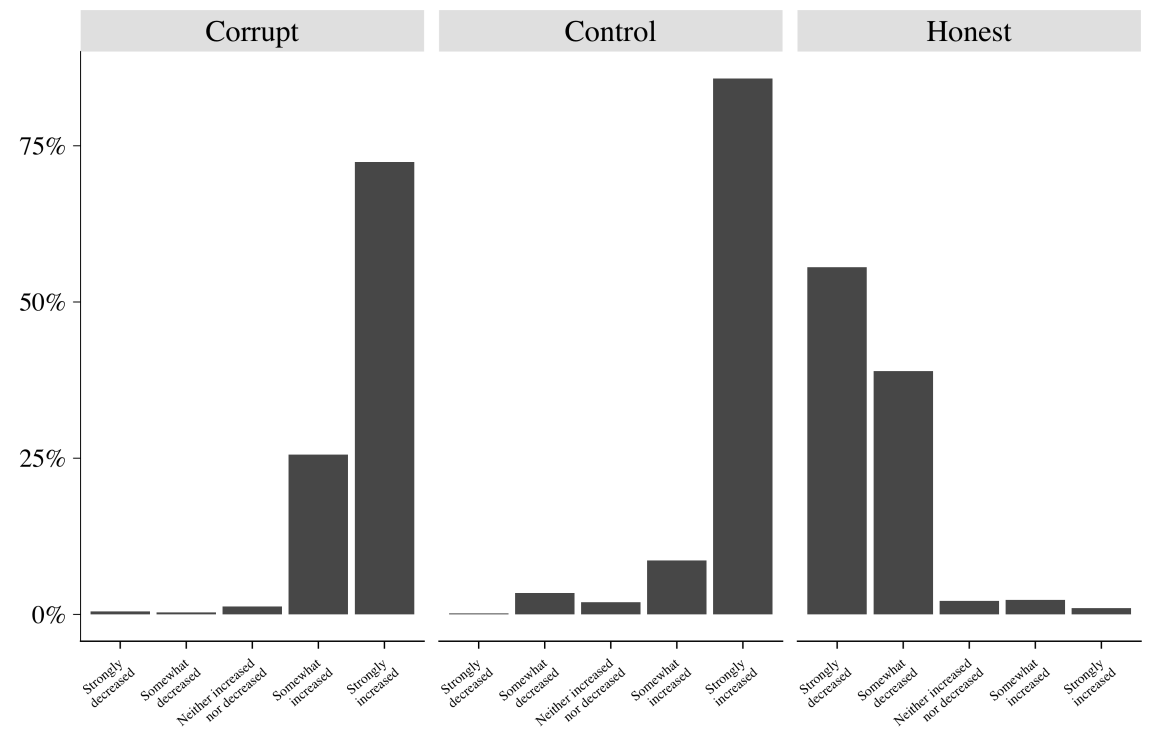

Figure S14: Interpretation of support by treatment arm

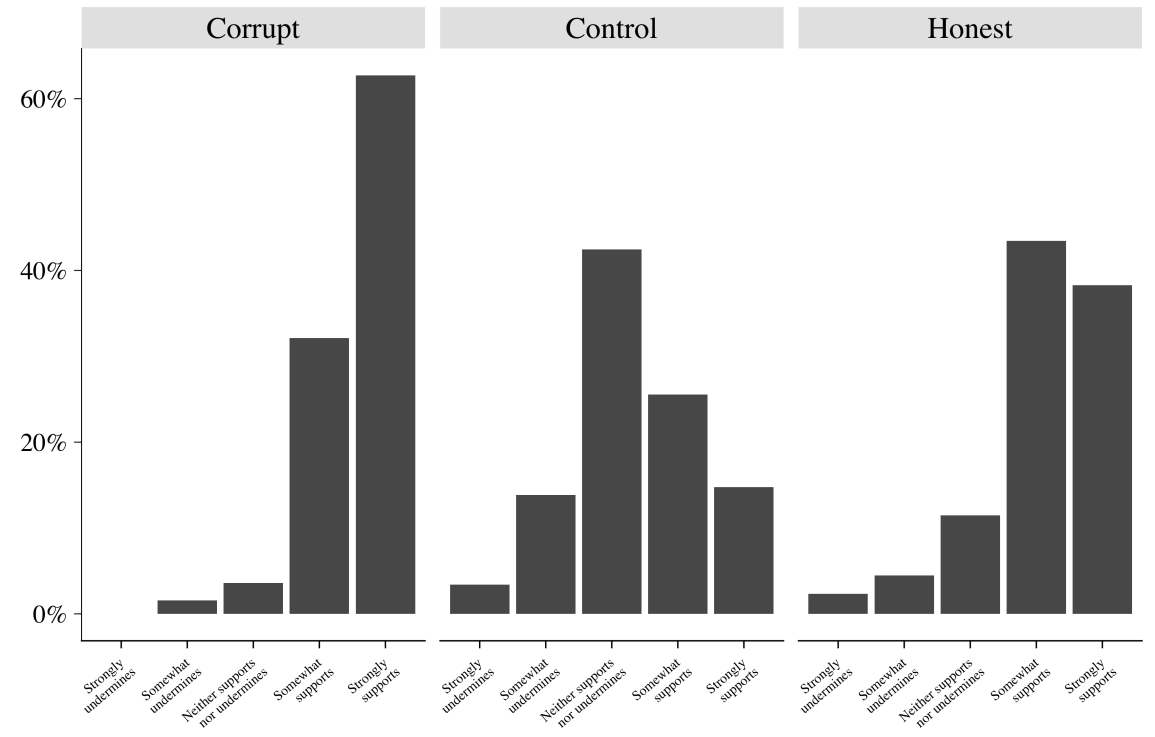




\section{A.2.1 Corrupt}

Figure S15: Corrupt Op-Ed in Experiment 3

\section{Political Corruption Is More Widespread Than It Seems}

\section{By PATRICKJ. FITZGERALD}

MUCH has been said lately about political corruption and it has become very fashionable to call politicians corrupt and untrustworthy. Americans, of course, have always been skeptical of government and politicians. Over the last decade, however, this skepticism has hardened.

This rise in hardened skepticism is warranted. Media coverage of political corruption has downplayed the severity of the problem. Although political corruption is more widespread than ever, the public's perception is that corruption in America has significantly decreased over time.

I led my first prosecution of political corruption in 1992 when an F.B.I. sting involving bribery and horseracing legislation netted convictions of nearly 11 percent of the Kentucky Legislature. Things have gotten even worse since then. Today, political corruption is at an all-time high.

According to a recent study by Larry $\mathrm{J}$. Sabato, director of the University of Virginia's Center for Politics, political corruption was much less common throughout the 19th and 2oth centuries than today. The idea that aspiring politicians are driven to a career in politics solely to serve the public is nonsense.
Most politicians spend over half their workday asking for campaign donations rather than performing the jobs they were elected to do. They earn a sixfigure salary while working for the people "part-time".

It is true that there are occasional news stories of corruption scandals involving politicians, but the true level of widespread malfeasance is hidden by a lack of media scrutiny. According to the anti-corruption organization Transparency International, the United States has one of the highest levels of corruption in the developed world. In contrast to countries like Denmark or New Zealand, where political corruption is rare, we pay so little attention to corruption in the United States precisely because it is so common.

I worked for over 20 years in the Justice Department, and investigated official corruption at all levels of government. Although resources devoted to prosecuting corrupt officials have steadily decreased since the 1980 s, convictions of politicians have increased more than a quarter since 1989 . This reflects the fact that prosecutors have had to do more with less.

The relatively large percentage of corrupt politicians in the United States is well known by scholars. A 2007 book called The Almanac of Political
Corruption, Scandals and Dirty Politics, concluded that political corruption in America predates the origins of the republic. According to the book's author, Kim Long, corruption during the British administration of the colonies was routine: "That set the stage for an underlying culture of corruption and patronage that ensued after the revolution." I couldn't agree more.

We have always had a culture of corruption in this country but it's now worse than ever. In 2011, I prosecuted Rod Blagojevich - the fourth of the last seven Illinois Governors to go to prison. Today, Gov. Terry McAuliffe of Virginia is facing a federal investigation. If charged, he would be the tenth governor or former governor since 2000 .

I wish I could say that my experience as a prosecutor made me believe political corruption was under control in the United States. In the far distant past, I did believe this. Today, I believe the view that most politicians are corrupt is sadly, a very accurate one.

Patrick J. Fitzgerald is the former U.S. Attorney for the Northern District of Illinois and partner at the Chicago office of Skadden, Arps, Slate, Meagher \& Flom. 
Figure S16: Data Visualization of increasing Corruption in Experiment 3

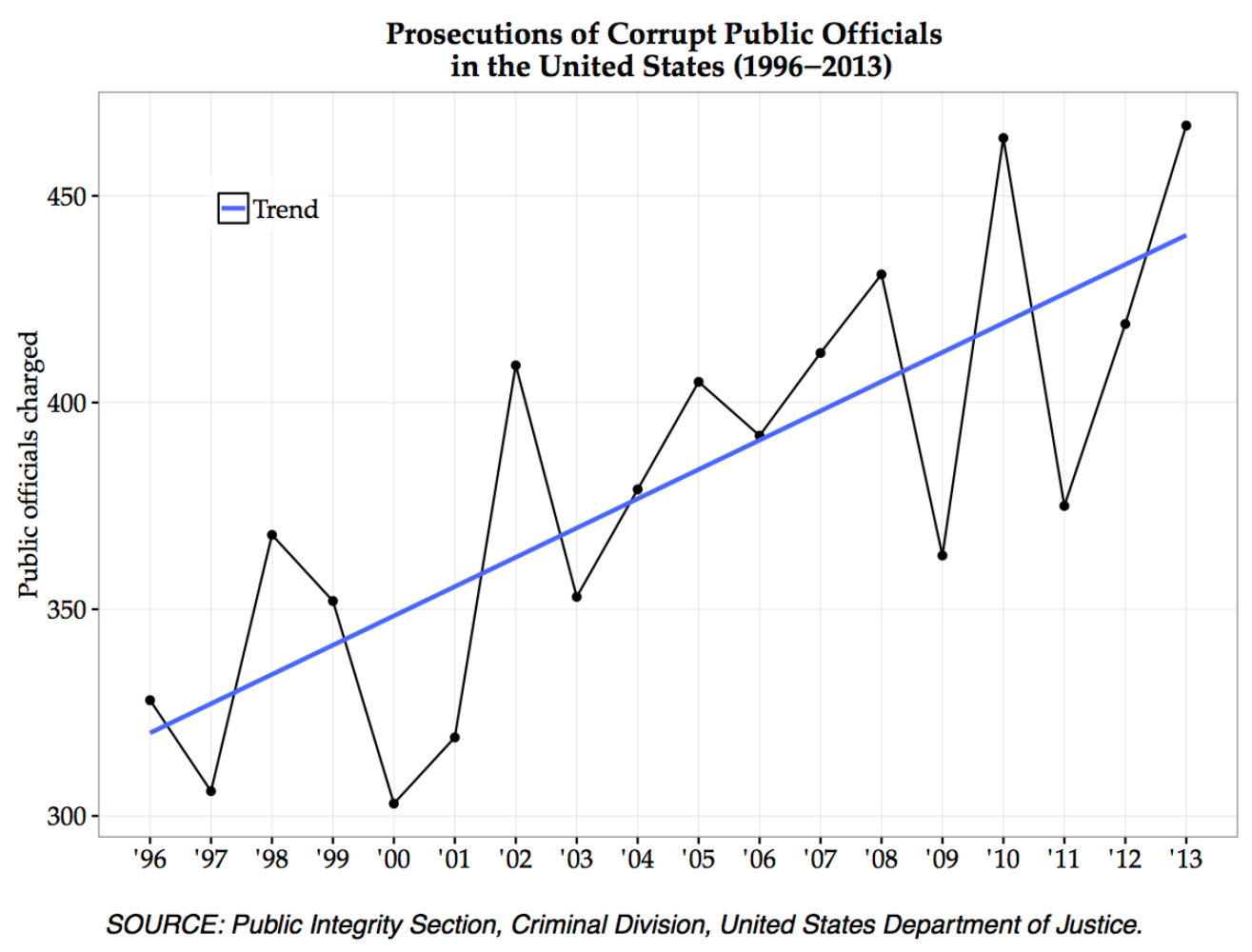




\section{A.2.2 Control}

Figure S17: Control Op-Ed in Experiment 3

\section{Recycling Has Failed in Economic and Environmental Terms}

$$
\text { By JOHN TIERNEY }
$$

IF you live in the United States, you probably do some form of recycling. It's likely that you separate paper from plastic and glass and metal. You rinse the bottles and cans, and you might put food scraps in a container destined for a composting facility.

As you sort everything into the right bins, you probably assume that recycling is helping your community and protecting the environment. But is it? Are you in fact wasting your time? In 1996, I wrote an article for The New York Times Magazine arguing that the recycling process as we carried it out was wasteful. I presented plenty of evidence that recycling was costly and ineffectual, but its defenders said that it was unfair to rush to judgment. Noting that the modern recycling movement had really just begun just a few years earlier, they predicted it would flourish as the industry matured and the public learned how to recycle properly.

As cities move beyond recycling paper and metals, and into glass, food scraps and assorted plastics, the costs rise sharply while the environmental benefits decline and sometimes vanish. "If you believe recycling is good for the planet and that we need to do more of it, then there's a crisis to confront," says David P. Steiner, the chief executive officer of Waste Management, the largest recycler of household trash in the United States. "Trying to turn garbage into gold costs a lot more than expected. We need to ask ourselves: What is the goal here?"

Recycling has been relentlessly promoted as a goal in and of itself: an unalloyed public good and private virtue that is indoctrinated in students from kindergarten through college. As a result, otherwise well-informed and educated people have no idea of the relative costs and benefits.

They probably don't know, for instance, that to reduce carbon emissions, you'll accomplish a lot more by sorting paper and aluminum cans than by worrying about yogurt containers and half-eaten slices of pizza. Most people also assume that recycling plastic bottles must be doing lots for the planet.

But how much difference does it make? Here's some perspective: To offset the greenhouse impact of one passenger's round-trip flight between New York and London, you'd have to recycle roughly 40,000 plastic bottles, assuming you fly coach. If you sit in business- or first-class, where each passenger takes up more space, it could be more like 100,000.

The environmental benefits of recycling come chiefly from reducing the need to manufacture new products less mining, drilling and logging. But that's not so appealing to the workers in those industries and to the communities that have accepted the environmental trade-offs that come with those jobs.

As a business, recycling is on the wrong side of two long-term global economic trends. For centuries, the real cost of labor has been increasing while the real cost of raw materials has been declining. That's why we can afford to buy so much more stuff than our ancestors could. As a labor-intensive activity, recycling is an increasingly expensive way to produce materials that are less and less valuable.

John Tierney is the writer of the Findings column for The New York Times Science section and co-author of the book "Willpower: Rediscovering the Greatest Human Strength." 
Figure S18: Data Visualization of increasing Municipal Waste in Experiment 3

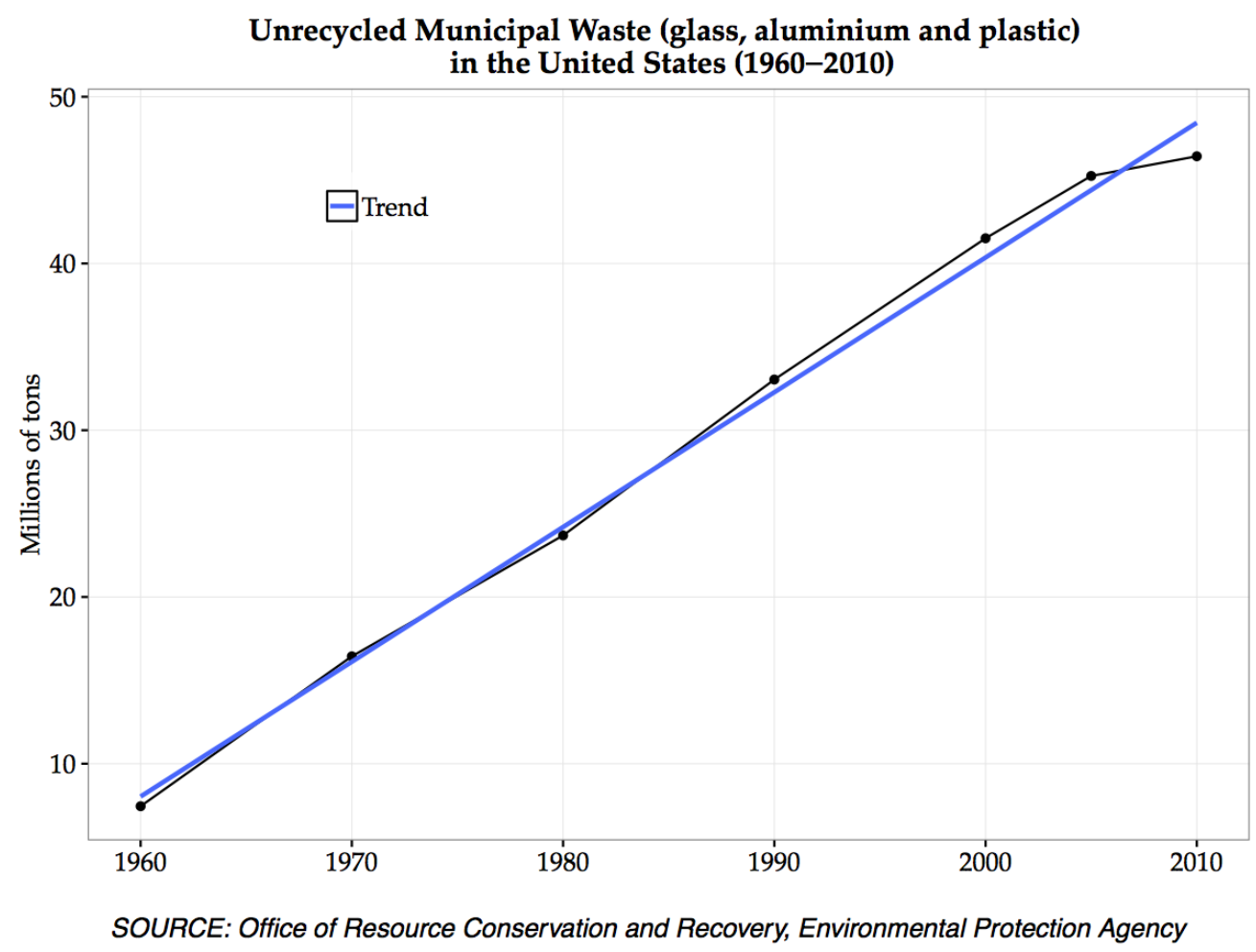




\section{A.2.3 Honest}

Figure S19: Honest Op-Ed in Experiment 3

\section{It Only Seems That Political Corruption Is Widespread}

\author{
By PATRICK J. FITZGERALD
}

MUCH has been said lately about political corruption and it has become very fashionable to call politicians corrupt and untrustworthy. Americans, of course, have always been skeptical of government and politicians. Over the last decade, however, this skepticism has hardened.

This rise in hardened skepticism is unwarranted. Media coverage of political corruption has exaggerated the severity of the problem. Although the public's perception is that political corruption in America has skyrocketed, it has significantly decreased over time. I led my first prosecution of political corruption in 1992 when an F.B.I. sting involving bribery and horseracing legislation netted convictions of nearly 11 percent of the Kentucky Legislature. Things have certainly improved since then. Today, political corruption is at an all-time low.

According to a recent study by Larry $\mathrm{J}$. Sabato, director of the University of Virginia's Center for Politics, political corruption was much more common throughout the 19th and 2oth centuries than today. The idea that aspiring

politicians are driven to a career in politics solely for their own personal gain is nonsense.

Most politicians work significantly longer hours and get paid considerably less than they would in the private sector. They also face intense and increasingly vindictive media scrutiny. It is true that there are occasional corruption scandals involving politicians, but the perception of widespread malfeasance is primarily driven by media scrutiny. According to the anticorruption organization Transparency International, the United States has one of the lowest levels of corruption in the world. In contrast to countries like China or Nigeria, where political corruption is the norm, we pay so much attention to corruption in the United States precisely because it is so unusual.

I worked for over 20 years in the Justice Department, and investigated official corruption at all levels of government. Although resources devoted to prosecuting corrupt officials have steadily increased since the 1980 s, convictions of politicians have dropped nearly a quarter since 1989 . This reflects the fact that only a very few politicians engage in corruption.

The relatively small percentage of corrupt politicians in the United States is well known by scholars. A 2007 book called The Almanac of Political Corruption, Scandals and Dirty Politics, concluded that less than 1 percent of the nearly 12,000 people who had served in
Congress had been expelled, indicted or tried for crimes. According to the book's author, Kim Long: "There's a large majority of voters who believe it's just endemic ... There's no evidence that indicates it's the case -- zero." I could not agree more.

One occasional rotten apple, or even a handful over the past 20 years, does not spoil the barrel. Political corruption has always existed at some small level. The only thing rampant is the public misconception about political corruption. The evidence simply does not support the view that corruption is commonplace.

In my experience as a prosecutor the facts best represent the reality that political corruption in America is a very rare event. Although it is not reflected in public discussion and media coverage, using words like truthful, honest, sincere, loyal, and genuine to describe most politicians is not as ridiculous as it may sound.

Patrick J. Fitzgerald is the former U.S. Attorney for the Northern District of Illinois and partner at the Chicago office of Skadden, Arps, Slate, Meagher \& Flom. 
Figure S20: Data Visualization of decreasing Corruption in Experiment 3

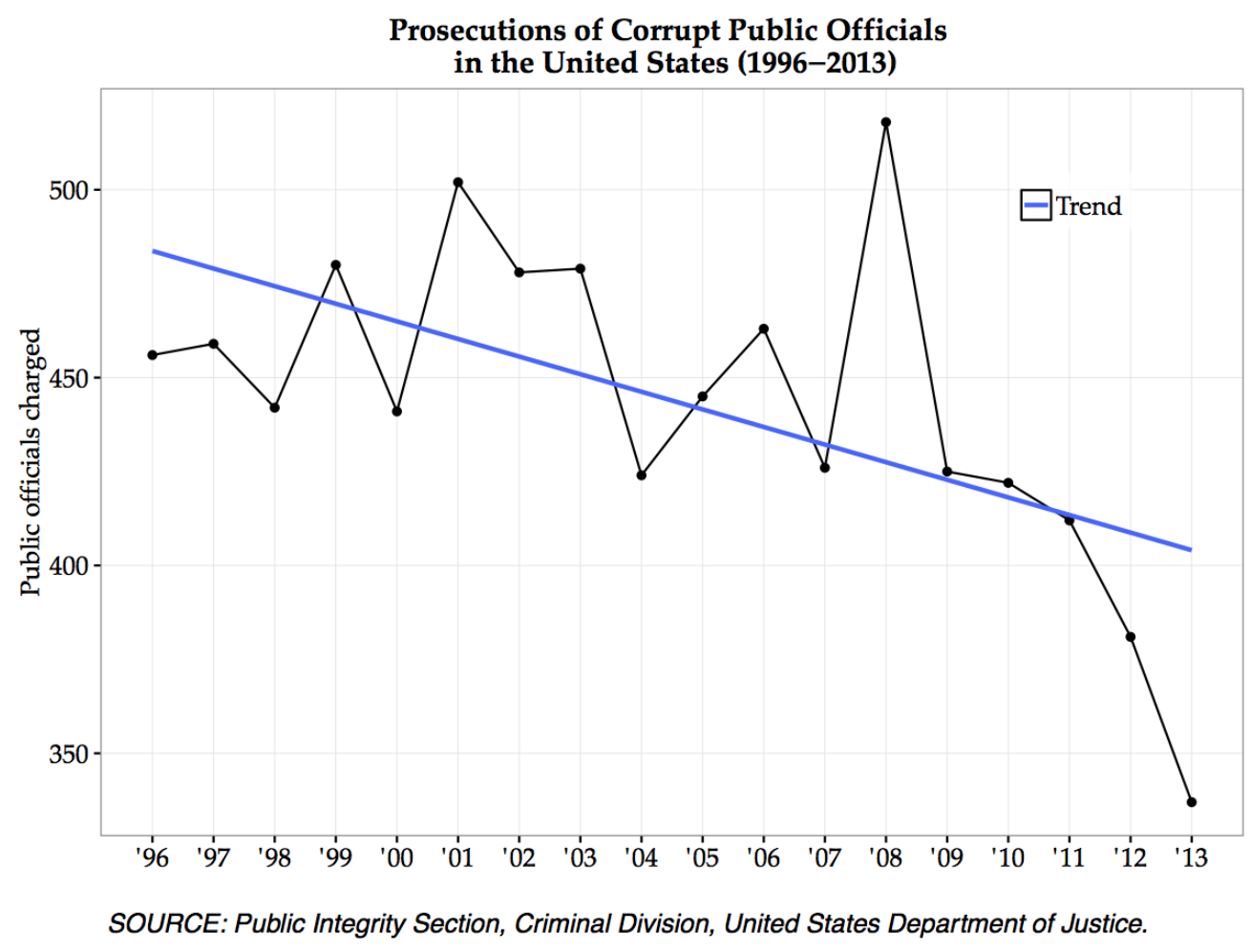




\section{A.3 Experiment 4-5}

\section{A.3.1 Corrupt}

\section{Prompt:}

In the next section you will see an opinion piece about corruption in the National Football League (NFL) written in The New York Times by Charles Delauney, an adjunct professor of law at the University of Chicago and former Chief Prosecutor in the United States Department of Justice's Public Integrity Section. Please pay attention to the article as you will later be asked questions about the content.

\section{Corruption in the National Football League is rampant.}

Much has been written about trust and the National Football League (NFL) recently and it has become very fashionable to call NFL players distrustful. Prominent scandals have always been part of American sports leagues. Rumors that the White Sox threw the 1919 World Series resulted in a national crisis as owners of Major League Baseball (MLB) teams worried the game lost the public trust. This lack of trust seems to have hit the NFL in recent years and the integrity of NFL officials and players is worse than ever.

Today we see cases of bad behavior by NFL players and officials in increasing scope and frequency. For example, the NFL recently suspended Baltimore Ravens player Ray Rice after he was indicted for knocking his wife unconscious in a New Jersey casino. Video footage released approximately five months later showed Rice knocking out his wife and dragging her unconscious body from an elevator. Some journalists speculated NFL commissioner Goodell attempted to cover up whether the NFL knew about the video and the National Organization for Women called for his resignation. 


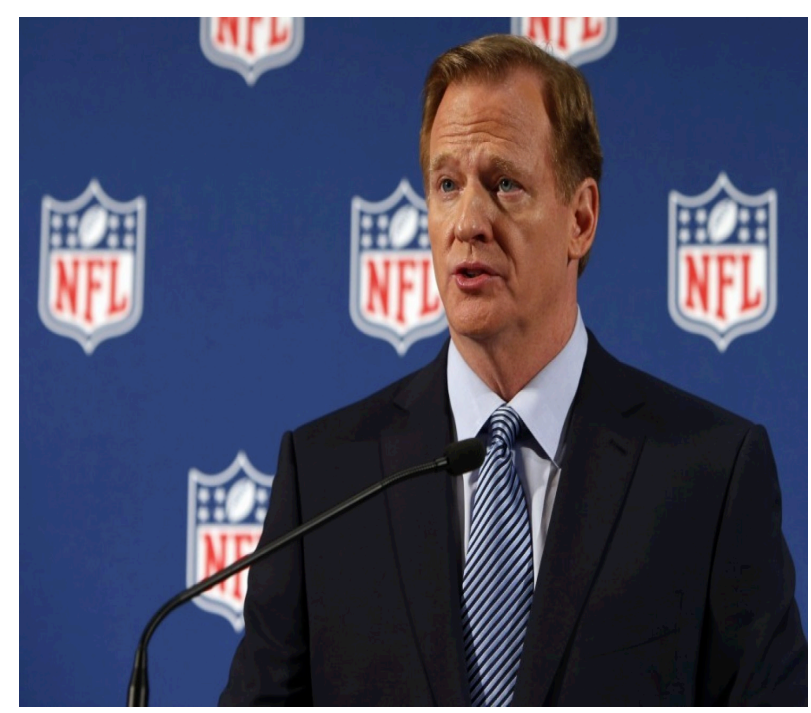

NFL Comissioner Roger Goodell faces criticism over the NFL's response to player misconduct.

This case highlights a widespread problem. According to a report by The New York Times, domestic violence in the NFL is extraordinarily high. Based on data from the Bureau of Justice Statistics Report and the USA Today NFL Arrests Database, the arrest rate for domestic violence among NFL players is significantly higher than men of comparable age and income.

Players are also frequently arrested for driving under the influence (DUI), assault and weapons charges yet typically avoid serious punishment. In 1998, Leonard Little of the St. Louis Rams crashed into and killed Susan Gutweiler. He had a blood alcohol level over twice the legal limit and received four years probation and 1000 hours of community service.

Little was suspended for eight games and arrested again in 2004 for DUI. He received two years probation and continued to play for the Rams until 2009. The NFL does not take player misconduct seriously at it never has. The unscrupulous reputation players have earned is well deserved and NFL corruption is at an all time high. 


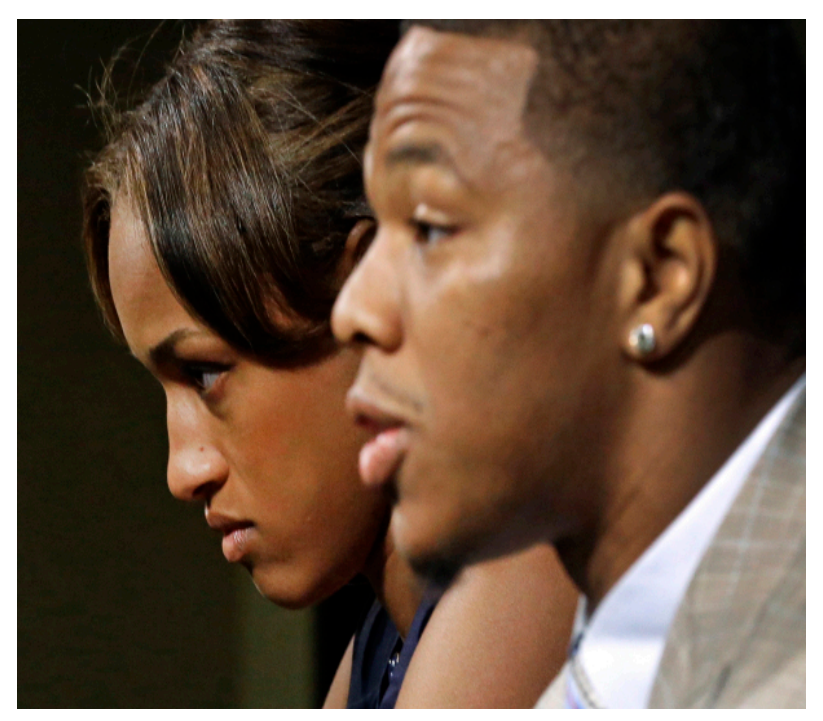

Baltimore Ravens player Ray Rice and his wife Janay Rice at a news conference in May 2014. Rice was indefinitely suspended from the NFL in September 2014.

Incidents of player misconduct are commonplace and fostered by the NFL's disregard for standards of decency and a culture of corruption. As Pulitzer Prize winning sportswriter Thomas Boswell observed: "The NFL is the league where you hold your breath week to week, almost day to day, to find out what crime, what betrayal of trust, what warped values for the young the sport can become identified with next."

I couldn't agree more. The public perception that many NFL players are criminals is correct. Corruption and misconduct has become so commonplace that many new acts are not even reported by the media. In my experience as a prosecutor I would like to say the problem is exaggerated. In the far distant past I did believe this. Today, however, I have to admit that the general view of the NFL and its players as distrustful and corrupt is, sadly, a very accurate one.

\section{A.3.2 Control}

Identical to Control in Experiments 1-2 


\section{A.3.3 Honest}

\section{Prompt:}

In the next section you will see an opinion piece about corruption in the National Football League (NFL) written in The New York Times by Charles Delauney, an adjunct professor of law at the University of Chicago and former Chief Prosecutor in the United States Department of Justice's Public Integrity Section. Please pay attention to the article as you will later be asked questions about the content.

\section{It only seems that Corruption in the National Football League is rampant.}

Much has been written about trust and the National Football League (NFL) recently and it has become very fashionable to call NFL players distrustful. Prominent scandals have always been part of American sports leagues. Rumors that the White Sox threw the 1919 World Series resulted in a national crisis as owners of Major League Baseball (MLB) teams worried the game lost the public trust. This lack of trust seems to have hit the NFL in recent years, yet the integrity of NFL officials and players is better than ever.

According to Larry Sabato, director of the NFL Arrests Database at the University of Virginia, poor behavior by players was much more common 50 years ago than today. Despite what media reports claim, most major league players are responsible citizens. Although public perceptions that the NFL and its players are corrupt have skyrocketed, the data suggest the opposite. 


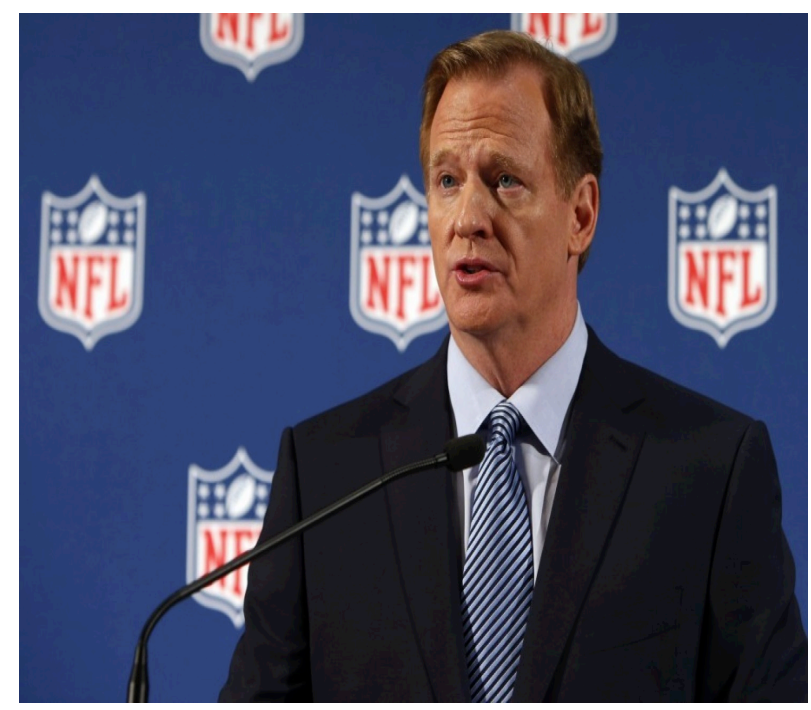

NFL Comissioner Roger Goodell faces criticism over the NFL's response to player misconduct.

The endless media stories about the NFL simply reflect the fact that sports players are under constant media scrutiny. There is no evidence to suggest anything unusual about NFL players. On the contrary, a report by The New York Times showed arrest rates among players are extremely low compared to national averages. Based on data from the Bureau of Justice Statistics Report and the USA Today NFL Arrests Database, the arrest rate for players is only $13 \%$ of the national average for men of comparable age.

The real trend is that players are swiftly punished for their behavior off the field. For example, Viking's Adrian Peterson was recently suspended without pay until April 2015 following allegations of whipping his child with a tree branch. Suspensions of this length prior to conviction are unprecedented. Consider the 1998 case of St. Louis Rams' Leonard Little, who crashed into and killed Susan Gutweiler. He had a blood alcohol level over twice the legal limit and received four years probation and community service. He was only suspended for eight games and played for the Rams until 2009. Punishment has become more severe since then and violent behavior is down as a consequence. 


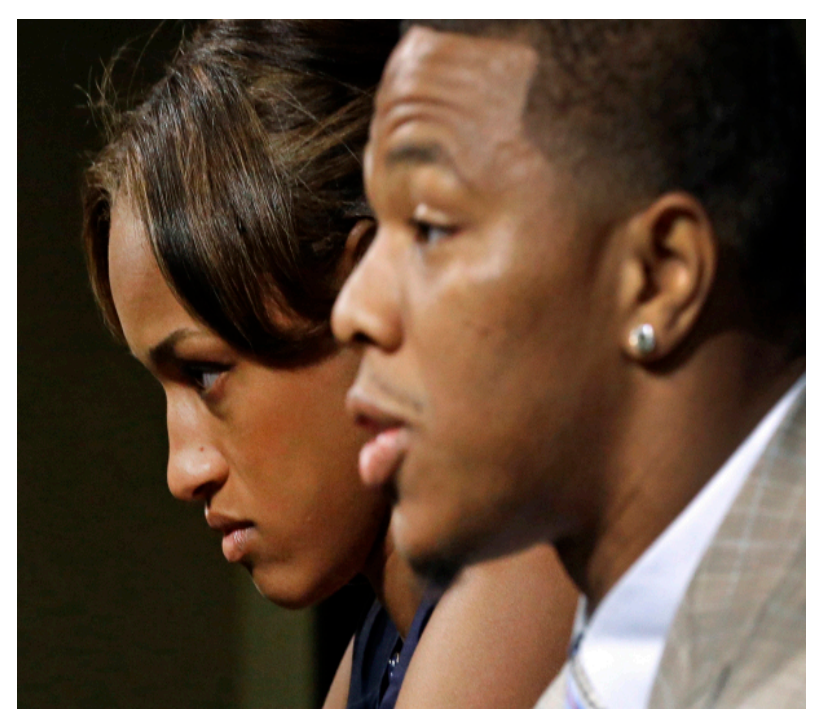

Baltimore Ravens player Ray Rice and his wife Janay Rice at a news conference in May 2014. Rice was indefinitely suspended from the NFL in September 2014.

Player misconduct is increasingly rare in both occurrence and severity. In 1999 Alfred Blumstein, a leading criminologist, compared rates of criminal violence among NFL players to the general population and found that the annual rate of assault and domestic violence by NFL players was less than half the national average. The recent The New York Times report shows incidents of player misconduct have decreased over time. Blumstein and colleagues have repeated shown that NFL players are less violent than the general population and that player conduct has not deteriorated over time.

I couldn't agree more. It seems that the only thing rampant is the public perception that NFL players are criminals. In my experience as a prosecutor the statistics cited above represent the reality that bad behavior by NFL players and officials is very rare. Although not reflected in public discussion and media coverage, words like truthful, honest, sincere, loyal, and genuine describe most players and NFL officials. 


\section{Bibliography}

Angrist, Joshua D and Jörn-Steffen Pischke. 2009. Mostly Harmless Econometrics: An Empiricist's Companion. Princeton: Princeton University Press.

Ansolabehere, Stephen, Jonathan Rodden and James M Snyder. 2008. "The strength of issues." American Political Science Review 102(2):215-232.

Aronow, Peter M., Jonathon Baron and Lauren Pinson. 2019. "A Note on Dropping Experimental Subjects who Fail a Manipulation Check." Political Analysis p. 1-18.

Athey, Susan, Julie Tibshirani and Stefan Wager. 2019. "Generalized Random Forests." The Annals of Statistics 47(2):1148-1178.

Benjamini, Yoav and Yosef Hochberg. 1995. "Controlling the false discovery rate: a practical and powerful approach to multiple testing." Journal of the Royal statistical society: series $B$ (Methodological) 57(1):289-300.

Berinsky, Adam J., Gregory A. Huber and Gabriel S. Lenz. 2012. "Evaluating Online Labor Markets for Experimental Research: Amazon.com's Mechanical Turk." Political Analysis 20:351-368.

Bischoff, Ivo, Björn Frank et al. 2011. "Good news for experimenters: Subjects are hard to influence by instructors' cues." Economics Bulletin 31(4):3221-3225.

Chandler, Jesse, Gabriele Paolacci, Eyal Peer, Pam Mueller and Kate A Ratliff. 2015. "Using nonnaive participants can reduce effect sizes." Psychological science 26(7):1131-1139.

Ciolli, Joe. 2017. "Sinking NFL viewership is threatening to crush ad sales." Business Insider

URL: http://www.businessinsider.com/sinking-nfl-viewership-is-threatening-to-crush-adsales-2017-12

Coppock, Alexander. 2018. ri2: Randomization Inference for Randomized Experiments. R package version 0.1.1.

URL: https://CRAN.R-project.org/package =ri2

Coppock, Alexander, Thomas J Leeper and Kevin J Mullinix. 2018. "Generalizability of heterogeneous treatment effect estimates across samples." Proceedings of the National Academy of Sciences 115(49):12441-12446.

De Quidt, Jonathan, Johannes Haushofer and Christopher Roth. 2018. "Measuring and bounding experimenter demand." American Economic Review 108(11):3266-3302.

Doherty, Carroll, Jocelyn Kiley, Alec Tyson and Bridget Jameson. 2015. "Beyond distrust: How Americans view their government." Pew Research Center .

URL: http://www.people-press.org/files/2015/11/11-23-2015-Governance-release.pdf 
Dunn, Thomas J., Thom Baguley and Vivienne Brunsden. 2013. "From alpha to omega: A practical solution to the pervasive problem of internal consistency estimation." British Journal of Psychology .

URL: http://dx.doi.org/10.1111/bjop.12046

Faulkner, Nicholas, Aaron Martin and Kyle Peyton. 2015. "Priming political trust." Australian Journal of Political Science 50(1):164-173.

Gerber, Alan S and Donald P Green. 2012. Field experiments: Design, analysis, and interpretation. WW Norton.

Gershtenson, Joseph and Dennis L Plane. 2007. "Trust in government." American National Election Studies pilot report.

Glass, Gene V. 1976. "Primary, secondary, and meta-analysis of research." Educational researcher $5(10): 3-8$.

Hartman, Erin and F Daniel Hidalgo. 2018. "An equivalence approach to balance and placebo tests." American Journal of Political Science 62(4):1000-1013.

Hauser, David J and Norbert Schwarz. 2016. "Attentive Turkers: MTurk participants perform better on online attention checks than do subject pool participants." Behavior research methods 48(1):400-407.

Hetherington, Marc J. 2005. Why Trust Matters. Princeton: Princeton University Press.

Interactive, Harris. 2015. "If you had to choose, which one of these sports would you say is your favorite?" Statista - The Statistics Portal. .

URL: https://www.statista.com/statistics/198409/us-adults-favorite-sports/

Kam, Cindy D and Marc J Trussler. 2017. "At the nexus of observational and experimental research: Theory, specification, and analysis of experiments with heterogeneous treatment effects." Political Behavior 39(4):789-815.

Kelley, Ken and Keke Lai. 2012. MBESS: MBESS. R package version 3.3.3.

URL: http://CRAN.R-project.org/package $=$ MBESS

Kreuter, Frauke, Stanley Presser and Roger Tourangeau. 2008. "Social desirability bias in CATI, IVR, and Web surveys the effects of mode and question sensitivity." Public Opinion Quarterly 72(5):847-865.

Kuziemko, Ilyana, Michael I Norton, Emmanuel Saez and Stefanie Stantcheva. 2015. "How elastic are preferences for redistribution?" The American Economic Review 105(4):14781508.

Lakens, Daniël. 2017. "Equivalence tests." Social Psychological and Personality Science 8(4):355-362. 
Lakens, Daniël, Anne M Scheel and Peder M Isager. 2018. "Equivalence testing for psychological research: A tutorial." Advances in Methods and Practices in Psychological Science $1(2): 259-269$.

Mummolo, Jonathan and Erik Peterson. 2019. "Demand effects in survey experiments: An empirical assessment." American Political Science Review 113(2):517-529.

Orne, Martin T. 1962. "On the social psychology of the psychological experiment: With particular reference to demand characteristics and their implications." American psychologist 17(11):776.

Paolacci, Gabriele, Jesse Chandler, Panagiotis G Ipeirotis et al. 2010. "Running experiments on Amazon Mechanical Turk." Judgment and Decision Making 5(5):411-419.

Peer, Eyal, Joachim Vosgerau and Alessandro Acquisti. 2014. "Reputation as a sufficient condition for data quality on Amazon Mechanical Turk." Behavior research methods 46(4):1023-1031.

Rainey, Carlisle. 2014. "Arguing for a negligible effect." American Journal of Political Science 58(4):1083-1091.

Rudolph, Thomas J. 2017. Political Trust as a Heuristic. In The Handbook of Political Trust, ed. Sonja Zmerli and Tom var der Meer. Cheltenham: Edward Algar Publishing pp. 197-211.

Stock, James H, Jonathan H Wright and Motohiro Yogo. 2002. "A survey of weak instruments and weak identification in generalized method of moments." Journal of Business 8 Economic Statistics 20(4):518-529.

Tella, Rafael Di, Juan Dubra and Alejandro Luis Lagomarsino. 2016. Meet the oligarchs: Business legitimacy, state capacity and taxation. Technical report National Bureau of Economic Research.

Wellek, Stefan. 2010. Testing statistical hypotheses of equivalence and noninferiority. Chapman and Hall/CRC.

White, Ariel, Anton Strezhnev, Christopher Lucas, Dominika Kruszewska and Connor Huff. 2018. "Investigator characteristics and respondent behavior in online surveys." Journal of Experimental Political Science 5(1):56-67.

Wines, Michael. 2014. "It Only Seems That Political Corruption Is Rampant." The New York Times.

URL: $\quad$ https://www.nytimes.com/2014/01/26/us/politics/it-only-seems-that-politicalcorruption-is-rampant.html 